\title{
The role of ultrasonography in diagnostic breast imaging
}

Citation for published version (APA):

Flobbe, K. (2003). The role of ultrasonography in diagnostic breast imaging. [Doctoral Thesis, Maastricht University]. Universitaire Pers Maastricht. https://doi.org/10.26481/dis.20030214kf

Document status and date:

Published: 01/01/2003

DOI:

$10.26481 /$ dis.20030214kf

Document Version:

Publisher's PDF, also known as Version of record

\section{Please check the document version of this publication:}

- A submitted manuscript is the version of the article upon submission and before peer-review. There can be important differences between the submitted version and the official published version of record.

People interested in the research are advised to contact the author for the final version of the publication, or visit the DOI to the publisher's website.

- The final author version and the galley proof are versions of the publication after peer review.

- The final published version features the final layout of the paper including the volume, issue and page numbers.

Link to publication

\footnotetext{
General rights rights.

- You may freely distribute the URL identifying the publication in the public portal. please follow below link for the End User Agreement:

www.umlib.nl/taverne-license

Take down policy

If you believe that this document breaches copyright please contact us at:

repository@maastrichtuniversity.nl

providing details and we will investigate your claim.
}

Copyright and moral rights for the publications made accessible in the public portal are retained by the authors and/or other copyright owners and it is a condition of accessing publications that users recognise and abide by the legal requirements associated with these

- Users may download and print one copy of any publication from the public portal for the purpose of private study or research.

- You may not further distribute the material or use it for any profit-making activity or commercial gain

If the publication is distributed under the terms of Article $25 \mathrm{fa}$ of the Dutch Copyright Act, indicated by the "Taverne" license above, 
THE ROLE OF ULTRASONOGRAPHY IN DIAGNOSTIC BREAST IMAGING 
(9) K. Flabbe, Maastricht 2003

ISBN $90-5278-370-5$

Printed by: Datawyse / Universitaire Pers Maastricht Cover Design: "La Nature", 1529

Niccole Péricoli, Château de Fontainebleau (F) 


\title{
THE ROLE OF ULTRASONOGRAPHY IN DIAGNOSTIC BREAST IMAGING
}

\author{
PROEFSCHRIFT
}

Ter verkrijging van de graad van doctor

Aan de Universiteit Maastricht"

Op gezag van de Rector Magnificus

Prof. Dr. A.C. Nieuwentuijzen Kruseman,

Volgens het besluit van het College van Decanen,

In het openbaar te verdedigen

Op vrijdag 14 februari 2003 om 12.00 uur

door

Karin Flobbe

Geboren te Wemeldinge (Z)d)

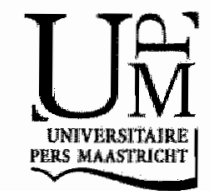




\section{Promotores}

Prof. Dr.J.M.A. wan Engelshoven

Prof. Dir. M.F. von Meyenteldt

\section{Co-promotor}

Dr. G.L. Beets

Beoordelingscommissie

Prof. Dr. M.H. Prins

Prof. Dr. H.F. Hillen

Prof. Dr. C. Spreeuwenberg

Prof. Dir. M.G.M. Hunink (Erasmus Universiteit Rotterdam) 


\section{Contents}

\section{Chapter 1}

Introduction

Chapter 2

Diagnostic value of radiological breast imaging in a non-screening

population

\section{Chapter 3}

The role of ultrasonography as adjunct to mammography in the

detection of breast cancer: a systematic review

Chapter 4

The additional diagnostic value of ultrasonography in the diagnosis of

breast cancer.

Chapter 5

Predictive diagnostic variables in the diagnosis of breast cancer: the role of ultrasonography

Chapter 6

Costs and effects of the use of ultrasonography in the evaluation of palpable breast masses

Chapter 7

General discussion and conclusions

Chapter 8

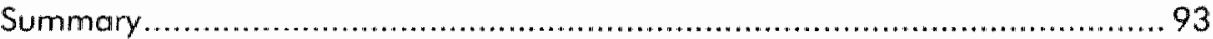

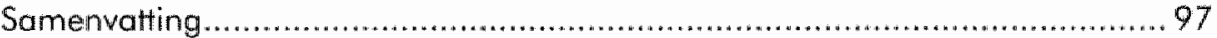

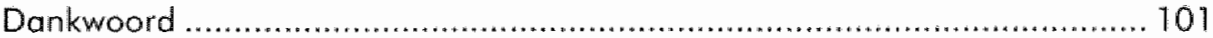

Curriculum Vitae .................................................................................... 103 


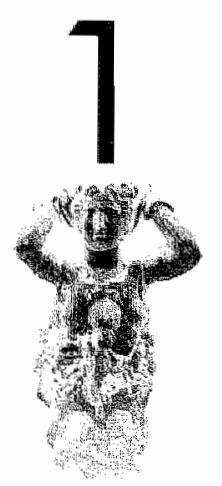

INTRODUCTION 


\section{Introduction.}

Breast cancer is the mast cammon malignancy in women and comprises $18 \%$ of all female cancers. Yearly, I million new cases of breast cancer are detected worldwide ". In The Netherlands, about 10,000 new breast cancers are reported every year and the lifetime risk is $10 \%$. Suggested risk factors for breast cancer include: increasing age with a slowing rate after menopause, low age at menarche or late menopause, late age at first pregnancy or nulliparity, a family history, previous benign breast disease like atypical epithelial hyperplasia, oral contraceptive use and use of hormone replacement therapy".

\section{Diagnosfic breast imaging}

Women with breast problems are generally referred for diagnostic breast imaging to the radiology department of a hospital by general practitioners and specialists. Reasons of referral can be the presence of a palpable mass, other symptomatology e.g. pain or nipple discharge, radiological follow up of a prior breast malignancy or a benign abnormality e.g. a fibroadenoma, an abnormal screening mammogram made as part of the national breast cancer screening program or asymptomatic reasons like a family history or fear of breast cancer.

Routine breast imaging consists of clinical examination and mammography, which may be complemented with ultrasonography when clinically indicated. The imaging work-up should have a high sensitivity and high specificity, in order to prevent diseased patients from being sent home wrongly (false-negative results) and prevent healthy patients from undergoing further unnecessary work-up (false-positive results). Many centers offer patients the service of a "one-stop diagnosis", in which all diagnostic tests are performed during one hospital visit and the patient is provided with the diagnosis within one day ${ }^{2,3}$.

In patients with a palpable breast lump, clinical guidelines recommend additional fine needle aspiration cytology (FNAC) to be included in the routine work-up, next to elinical examination and mammography. The "triple test" combines the results of these diagnostic tests in planning the treatment ${ }^{4.7}$. Furthermore, it is advised to investigate non-conclusive non-palpable abnormalities further by histological core needle biopsies ${ }^{8.10}$.

\section{Additional ultrasonography}

Although mammography has been the major breast imaging tool for decades, its accuracy is greatly dependent on the composition of breast parenchyma and the presentation of breast tumors. The sensitivity of mammography is lower in younger patients with dense, glandular breasts and in patients with noncalcified tumors.

Ultrasonography has become the most important adjunct to mammography ${ }^{11.13}$. It"s first application in the examination of the breast was described by Wild and Neal in 1951 is and the technique gained importance with the development of B-mode techniques which were able to visualize palpable lesions, as published first in $1954^{115}$. 
Currently, the most important indications for breast ultrasonography are:

- Differentiation between cyst and solid mass ${ }^{11.13,18-20}$.

Cysts are the most common benign breast masses. Ultrasonography can reacli a $100 \%$ accuracy in the diaginosis of a cyst when strict criteria are used: a round oval shape or gently lobulated, circumscribed margin, anechoic echogenicity and acoustic enhancement ${ }^{2 !}$.

- Evaluation of a palpable mass not visible in a dense breast $11,13,18-18,22$

In cases where normal fibroglandular tissue may partially or completely obscure masses on a mammogram, ultrasanography may determine whether the mass is cystic or solid. However, nonvisualization of a palpable mass by both mammography and ultrasonography suggests the lesion is solid and a biopsy should be strongly considered.

- Evaluation of nonpalpable or palpable abnormalities with an uncertain mammographic diagnosis 11.13

Concerns the evaluation of non-palpable oval, round and circumscribed mammographic lesions as well as palpable masses, which are difficult to place within the field of view on the mammogram.

- Initial evaluation of a palpable mass in young women (<35 years) $11-13_{*} 16,18 \cdot 21$

As breasts of young women are more sensitive to radiation and breast cancer is relatively rare in this group, ultrasonography should be performed as initial imaging study of a palpable mass.

Other indications for breast ultrasonography are inflammation or mastitis $11,13,18,19$, the evaluation of problems in breasts with breast implants ${ }^{19,21}$ and guidance for interventional procedures $11-13,17,19,20$.

There is an ongoing discussion about the use of ultrasonography in the differentiation between benign and malignant lesions. Although several studies have tried to define characteristic ultrasonographic features of benign and malignant breast masses $11,19$. 20, 23.25 "more research needs to be done to develop one universal lexicon which may be used in clinical practice.

Finally, ultrasonagraphy is being debated as a screening modality for breast cancer. It has been argued that in order to do so, it must not only detect all cancers visible on mammography, but also show a substantial number of non-palpable cancers that are mammographically occult. Ultrasonography does not yet perform either of these tasks and has shown to have a high false-positive rate when used as a screening madality $11,13,19,26,27$

The application of breast ultrasonagraphy as adjunct to mammography in clinical practice can greatly reduce the number of biopsies performed for benign breast disease and reduce patient anxiety 13, 28. Several studies have reported the diagnostic performance of mammography combined with ultrasonography and show a sensitivity of $87 \%-100 \%$ and a specificity of $64 \%-98 \%{ }^{20 \cdot 35}$.

After the performance of the tests, one final imaging assessment should be composed; reflecting combined mammographic and ultrasonographic findings. Final assessment and patient management should be based on the most suspicious features present ${ }^{21}$, although others believe that whenever the mammographic findings cannot be correlated with the ultrasonography findings, the mammographic findings should prevail, avoiding possible incorrect conversion ". 


\section{Context of the thesis}

The increasing availability and accessibility of ultrasonography in hospitals has led to an increase in its application. Other reasons for possible "excessive" testing in diagnosis can be found in the pressure from patients and their families, the clinician's concern about malpractice and fear of missing a diagnosis ${ }^{36}, 37$. Although this practice may comfort the patient and satisty the clinician's desire to use every possible diagnostic avenue, more tests do not necessarily produce more certainty ${ }^{35}$. Furthermore, an increaising use of tests will lead to an increase in healthcare costs resulting in a financial burden to the healthcare system.

Numbers from the radiology department of Maastricht University Hospital show an increase in the application of ultrasonography as adjunct to mammography from $28 \%$ of all patients referred for breast imaging in $1994^{38}$ to over $35 \%$ in 1999. This hospital is a 700-bed referral hospital with an important regional function for the south of The Netherlands. At the radiology department about 3500 breast examinations are performed yearly.

The increased use of breast ultrasonography leads to the question whether additional diagnostic information is obtained in all occasions where it is applied. In order to reduce the number of unnecessary examinations, ultrasonography should be mainly performed in the patients who benefit most from it. Furthermore, the test should be withheld from patients in whom it does not yield additional diagnastic information. To aptimize and facilitate the logistic planning of diagnostic breast imaging in the radiology department, the selection of patients for ultrasonography is, from a practical point of view, preferably made at the stage of referral and therefore based on patient characteristics known at referral.

\section{MAMMOED study}

In response to these clinical questions, the MAMMOED study (MAMmacarcinoomstudie Maastricht: Optimalisatie Echografische Diagnostiek: Breast cancer study Maastricht: Optimizing Ultrasonographic Diagnostics) was performed at Maastricht University Hospital as part of the Cost Containment Research Program of the Dutch Health Care Insurance Board. In this prospective study all patients referred for breast imaging underwent ultrasonography as adjunct to mammography and clinical examination.

The objectives of this thesis are:

1. To assess the diagnostic value of breast ultrasonography as adjunct to mammography and clinical examination in the diagnosis of breast cancer.

2. To study the feasibility of defining subgroups of patients who benefit most from additional ultrasonography.

3. To study the costs and effects of the application of breast ultrasonography in patients with palpable breast masses.

\section{Outline of the thesis}

In chapter 2 of this thesis, a prospective study is described which assesses the diagnostic performance of breast imaging in a non-screening population in daily clinical practice. In 3816 breasts in 1944 examinations, palpation and mammography 
was performed, supplemented with ultrasonography when clinically indicated. ROC curve analysis assessed the diagnostic value of radiological breast imaging and it"s value in addition to information from palpation and age of the patient.

To study the available evidence for the diagnostic value of ultrasonography as adjunct to mammography and to define clinical indications for ultasanagraphy, a systematic literature review was performed and discussed in chapter 3. All available publications between 1990 and 2000 describing the diagnostic performance of ultrasonography as an adjunct to mammography, were selected. Apart from the diagnostic performance, the methodologicall quality of the different studies is discussed.

In chapter 4, results of the MAMMOED study are reported, in which the diagnostic value of ultrasonography as an adjunct to mammography and clinical examination was studied in 2020 consecutive patients referred for breast imaging. ROC curve analysis assessed the additional diagnostic value of ultrasonography in the whole study population as well as in subgraups of patients according to the reason for referral for breast imaging and age.

Following, multivariate lagistic regression analysis was performed an diagnostic variables of the medical history, clinical examination, mammography and ultrasonography, on patient data from the MAMMOED study to assess the specific contribution of each consecutive test in the prediction of breast cancer. The results of this analysis are reponted in chapter 5 .

Chapter 6 describes a decision analytical model of the costs and effects of incorporating ultrasonography in the triple test for evaluating palpable breast masses. A conventional strategy of immediate fine needle aspiration cytology (FNAC) following mammography and clinical examination was compared with 3 different experimental strategies of prior ultrasonography.

Chapter 7 discusses the results of the studies presented in this thesis and emphasizes their clinical impact. Finally, chapter 8 summarizes the most important findings. 


\section{References}

1. McPherson $K$, Steel $C M$, Dixon $J M$. ABC of breast diseases. Breast cancer-epidemiology, risk fuciors, and genelics. Bmi $2000,321,624-8$.

2. Gui GP. Allom WH, Perry NM, al. One-stop diagnosis for symptomatic breast disease "Ann $R$ Coll Surg Eng $1995,77: 24-7$

3. Gu GP, Alum WH, Perry NM, al. Clinical audit of a specialist symptomatic breast dinic. J R Soc Med 1995; $88.330-3$.

4. Morris KT, Pammier RF, Morris $A$, al al. Usefulness of the triple test score for palpable breast masses; discussion 1012-3. Arch Surg 2001: 136:1008-12.

5. Morris A, Pommier RF, Schmidt WA, Shih RL, Alexander PW, Vetto JT. Accurate evaluation of palpable breast masses by the triple lest score. Arch Surg 1998; 133:930-4.

6. Vetto $\mathrm{J}$, Pommier $\mathbb{R}$, Schmidt $W$, elt al. Use of the "triple test" for palpoble breast lesions yields high diagnostic accuracy and cost savings. Am J Surg 1995; 169:519-22.

7. Hermansen $C_{,}$skovgaard Poulsen $H_{i}$ Jensen $J_{,}$et al. Diagnostic reliability of combined physical examination, mammography, and fine-needle puncture "triple-test") in breast tumors. A prospective study. Concer 1987; 60:1866-71.

8. Teh WL, Evang AJ, Wilson AR. Definitive non-surgical breast diagnosis: the role of the radialogist. Clin Rodiol 1998; 53:81-4.

9. Pijmappel RM, van Dalen A, Rinkes $1 H$, wan dien Tweel 16 , Malli WP. The diagnostic accuracy of core biopsy in palpable and non-palpable breast lesions. Eur I Radiol 1997; 24:120-3.

10. Parker SH, Lovin JD, Jobe WE, al Stereotactic breast biopsy with a biopsy gurt. Radiology $1990 ; 176: 741-7$.

11. Skadne P. Ultrasonography as adjund to mammography in the evaluation of breast tumars. Acta Radial Suppl 1999; 420:1-47.

12. Mendelson EB. Tobin CE. Critical pathways in using breast US. Radiographiics: 1995; 15:935-45.

13. Jackson VP, Reynolds HE, Hawes DR, Sanography of the breast. Semin Ultrasound CT MR: 1996; $17: 460-75$

14. Wild $\mathrm{J} J$, Neal $\mathrm{D}$. the use of high frequency ultrasonic waves for detecting changes of texture in the living thssue. Lancet 1951; 1:655-657.

15. Howry DH, Stott DA, Bliss WR. The ultrasonagraphic visualization of carcinoma of the breast and other soft-tissue structures. Cancer $9.54: 7.354$

16. Wossell LW. Imaging of breast masses. Radiol Clin North Am 2000; 38:669.91, wii-viii.

17. Zonderland HA. The role of ultrasound in the diagnosis of breast concer. Semin Ulirasound CT MR 2000:21:317:24.

18. Sabel MS, Staren ED. Innowations in breast imaging: How ultrasound can enthance the early detection of breast cancer. Medscape Womens Health 1997; 2.

19. Smith DW. Breast ultrasound. Radiol Clin North Am 2001; 39:485-97.

20. Baker JA, Soo MS. The evolwing role of sonography in evaluating salid breast masses. Semin Ultrasound CT MR 2000; $21: 286-96$.

21. Mendelson EB, Berg WA, Merrit CR. Toward o standardized breast ultrasound lexican, BI-RADS: ultrasound. Semin Roentgenol $2001 ; 36: 217-25$.

22. Jackson VP. The eurrent role of ultrasonography in breasit imaging. Radial Clin North Am 1995 ; 33:1161-1170.

23. Stavros AT, Thickman D, Rapp CL, Dennis MA, Parker SH, Sisney GA. Solid breast nodules: use of sonography to distinguish between benign and malignant lesions. Radiology 1995; 196:123134.

24. Zonderland HM, Hermans J, Coerkamp EG. Ultrasound variables and their prognostic volue in a population of 1103 patients with 272 breast concers. Eur Radiol 2000; 10:1562-8. 
25. Rahbar G, Sie AC, Hansen GC, et al. Benign versus malignant salid breast masses. US differentiation. Radiology 1999; $213: 889-94$.

26. Kaplan SS. Clinical utility of bilateral whole-breast US in the evaluation of women with dense breast tissue. Radialogy 2001; $221: 641-9$.

27. Kopans DB. Breast-cancer screening with ultrasonography. Lancet 1999; 354:2096-97.

28. Taylor $\mathrm{KJ}$, Merritt $\mathrm{C}$, Piccoli $\mathrm{C}$, et al. Ultrasound as a complement to mammography and breast examination to characterize breast masses. Ultrasound Med Biol 2002; 28:119-26.

29. Duilim LEM, Guif GL, Koomen AR, Willebrand D. Sensitivity, specificity and predictive values of breast imaging in the detection of cancer. Br $\rfloor$ Cancer 1997; 76 (3):377-381.

30. Hardy JR, Powles TJ, Judson I, ef al. How many tests are required in the diagnosis of palpable breast abnormolities? Clin Oncol (R Coll Radiol) 1990: 2:148-52.

31. Zonderland $H M$, Coerkamp EG, Vijuer $M, J$, wan de, Voorthuisen $A, E$. Diagnasis of breast cancer: Contribution of US as an adjunct to mammography. Radiology 1999; 213:413-1422.

32. Ozdemir A, Oznur, II, Vural $G$, et al. TI-201 scintigraphy, mammography and ulfrasonography in the evaluation of palpable and nonpalpable breast lesions: a correlative study. Eur I Radiol 1997; 24:145-54.

33. Moss HA, Britton PD, Flower CD, Freeman AH, Lomas DJ, Warren RM. How reliable is modern breast imaging in differentiating benign from malignant breast lesions in the symptomatic population? Clin Radiol 1999; 54:676-82.

34. Ruhland $F$, Heinrich J, Budner $M$, Jeschike A. [Diagnostic value of Mammography and Breast Uttrasound for Clinically Occult Lesions of the Breast]. Geburtsh-Frauenheillk. 2000; 60: 104-110.

35. Skaane $P$, Engedal K, Skjennald $A$. Interobserver variation in the interpretation of breast imaging. Comparison of mammagraphy, ultrasonography, and both combined in interpretation of palpable noncalcified breast masses. Acta Radiol 1997; 38:497-502.

36. Kassirer JP. Our stubborn quest for diagnostic certainty. N Engl J Med 1989; 320:1489-1491.

37. Putterman C, Ben-Chetrit E. Clinical problem-solving. Testing, hesting, testing. N Engl J Med 11995; 333:1208-11.

38. Flobbe $K$, van der Linden ES, Kessels AG, wan Engelshoven JM. Diagnostic value of radiological breast imaging in a nan-screening population. Int II Cancer 2001; 92:616-8. 
Chopter 1 


\section{DIAGNOSTIC VALUE OF RADIOLOGICAL BREAST IMAGING IN A NON-SCREENING POPULATION.}

Karin Flobbe, Ed S. van der Linden, Alfons G.H. Kessels, Jos M.A. van Engelshoven Int J Canc 2001;92:616-618. 


\section{Abstract}

\section{Aim}

The aim of this study was to assess the diagnostic performanice of breast imaging in the diagnosis of breast cancer in a non-screening population.

\section{Methods}

In a consecutive set of patients referred for mammography in one year, the results of palpation and radiological breast imaging were scored on a 5-point grading scale and linked to pathology as gold standard after a follow up period of one year. The diagnostic performance was studied by logistic regression analysis and $\mathrm{ROC}$ curves.

\section{Results}

There were 1944 breast examinations in 1890 patients and 3816 breasts. Pathology results reparted 118 malignancies in 115 women. With a cut-off point between benign and uncertain benign a sensitivity of $89 \%$ and a specificity of $98 \%$ was found for radiolagical imaging.

ROC curves showed a significant increase in diagnostic performance when radiology was added to results of palpation and age $(p=0.007)$.

\section{Conclusion}

Radiological imaging tests have a large diagnostic walue in the detection of breast cancer in addition to palpation and age. A sensitivity cllose to $100 \%$ could be reached. 


\section{Introduction}

Breast cancer is one of the leading causes of death among women in Western countries. The overall risk for the development of breast cancer over lifetime is estimated to be $12.5 \%$ among American women 1.2 and about $10 \%$ among women in The Netherlands ${ }^{3}$.

The diagnostic triad for evaluation of breast symptoms, the so-called "triple assessment system" inwolves clinical examination, radiological imaging and fine needle aspiration (FNA) cytology. If all investigations are carried out together a sensitivity of more than $99 \%$ can be obtained ${ }^{4,5}$.

The value of mammography in screening for breast cancer is well studied, but the diagnostic value of non-screening breast imaging, using a combination of mammography and ultrasonography when indicated, is not well established.

Many studies discussing the value of non-screening breast imaging describe populations diagnosed with breast cancer ${ }^{5.9}$. Very few studies describe breast imaging in a clinical population 10, 11 , and these studies did not examine the role of palpation and age in the diagnostic process.

The aim of this prospective study was to assess the diagnastic performance of breast imaging in the diagnosis of breast cancer among a non-screening population.

\section{Material and methods}

All consecutive patients referred for mammography to the Radiology Department of the University Hospital Maastricht in 1994 were included in the study.

Investigations were performed in fixed order. Palpation was followed by standard craniocaudal and mediolateral oblique mammograms. When indicated according to the opinion of the radiologist, patients subsequently underwent ultrasonography. For the purpase of this study, the combination of mammography and ultrasonography will be called 'radiological breast imaging'.

Ilmaging examinations obtained as follow up to breast saving surgery or amputation were excluded. For patients with multiple examinations during the study period, all examinations were included except those done after breast cancer was already diagnosed. Furthermore, when cancer was detected at later examinations the result of the first examination was considered false negative and anly this examination was included in the analysis. When ultrasonography was performed without mammography, patients were not included in the study.

Registration forms were used to score all examinations. Palpation was scared per breast as: $0=$ palpation not performed, $1=$ no palpable abnormality, $2=$ vaguely palpable abnormality, $3=$ circumscript abnormality, $4=$ evident abnormality, not sharply defined.

The results of mammography and ultrasonography were combined into an overall radialogical imaging conclusion, according to the BI-RADS lexicon as developed by the American College of Radiology, classified as: $1=$ normal, $2=$ benign, $3=$ uncertain benign, $4=$ suspect malignant, $5=$ malignant ${ }^{12}$.

Mammography was performed using a Siemens Mammomat-2 unit and a Kodak MinR film screen combination. Ultrasonography was done with a General Electric scanner (RT3600) and a $7.5 \mathrm{MHz}$ linear array transducer. Palpation and radiological examinations were carried out and reported by a radiologist with a special interest in mammography and over 5 years of experience in this field. 
A follow up period of one year after breast imaging was used. Pathalogy results retrieved from our hospital pathology department and the Dutch National Archives of Pathology (PALGA) were used as the gold standard for the presence or absence of breast cancer and linked to the imaging results. As all pathology laboratories in The Netherlands are connected 10 PALGA, we covered the whole study population, including patients who were diagnosed elsewhere. Patients for whom no pathology results were reparted in either system were interpreted as free of malignancy.

Logistic regression analysis was used to identify the role of radiological imaging, palpation and the age of the patient in predicting the presence or absence of malignancy.

By dichotomizing the results of logistic regression and calculating the sensitivity and specificity for different cut-off points of the predicted probabilities that were generated, receiver operating characteristic ( $R O C$ ) curves were drawn for palpation and age and for the whole process of breast diagnosis, consisting of radiology, palpation and age results.

The areas under the curve (AUC) were calculated according to the method of Hanley and MCNeil ${ }^{13}$ and differences between AUC were tested ${ }^{14}$.

\section{Results}

A total of 2676 breast examinations were recorded during the study period.

Six hundred twenty-two examinations were not included in the study because mammography was done as a follow up to breast-saving surgery or amputation and 92 examinations were not included because ultrasonography was done without marnmography.

Furthermore, 18 examinations were excluded because breast cancer was diagnosed on a previous visit during the study periad and no examination was excluded because breast cancer was diagnosed at a subsequent visit.

Consequently, 1944 examinations were included for 1890 different patients: 1840 patients were included once, 46 were included twice $(2 \%)$ and 4 were included three times $(0.2 \%)$. In the analysis the total number of examinations included (1944) was taken as the total number of patients.

Referral for breast imaging was made by general practitioners in 1507 patients $(77 \%)$, specialists in 420 patients (22\%) and others in 17 patients $(1 \%)$.

The main reasons for referral were the accurrence of a breast lump (nn=528, 27\%), pain $(n=408,21 \%)$, control mammography of former benign pathology $(n=208$, $11 \%)$, mastitis $(n=177,9 \%)$, family history of breast cancer $(n=146,8 \%)$, patients' own requests $(n=95,5 \%$ ) and further investigation of an abnormality found by the nation-wide breast cancer screening program $(n=33,2 \%)$. The mean age of the patients was 46.1 years (range $14-94$ years).

Bilateral mammography was performed in 1872 patients $(96 \%)$, and a single breast was investigated in 72 patients $(4 \%)$. The total number of breasts examined was 3816 .

Additional ultrasonography was performed in 542 patients $(28 \%)$ in 791 breasts. The main reason to perform ultrasonography was to differentiate cystic from solid masses. These patients were significantly younger than the group who did not undergo ultrasonography ( 4.6 years).

Further results are presented on the level of breasts, referred to as cases.

After 12 months pathology results were available for 393 cases, obtained from FNA cytology $(n=193)$, lumpectomy $(n=69)$, surgical biopsy $(n=47)$, amputation $(n=47)$ and excision under radiological localization $(n=37)$. There were 118 malignancies, of 
which 116 were diagnosed within 3 months after mammography. The remaining 2 cases of cancer were reported 7 and 10 months after breast imaging. All cases without pathology data were assumed to be free of malignancy $(n=3698)$. No malignancies were found within the group patients with multiple examinations. In 3 patients breast cancer was diagnosed in both breasts, leading to a prevalence of breast cancer in this population of $6.1 \%$ (115/1890 patients).

Table 1: Palpation and radiological breast imaging scores for pathology positive and negative coses. $\ln =3816)$.

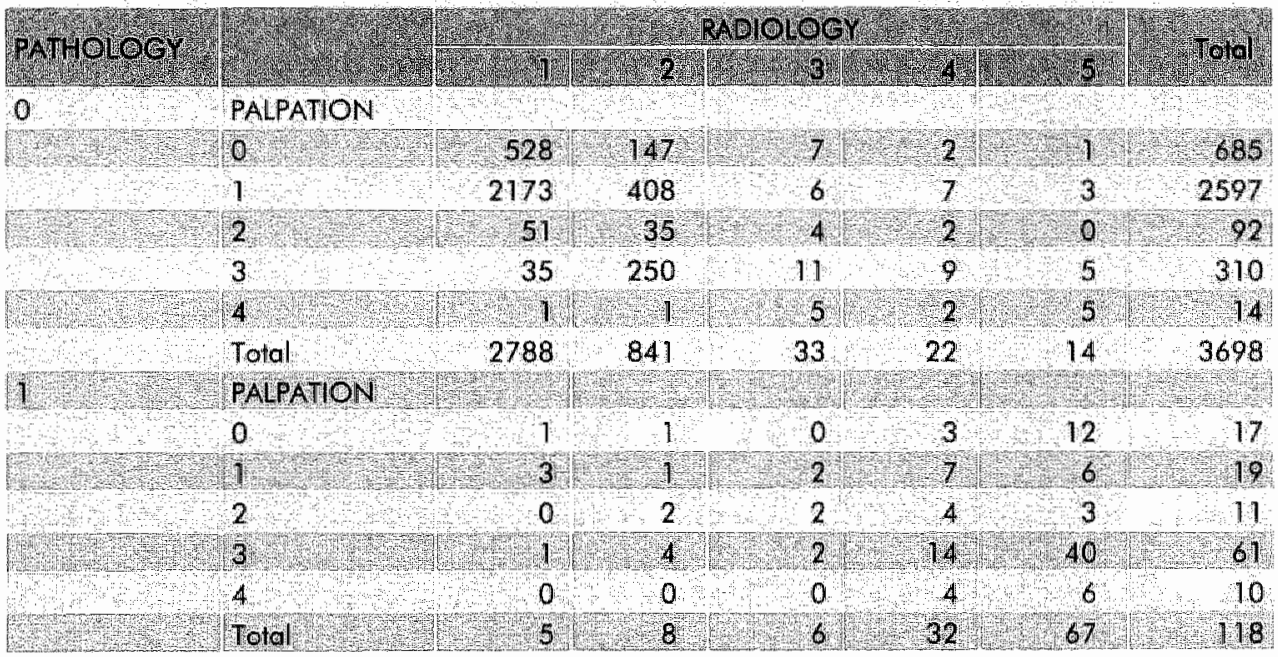

Pathology scores: $0=$ Normal, benign, $1=$ Malignant.

Radiology scores: $1=$ Normal, $2=$ Bienign, $3=$ Uncertain benign, $4=$ Suspect malignant ${ }_{4} 5=$ Malignant. Palpation scares: $0=$ Palpation not performed, $1=$ No palpable abnormality, $2=$ Vaguely palpable cabnormality, 3 = Circumscript abnormality, 4 : Evident abnormality, not sharply defined.

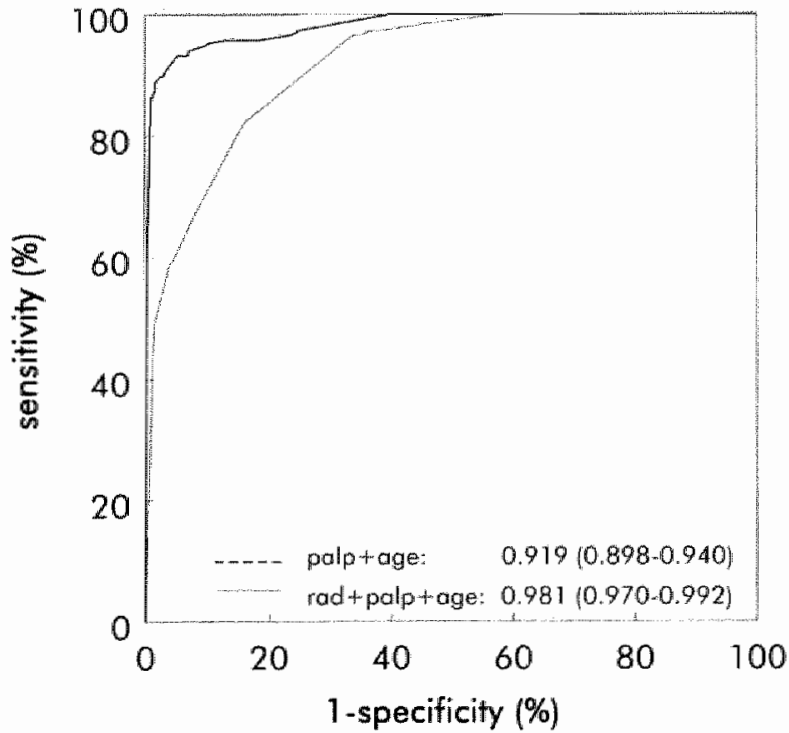

Figure 1: $\mathrm{ROC}$ curves for palpation with age and for radiological breast imaging combined with palpation and age (AUC, $95 \% \mathrm{Cl}$ betwaen brackets)

The results on palpation and radiological breast imaging in the presence and absence of malignancy for all 3816 cases are shown in Table 1. The sensitivity and specificity of radiological imaging depends on the cut-off point used to define positive cases and can be calculated using data from Table 1. The largest diagnostic value of radiological imaging was found at the cut-off point 
between berign and uncertain benign, with a sensitivity of $89 \%$ and a specificity of $98 \%$ on the level of individual breasts (sensitivity=1105/118.100\%, specificity $=3629 / 3698 \times 100 \%$. There were 69 false-positive and 13 false-negative cases. When analyzing on potient level, the sensitrity and specificity at this cut-off point was $90 \%$ and $97 \%$, respectively.

Logistic regression analysis showed that radiolagical imaging, palpation and the age of the patient were all significant predictors of malignancy $(p<0.00), p=0.004$, $p=0.01$, respectively). Using the results of this analysis $R O C$ curves were plotted for the results of palpation and age ( $A \cup C=0.919,95 \% \mathrm{Cl}=0.898-0.940$ ) and for the process of breast diagnosis, consisting of radiology combined with palpation and age $(A \cup C=0.981,95 \% \mathrm{Cl}=0.970-0.992)$ (Figure 1). The AUC differed significantly $(p=0.007)$. From these curves it can be deduced that, hypothetically, breast imaging can reach a sernsitivity of $100 \%$, with a specificity of $60 \%$ as a consequence. The AUC for results of radiological imaging only was 0.961 (95\% $\mathrm{Cl} 0.936-0.986)$, which was similar to the AUC for breast diagnosis ( $p=0.2$, curve not shown).

\section{Discussion}

In our non-screening clinical population, radiological breast imaging had a sensitivity and specificity of $89 \%$ and $98 \%$. These results are comparable to of Zonderland et al." , who reported a sensitivity of $91 \%$ and specificity of $98 \%$ for mammography combined with ultrasonography, and to those of Duilim et al. ${ }^{10}$, who reported a sensitivity of $92 \%$ and specificity of $98 \%$ for integrated mammography and ultrasonography in a clinical population. In our study population a $6.1 \%$ prevalence of breasit cancer was found, which is similar to Zonderland et al. and Duijm et al., who reported a prevalence of $7 \%$ and $5 \%$, respectively $10,11,15$.

Our follow up period is shorter than that used in these other studies. A 1 -year follow up was chosen to maximize the chance of detecting malignancies that were actually missed and to minimize the chance of finding newly developed cancers $q_{1} 1 \sigma_{n} 17$. Because only 2 of 118 malignancies were detected after 3 months of follow up, we believe that only a few additional cases of cancer would have been found through longer follow up and that these cases are likely to be newly developed rather than missed cases.

Uitrasonography was performed in $28 \%$ of all patients. Other descriptive studies report a range of $23.51 \%$ of patients undergoing additional ultrasonographic examination on clinical indication $3,8,10,11,18$.

Radiological imaging, palpation and age were all significant predictors of malignancy in this study, which is concordant with the results of Purasiri et al. ${ }^{8}$.

Procedures were carried out in fixed order by the same radiologist, leading to included prior knowledge of the clinical status and age of the patient in the interpretation of radiological imaging tests. Furthermore, knowledge of mammography results probably influenced the interpretation of the ultrasonographic examination. As it would be impossible to study them as separate modalities here, one integrated radiological diagnosis was registered for mammography and ultrasonography together.

The dependence of the diagnostic modalities in this study is shown by the equality of the AUC of ROC curves for radiological imaging tests with and without results on palpation and age. This finding suggests that prior results of palpation and age have influenced the interpretation of radiological breast imaging. A possible way to fully 
separate these diagnostic modalities would be to blind the radiologist to results af prior examinations when scaring the diagnostic test under study. Nevertheless, current procedures represent the way breast imaging is performed in most clinics, which makes our results applicable to daily practice.

The ROC curve shows that the process of breast diagnosis can theoretically detect all breast cancers. The clinical work-up in this population confirms these results as 116 of $118(98 \%)$ cancers were diagnosed.

This study shows the large diagnostic value of radiological imaging tests in addition to results on palpation and age in the detection of breast cancer. A sensitivity close to $100 \%$ can be reached. 


\section{References}

1. Parker S, Tong T, Bofden S. Canicer statisfics, 1997. CA cancer J Clin 1997; 47:5-27.

2. White $G$, Griffith $C J$, Nenstiel RO, Dyess DL. Breast cancer: reducing mortality through early detection. Clinician Reviews 1996; 6 (9):77-79, 83-84, 88-94, 100-106.

3. Visser 0 . Incidence of cancer in The Netherlands; 1995. Seventh report of The Netherlands

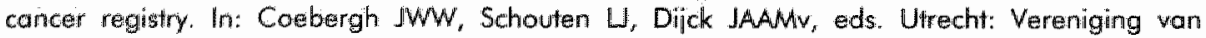
Integrale Kankercentra, 1998:1-88.

4. Hindle WH, Davis $L$, Wright D. Clinical value of mammography for symptomatic women 35 years of age and younger. Am J Obstet Gynecol 1999; 180:1484-90.

5. Roche NA, Given-Wilson RM, Thomas VA, Sacks NPM. Assessment of a scoring system for breast imaging. Br J Surg 1998; 85:669-672.

6. Day PJ. O'Rourke MGE. The diagnasis of breast concer: a clinical and mammographic comparison. Med J Aust 1990; 152:635-639.

7. Meden $H_{,}$Neves K.P. Röben-Kämpen $S$, Kuhn W. A clinical, mammographic, sonographic and histologic evaluation of breast cancer. lint J Gynaecol Obstet 1995; 48:193-199.

8. Purasiri P, Abdalla M, Heys SD, et al. A novel diagnostic index for use in the breast dinic. J R Coll Surg Edinb 1996; 41:30-34.

9. Wallis MG. Walsh MT, Lee JR. A review of false negative mammography in a symptomatic population. Clin Radiol 1991; 44:13-15.

10. Duijm LEM, Guit GL, Koomen AR, Willebrand D. Sensitivity, specificity and predictive values of breast imaging in the detection of cancer. Br J Cancer 1997; 76 (3):377-381.

11. Zonderland HM, Coerkamp EG, Viijver $M, J$, van de, Voorthuisen A, E. Diagnosis of breas: cancer: Contribution of US as an adjunct to mammagraphy. Radiology 1999; 213:413-1422.

12. American College of Radiology. Assessment categaries. \|llustrated breast imaging reporting and data system (lllustrated BI-RADS). Reston: VA: American College of Radialogy, 1995.

13. Hanley JA, MCNeil BJ. The meaning and use of the area under a receiver operating charactleristic (ROC) curve. Radiology 1982; 143:29-36.

14. Hanley JA, MC Neil BJ. A method of comparing the areas under receiver operating characteristic curves derived from the same cases. Radialagy 1983; 148:839-843.

15. Robertson $\mathrm{CL}$. A private breast imaging practice: medical audit of 25,788 screening and 1,077 diagnostic examinations. Radiology $1993 ; 187: 75.79$.

16. Joansuu H, Asola R, Holli K, Kumpulainen E, Nikkanen V, Parvin L. Delaved diagnosis and large size of breast cancer after a false negative mammogram. Eur J Cancer 1994; 30:1299-302.

17. Patel MR, Whitman GJ. Negative mammagrams in symptomatic patients with breast cancer. Acad Radiol 1998; 5:26-33.

18. Den Heeten GJ, Van Rooij WJJ Roukema JA. Echografie is van belang als aanvullend onderzoek bij mammografie. Ned Tildschr Geneeskd 1993; 137:2378-2383. 


\section{THE ROLE OF ULTRASONOGRAPHY AS ADJUNCT TO MAMMOGRAPHY IN THE DETECTION OF BREAST CANCER: A SYSTEMATIC REVIEW}

Karin Flabbe, Patricia J. Nelemans, Alfons G.H. Kessels, Geerard L. Beets, Maarten F. von Meyenfeldt, Jos M.A. van Engelshoven

Eur J Canc 2002;38:1044-1050. 


\section{Abstract}

\section{Aim}

To summarize the diagnostic performance of ultrasonography as adjunct to mammography in the detection of breast cancer and to ridentify clinical indications.

\section{Methods}

A systematic review was performed of all publications in MEDLINE and EMBASE between 1990-2000 on the role of ultrasonography as an adjunct to mammography.

\section{Results}

22 studies were included, showing a large variety in indications for uttrasonography and variations in the diagnostic performance of mammography and ultrasonography.

There were six studies comparing a combined diagnosis of mammography and ultrasonography together with mammography alone, of which three studies had an increased sensitivity at the cost of a lower specificity.

The methods of selecting the study population and interpretation of ultrasonography significantly influenced the diagnostic performance of mammography and ultrasonography relative to each other $(p=0.003, p=0.03$, respectively).

\section{Conclusion}

Based on the studies reviewed, little evidence-based support was found to confirm the well recognized value of ultrasonography as an adjunct to mammography in the detection of breast cancer in clinical practice. Furthermore, no clinical indications for additional ultrasonography could be defined. The heterogeneity in the diagnostic performance in these studies may be explained by the methods of patient selection and ultrasonography interpretation, as well as by their poor quality. 


\section{Intraduction}

Mammography is the basic imaging modality for the evaluation of patients with breast abnormalities. In response to the diagnostic deficiency of mammography in the differentiation between cysts and solid tumors, other imaging modalities have been developed and optimized for their use in breast diagnosis, with the most relevant method being ultrasonography.

Additional breast ultrasonography can lower the number of indeterminate mammographical findings by downgrading them to benign findings or upgrading them to suspect malignant findings and is expected to increase the specificity of mammography and clinical examination ${ }^{2}$.

Apart from differentiating cysts from solid masses, other indications for ultrasonography mentioned in the literature are: evaluation of palpable masses not visible in a radiographically dense breast, especially in young women, evaluation of masses not completely evaluated with mammography, inflammation, guidance for intervention procedures, evaluation of mammographic asymmetry and evaluation after augmentation mammoplasty and breast conservation surgery 1.5 .

Lang-term clinical experience has shown the value of ultrasonography in differentiating cysts from solid breast tumors, but its role in the differentiation between mallignant and benign lesions is still under discussion 6.8 . Furthermore, the use of ultrasonography as screening tool is discouraged because of unacceptably high falsenegative and false-positive rates $4,9.10$.

The proportion of patients in whom breast ultrasonography is considered necessary is increasing. In most hospitals in The Netherlands, ultrasonography is currently being used as a supplement to mammography in approximately $40 \%$ of patients who are referred for breast imaging. This fact implies that in the remaining $60 \%$ of cases it is decided by the consultant that additional ultrasonography examination is not indicated.

This development raises questions as to what the available evidence is for the diagnostic value of ultrasonography as an adjunct to mammography in the detection of breast cancer and what the indications are for referring patients who have had mammagraphy to undergo ultrasonography.

To answer these questions, a systematic review was performed of studies in which both mammography and ultrasonography were performed.

\section{Methods}

The MEDLINE, EMBASE and Cachrane databases were searched for all available publications between 1990-2000 describing the diagnostic performance of ultrasonographic examination as an adjund to mammography in the detection of breast cancer. Titles and abstracts were screened for possible inclusion in the study and the references were screened for additional publications.

Studies were sellected when meeting the following inclusion criteria: estimates on sensitivity and specificity of both mammography and ultrasonagraphy had to be reported or had to be calculable, articles had to written in English, German, French, Italian or Dutch and the gold standard should be pathology preferably from histological needle biopsy or surgery, or follow up of preferably 1 year or longer of patients with negative imaging results. 
The selected papers were read separately by four reviewers. The following data were extracted when available: year of publication, selection of the study population. number of patients examined by ulfrasonography, characteristics of patients in whom ultrasonography was performed, the definition of a positive imaging result, the way in which ultrasonography was interpreted (with or without prior knowledge of mammographical results), the mean or median age of the study population, the age distribution, the percentage of patients with dense breast parenchyma and the prevalence of malignant and benign lesions. Furthermore, estimates of sensitivity and specificity were recorded for mammography and ultrasonagraphy separately and. when available, for the radiological diagnosis in which mammographic and ultrasonographic results were combined into one conclusion.

As a measure for diagnostic accuracy, the diagnostic odds ratio (DOR) was used. The DOR combines the sensitivity and specificity into one estimate and can be deriwed by dividing the odds of a positive test result among diseased persons by the adds of a positive test result among non-diseased persons ((sensitivity/(1-sens)) * (specificity/(1spec)]l.

In ordeir to obtain a symmetrical distribution, the natural logarithm of the DOR was calculated for mammography and ultrasonography in each study. The difference between the InDOR for ultrasonography and mammography (InDORus-InDORmam) was taken as the diagnostic performance of mammography and ultrasonography relative to each other.

The influence of the methods of selecting the study population and interpreting ultrasonographic results on the diagnostic performance was evaluated by nonparametric testing.

Three groups of studies were distinguished based on the way in which the study population was selected. Studies classified in group 1 included patients who were referred for breast imaging because of palpable breast lumps or other abnormal findings on clinical examination. Studies in group 2 included patients who underwent ultrasonggraphy because of suspicious lesions on mammography or clinical examination and studies in group 3 included only patients who were referred for biopsy or surgery.

Within these three groups, a further distinction was made between studies in which ultrasonographic images were interpreted independently or blinded from mammography results and studies in which ultrasonographic interpretation was done with prior knowledge of mammography results. The diagnosis from ultrasonographic interpretation with prior knowledge of mammography differs from the combined radiological diagnosis in that mammography results facilitated the detection of abnormalities by ultrasonography, but the diagnosis was still based on the ultrasonogiraphic results.

In order to identify subgroups of patients with the highest diagnostic yield for ultrasonography, ultrasonographic performance was studied for different indications. Finally, the impact of the prevalence of breast cancer, mean or median age of the population, the size of the study population and the year of publication on the diagnostic performance of mammography and ultrasonography relative to each other was studied. Analyses were performed for all patients in whom both mammography and ultrasonography were performed. 


\section{Results}

The literature search identified 164 publications in MEDLNE, 51 publications in EMBASE and no hits in the Cochrane database. MEDLINE and EMBASE hits partly overlapped. Screening all titles and abstracts resulted in 47 suitable papers, while screening of the references added another 16 papers. Thus, a total of 63 publications were collected, read and tested on the inclusion criteria.

Twenty-one papers were found suitable for inclusion in the review. Reasons for exclusion $(n=42)$ are shown in table 1. Eighteen studies were excluded as they investigated the role of ultrasonography in breast cancer-positive patients $111-27$. From these studies, only numbers of true-positive and false-negative results can be derived. The sensitivity of mammography and ultrasonography in these studies ranged from 66 to $95 \%$ and 68 to $100 \%$, respectively.

One publication was divided into two studies as data were given for two separate study centers ${ }^{28}$.

The review therefore included 22 studies.

Table 1: Reasons for exclusion of publications $(n=42)$.

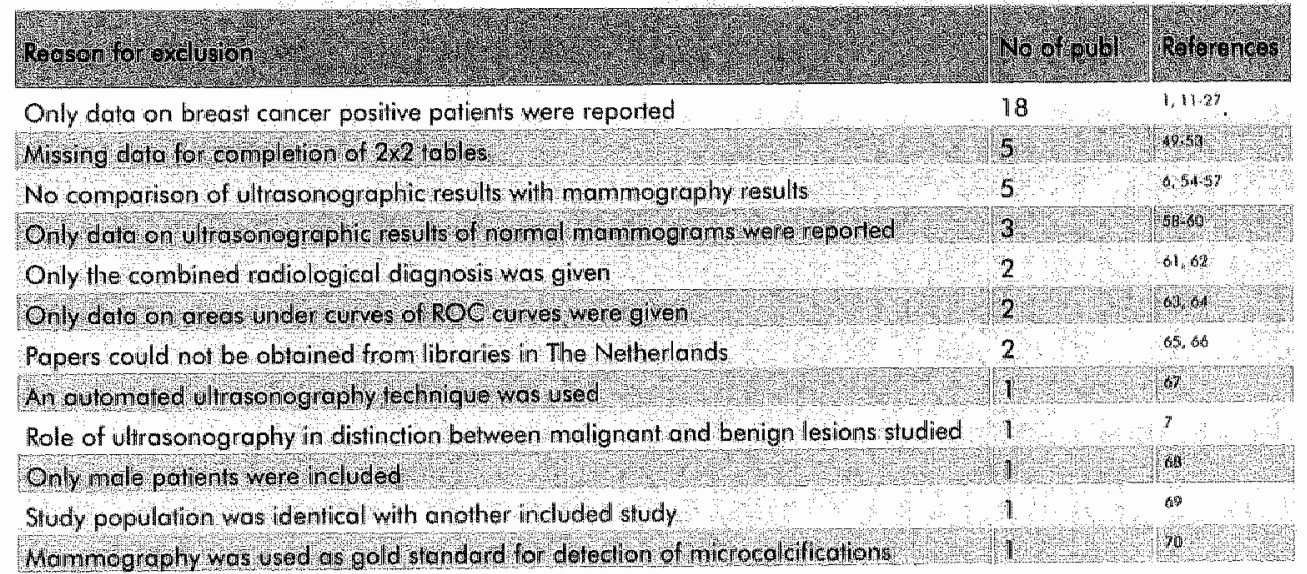

The median study size was 213 (range 37-2079 patients). The median prevalence of breast cancer in these populations was $45 \%$ (range $5.5-72.2 \%$ ). The studies included were mostly European, with nationalities of the authors being British ( $\mathrm{n}=6$ ), German $(n=4)$, Dutch $(n=3)$, Italian $(n=3)$, Norwegian $(n=1)$, Finnish $(n=1)$ and Turkish $(n=1)$. The non-European studies were from Australia $(n=1)$, Japan $(n=1)$ and China $(n=1)$.

The study size, prevalence of breast cancer, mean or median age of the study population and the diagnostic performance of mammography and ultrasonography in these studies are shown in table 2 .

In order to study the diagnostic role of ultrasonography, most studies compared the sensitivity and specificity of ultrasonography (range $49 \%-100 \%$ and $29-100 \%$, respectively) with those for mammography (range $57 \%-97 \%$ and $36 \%-97 \%$, respectively). Six studies compared the results of a combined diagnosis of mammagraphy and uitrasonography with the results of mammography alone ${ }^{29-34}$. 
In all six studies, the sensifivity increased by using ultrasonography as an adjunct to mammography. However, in three of the six studies the specificity decreased.

Table 2: Oyerview of the study size, prevalence of breast cancer, mean or median oge and diagnostic performance of mammography (MAM) and ultrosonography (US) in 22 studies included in the review.

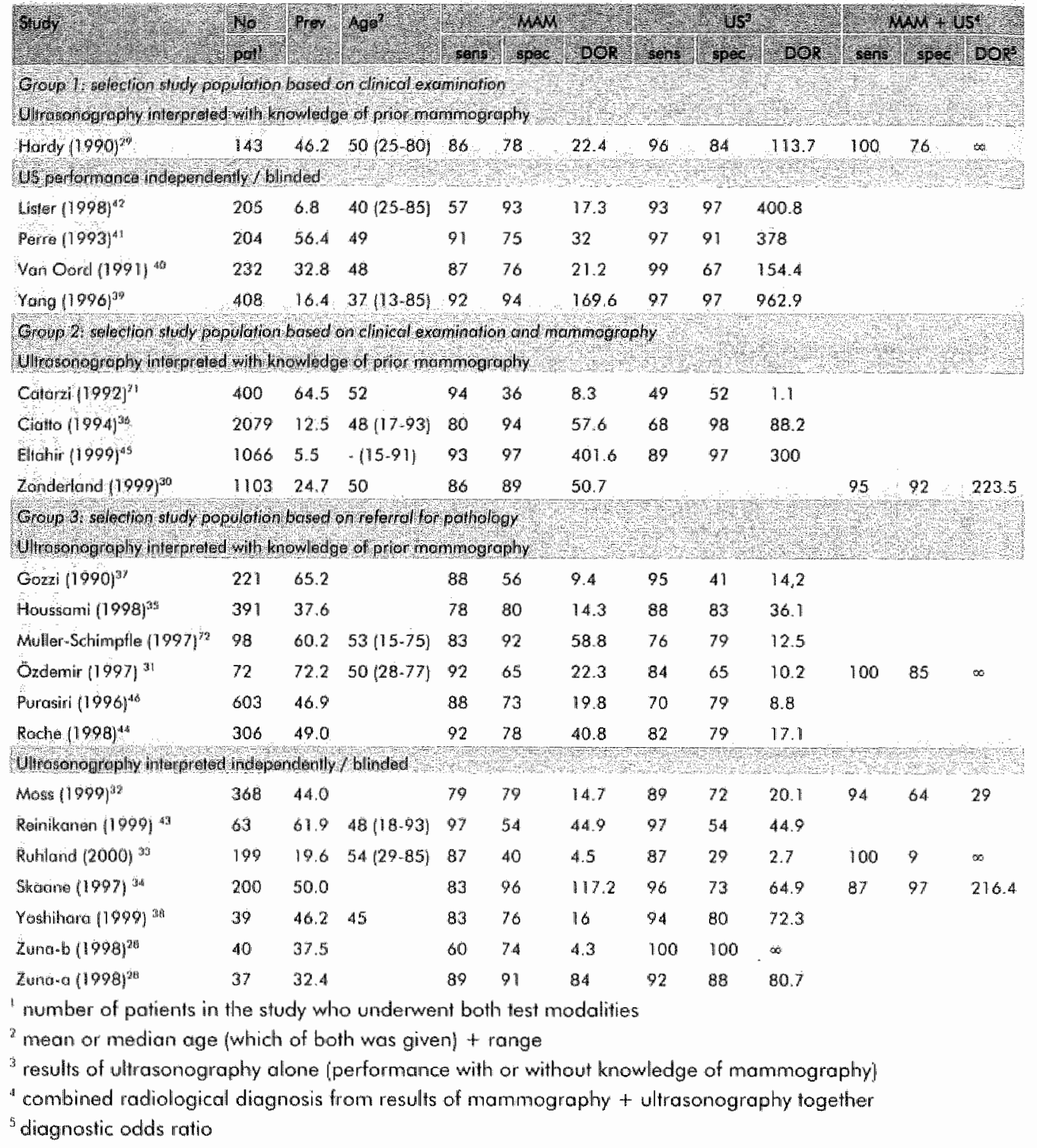

As shown in table 2, five studies were allocated to group 1, four studies to group 2 and 13 studies to group 3. The influence of the selection of the study population on the diagnostic performance of mammography relative to ultrasonography was 
statistically significant ( $p=0.003$ ), suggesting a higher relabve diagnostic performance in patients selected through clinical examination, which is illustrated in figure I.

A difference between InDORus and InDORmam larger than 0 indicates that ultrasonography performed better than mammography, whereas a difference below 0 indicates that mammography performed better. In more than half of the studies, the diagnastic performance of ultrasonography was better than for maimmography..

Moreover, figure 1 distinguishes between studies in which ultrasonography was. interpreted with prior knowledge of mammography results $(n=10)$ and studies in which ultrasonography was interpreted independently $(n=11)$. In one study, anly a final diagnosis of mammography and ultrasonography together was given 30 . Ultrasonagraphy performed better than mammography in four of the 10 studies in which prior knowledge of mammography results was available when interpreting ultrasonography 29.35-37 and in eight of 11 studies in which ultrasonography was interpreted independently 28,32. 38-42. These results indicate a higher relative diagnostic performance when no prior knowledge of mammography was available $(p=0.03)$.

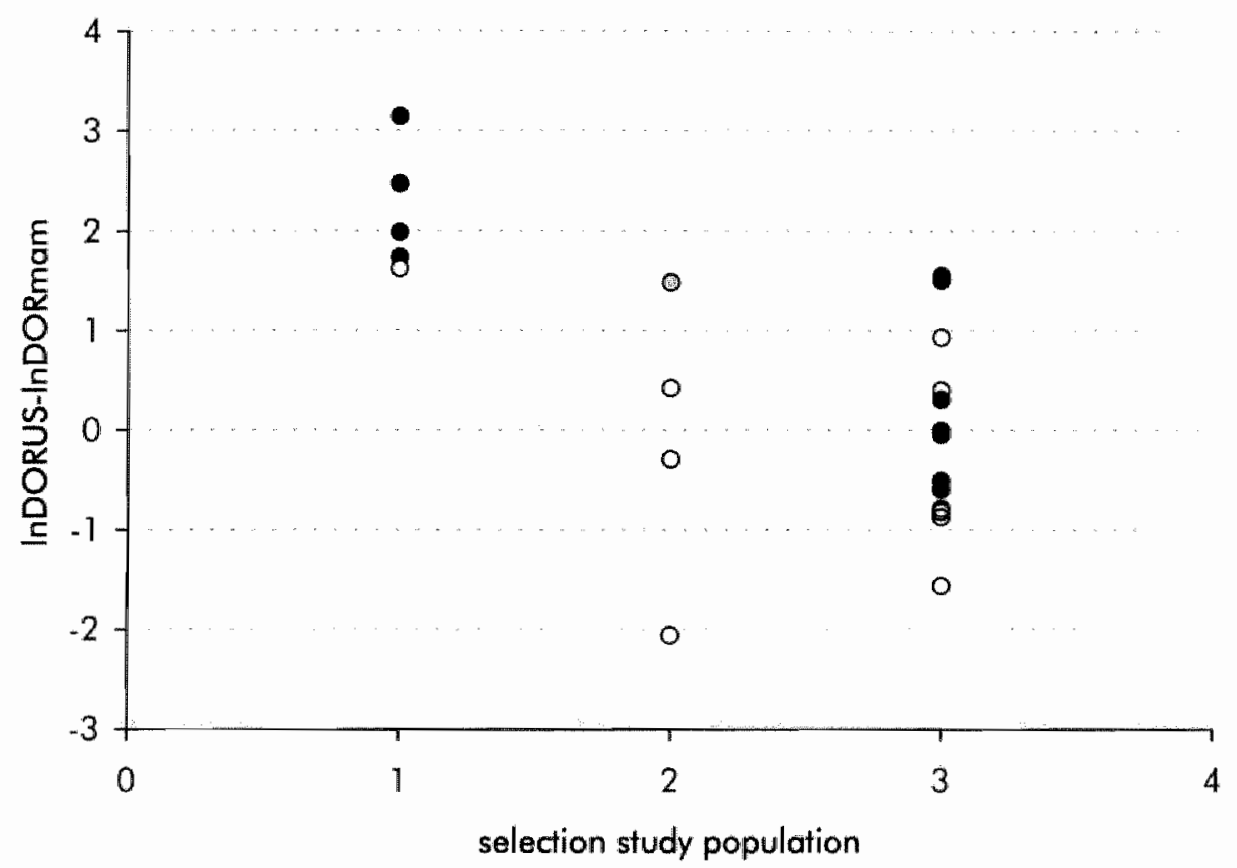

Figure 1: Diagnostic performance of uthrasonagraphy relative to mammography UnDORus-1nDORmom in studies in the review, according to the selection of study population and procedures of uttrasonographic interpretation. Igroup $1=$ selection potients based on clinical examination, group $2=$ selection of patients based on mammagraphy, group $3=$ selection of patients based on pathology; - = ultrasonography performed without knowledge of prior mammography, $O=$ uttrasonography performed with knowledge of prior mammography and clininical examination, $O$ = ultrasonography results anly as combined radiological diagnosis with mammographyl.

A large variety of indications for breast ultrasonography were found, which made it impossible to study the diagnostic performance of mammography and ultrasonography for different subgroups of patients. In some studies on patients with 
paipable breast lesions, ultrasonography was performed in all patients $34.38-41.43$. In one study, the presence of palpable lesions was an indication for ultrasonography 30 . Other indications were patients' age $<3532,44,45$ or $<25$ years 35 , non-conclusive abnormalities 30.35 .45 or dense breast tissue ${ }^{32}$ on mammography. In two studies, ultrasonography was performed only in the last part of the study 29, 46 and one study failed to specify the indications for ultrasonography at all 4.4.

Finally, a reverse correlation was found between the mean or median age of the study population, as well as for the prevalence of breast cancer, with the diagnostic performance of mammography and ultrasonography relative to each other (Kendall's tau correlation, $p=0.01$ and $p=0.1$, respectively).

The number of included patients or the year of publication did not influence the diagnostic performance $(p=0.2$ and $p=0.4$, respectively).

\section{Discussion}

This review shows that the indications for ultrasonography as an adjunct to mammography vary among different studies and that evidence for the additional diagnostic value of ultrasonagraphy as an adjunct to mammography is almost lacking in the available literature.

Initially, the aim of this study was to perform a meta-analysis on the diagnostic performance of ultrasonography as an adjunct to mammography in the detection of breast cancer, but because of the lack of required data, a systematic literature review was conducted instead.

We showed that the method of sellecting the study population strongly influenced the performance of mammography and ultrasonography relative to each other. The majarity of studies in this review included patients who proceeded to biopsy or surgery (group 3), as, for these patients, the results from a gold standard was readily available. However, in daily practice, patients will be selected for ultrasonography on the basis of results of clinical and mammographic examination and ultrasonography will be interpreted with full knowledge of these results.

The role of ultrasonography as an adjunct to mammography in the detection of breast cancer is therefore studied mast accurately with reference to daily practice, by comparing the accuracy of a diagnosis based on mammography alone with the accuracy of a diagnosis based on the use of mammography and ultrasonography as integrated diagnostic modalities within consecutive patients who are selected for ultrasonography based on clinical and mammagraphic results.

In this review, six studies compared a combined radiological diagnosis of mammography and ultrasonography together with mammography results alone. The acquisition of the combined radiological diagnosis was poorly described or not given at all, although it may be assumed that a positive radiological diagnosis was reached when either mammography or ultrasonography reported a positive diagnosis. The results of these studies seem to conform to the expectation that combining ultrasonography with mammography results in a higher sensitivity, but in three of the six studies the increase in sensitivity was reached at the expense of a substantial decrease of specificity.

In only one of these six studies were patients selected through mammographic results 30. Within this population tested with both modalities, the sensitivity increased 
significantly ( $86 \%$ and $95 \%$, respectively) while the specificity increased as well $189 \%$ and $92 \%$, respectively).

We also showed that the method of interpreting the ultrasonographic images significantly influenced the performance of mammography and ultrasonography relative to each other. Surprisingly, in six of the 10 studies in which prior knowledge of mammography was available when interpreting ultrasonography, the diagnostic performance of ultrasonography did not exceed the performance of mammography. We have no acceptable explanation for this finding, other than that ultrasonography can have false-negative and false-positive results. Furthermore, the operator dependence of the technique and the quality of equipment may have an effect on these results.

The influence of methodology on the diagnostic performance emphasizes that one should be cautious in pooling the results of all studies. This is frequently done by employing meta-analytical techniques and may introduce bias in the overall results.

In many papers, basic information on study procedures and the study population was insufficient or missing, as a result of which it remains unclear to which category of patients the results can be applied. This failing made it very difficult to extract the required data from the papers. As an example, nine studies in this review failed to report the mean age of the study population $28,32,34,35,37,44-47$, while the remaining studies reported only mean or median values, the range or the age distribution of the study population. A detailed description of the study population is required to be able to compare the results of studies in a sensible way ${ }^{30}$.

The frequent use of breast ultrasonography has had a significant impact on healthcare dellivery because it has greatly reduced the number of cytological and histological biopsies performed for benign breast cysts 5. However, routine application of ultrasonography may generate many unnecessary biopsies 48. Furthermore, it has a large impact on the time schedule of breast imaging dinics, as it is a time-consuming and operator-dependent technique.

The application of ultrasonography as an adjund to mammography in the differentiation between cysts and solid breast tumors and in the evaluation of palpable masses in young women is well recognized in clinical practice based on long-term clinical experience.

Meanwhille, ultrasonography is being used in a number of clinical situations in which no efficacy has been demanstrated, such as the routine evaluation of the postoperctive breast and asymmetric breast density. Whereas breast ultrasonography causes no harm to the patient, its cost and lack of clinical benefit for the patient make the use of ultrasonography in these situations unwise 10 .

Unfortunately, based on this review no subgroups of patients could be selected with the highest or lowest diagnostic yield for ultrasonography. However, such information is necessary to advise in restricting the application of ultrasonography to specific subgroups of patients. Deeming the use of ultrasonography in the remaining patient groups redundant would significantly reduce claims on health care resources (time, personnel, appliances). Therefore, further research is meeded in consecutive patients to identify the subgroups of patients in which the highest diagnostic yield from ultrasonography would be obtained.

Concluding, based on the studies reviewed, little evidence-based support was found to confirm the well-recognized value of ultrasonography as adjunct to 
mammography in the detection of breasi cancer in clinical practice. Furthermore, no clinical indications for additional ultrasonography could be defined. The heterogeneity in the diagnostic performance in these studies may be explained by the methods of patient selection and ultrasonography interpretation, as well as their poor quality. 


\section{References}

1. Skaane P. Ultrasonography as adjunct to mamnography in the evoluation of breast tumors. Acto Radiol Supp: 1999; $420: 1 \times 47$.

2. Mendelson EB, Tobin CE. Critical pathways in using breast US. Radiographics 1995; 15:935-45.

3. ACR standards for the performance of breast ultrasound examination. ACR STANDARDS, 1998 (Re.33): $1=4$.

4. Hurd TC, Edge SB. Breast cancer imaging. Surg Oncol Clin N Am 1999: 8:1-15.

5. Jackson VP, Reynolds HE, Hawes DR. Sonography of the breast. Semin Ultrasound CT MR 1996; $17: 460-75$.

6. Rahbar $G_{x}$ Sie $A C$, Hansen $G C_{n}$ et al. Benign versus malignant sollid breast masses: US differentiction. Radiology 1999; 213:889-94.

7. Stavros AT, Thickman D, Rapp CL, Dennis MA, Parker SH, Sisney GA. Solid breast nodules: use of sonography to distinguish between benign and malignant lesions. Radiology 1995; 196:123. 134.

8. Zonderland HM, Hermans J, Coerkamp EG. Ultressound variables and their prognostic value in a population of 1103 patients with 272 breast cancers. Eur Radiol 2000; 10:1562 -8.

9. Kopans DB. Breast-cancer screening with ultrasonography. Lancet 1999; 354:2096-97.

10. Jackson VP. The current role of ultrasonography in breast imaging. Radiol Clin North Am 1995; $33: 1161.1170$.

11. Chew $\mathrm{SB}$, Hughes $M$, Kennedy $C$, Gillett $D$, Carmalt $H$. Malmmographically negative breast cancer at the Strathfield Breast Centre. Aust N Z J Surg 1996; 66:134.7.

12. Cressa $C$, Gozzi $G$, Tonutti M, Macorig D, Tessa I. The diagnostic contribution of direct radiographic enlargement and of echography in the study of breast neoplasms]. Radiol Med (Torino) 1994; 87:405-11.

13. Croce P, Pricalo R, Montanari G, Mancastroppa A, Bertolotti P. [Diagnosis of breast carcinoma. Comparison of clinical, mammographic, echographic and cytological aspiration diagnosis in a group of 50 patients]. Minerva Chir 1991; 46:379-84.

14. Escollano E, Toumegras JM, Le Marchadour F, Bernard P. [Diagnastic difficulties in infilltrating labullar breast cancer: value of ultrasonography. 33 cases]. J Gynecol Obstet Biol Reprod 1997; 26:781-8.

15. Evans $N$, Lyons $K$. The use of ultrasound in the diagnosis of invasive lobular carcinoma of the breast less than $10 \mathrm{~mm}$ in size. Clin Radial 2000; $55: 261.3$.

16. Framarino dei Malatesta $M$, Fiorelli $C$, Bandiera $A F$, Veneziano M, Galati GM, Porfiri L Infiltrating lobular carcinoma of the breast (ILC). Diagnastic and therapeutic aspects. Eur. J. Gyncec. Oncol. 1995; XVI:36-39.

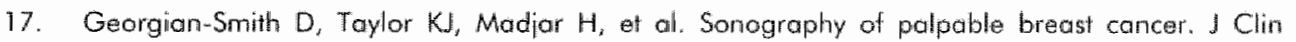
Ultrasound 2000; $28: 211 \% 6.6$.

18. Meden H, Neves KP, Räben-Kämpen $S$, Kuhn W. A clinical, mammographic, sonagraphic and histalogic evaluation of breast cancer. Int J Gyncecol Obstet 1995; 4.8:193-199.

19. Mitnick JS, Gianutsos R, Pollack AH, el al. Tubular carcinama of the breast: sensitivity of diagnostic techniques and correlation with histopathology. A.JR 1999; 172:319-323.

20. Pamilo M, Soiva M, Anthinen I, Roiha $M$, Suramo I. Ultrasonography of breastlesions deteded in mammography screening. Aet Radiol 1991; 32:220-225.

21. Paramagul CP, Helvie MA, Adler DD. Invasive lobular carcinoma: sonographic appearance and role of sonography in improwing diagnostic sensitivity. Radiology 1995; 195:231-4.

22. Pointon KS, Cunningham DA. Ulltrasound findings in pure invasive lobular carcinoma of the breast: comparison with matched cases of invasive ductal carcinoma of the breast. The Breasf $1998 ; 8: 188 \sim 190$. 
23. Risonan T, Thkokoski T, Autio AL, Apoja-Garkkinen M. Utrosonography of invosive lobular breast carchoma. Aicta Radiol 1998; 39:285.91.

24. Rotien $D$, Levollant $J M$. The walue of ufrasonic examination to delect and diagnose breast carcinomos. Andisis of the results obtained in 125 fumors using radiographic and ultrasound mammography. Ultrasound Obstet Gynecol $1992 ; 2: 203-214$.

25. Saarella 40 , Rissangen TJ, Kiviniemi HO, Paloneva TK. Mammographic and uttrasonographic findings in bilaterol breast cancer: o compiarative study. Eur Radiol 1998; 8:634-8.

26. Skadne P. The odditional walue of US to mammagraphy in the diagnosis af breast cancer. A prospective study. Acta Radiol 1999; 40 486-90.

27. Tohnosu $N$, Okuyama $K$, Kaide $Y$, et al. A comparison between ultrasanography and mammography, computed tomagraphy and digital subtraction angiography for the detection of breast cancers. Surg Today $1993 ; 23: 704-10$.

28. Zuna , Delome $S$, Huber $S$, ef al. Eine multizentrische studie zu diagnostischen kriterien in der mammasonagraphie. Statistische fallstricke und wege aus dem datendschungel. Radiologe 1998; 38.355 .363

29. Hardy $I R$, Powes $T H$, Judson I, al. How many tests are required in the diagnosis of palpable breast abnormalities? Clin Oncol (19: Coll Radiol 1990;2:148-52

30. Zanderland HM, Coerkamp EG, Viver M, J, wan de, Voorthuisen A, E. Diagnosis of breast cancer: Contribution of US as an aldjund tio mammography. Radiology" 1999; $213: 413-1422$.

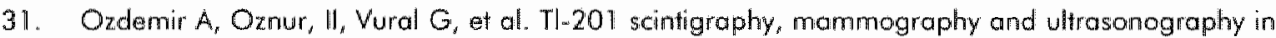
the exaluation of palpable and nonpalpable breast lesions: a correlative study. Eur I Radiol $1997,24: 145-54$

32. Mass HA, Britton PD, Flower CD, Freeman AH, Lomas DI, Warren RM. How reliable is modern breast imaging in differentiating benign from malignant breast lesions in the symptomatic population? Clin Rediol 1999; 54:676-82.

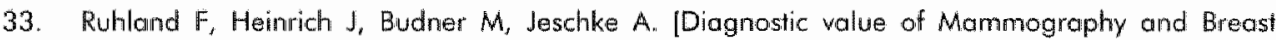
Ultrosound for Clinically Occult Lesions of the Breast]. Geburtshum Fravenheillk 2000; 60:104.110.

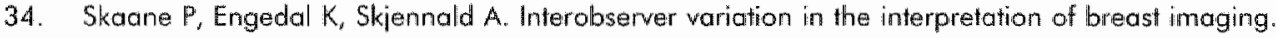
Comparison of mammagraphy, ultrasonography, and both combined in interpretation of palpable noncalcified breast masses. Acta Radioll 1997; 38:497-502.

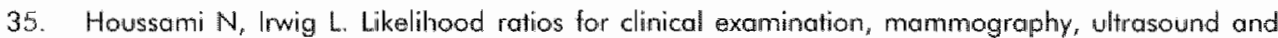
fine meedle biopsy in wamen with bireast problems. The Breast 1998; 7:85-89.

36. Cidtlo S, Rosselli dell Turco M, Catarz: S, Morrone D. The contribution of ultrasonography to the differential diagnosis of breast cancer. Neoplasma 1994; 41:341-345.

37. Gozri G, Stacul F Bassini A, Macorig D, Ukowich W. Evaluation of the role of mammography and echography in breast diseases in a controlled coseloadl. Radiol Med (Torino) 1990; 80:477. 82

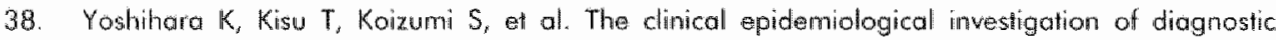
modalities in breast cancer detection--a comparison of ultrasonography and mammography. Fukuka ligaku Zorshi 1999; 90:39-45.

39. Yang WTY, Mok CO, King W "Tang $A_{*}$ Metrewell C. Role of high frequency ultrasonography in the evaluation of pelpable breast masses in Chinese women. JUltrasaund Med 1996; 15:637. 64.4

40. Oord JCv, Viet AMvd, Thyn CJP, Mak B, Hoogeboom GJ. The value of ultrasound mammography in palpable breast masses. Fortschr Röntgensir 1991, 155, 1:63-66

41. Perne Cl, de Hooge P. Hustinx PA, Muller WW. UUltrasonographic study of the palpable breast tumor is very useful]. Ned Tijdschr Geneeskd 1993; 137:2374.7.

42. Lister D, Evans $A$, Burrell $H C$, et al. The accuracy of breast ultrasound in the evaluation of dinically benign, symptomatic breast lumps. Clin Rodial 1998; 53:490.492. 
43. Reinikainen HT, Rissanen TJ, Pippo UK, Paivansalo M. Contribution of ulfrasonography and line-needle ospiration cytology to the differential dignosis of palpoble solud breast lesions. Acta Radiol 1999; 40:383-9.

44. Roche NA, Given-Wilson RM, Thomas VA, Sacks NPM. Assessment of a sconing system for breost imaging. Br $\$ Sulg 1998; 85:669-672.

45. Elohir $A$, Jibril $\mathcal{A}_{*}$. Squair 1 , et al. The accuracy of "one-stop" diagnosis for 1110 patients presenting to a symptomatic breast dinic. I R Coll Surg Edinb 1999.44:226-30.

46. Purasiri P, Abdalla M, Heys SD, ef al. A novel diagnostic index for use in the breast dinic. IR Coll Surg Edinb 1996; 41:30-34.

47. Muiler-Schimpfle M, Stoll P, Stern W, Kurz S, Danmann F, Claussen CD. Do mammography, sonography and MR mammography have a diagnositic benefit companed with nommography and sonography? AJR 1997; 168.

48. Bassett LW. Imaging of breast masses. Radiol Clim Morth Am 2000, 38:669-91, wii- whit.

49. BasseH LW, Ysrael M, Gold RH, Ysrael C. Usefulness of mommagrophy and sonography un women less than 35 years of age. Radiology 1991; $180.831-835$.

50. Jacob D, Brombart JC, Muller C, Lefebrre C, Massa F, Depoerck A. IAnalysis of the results of 737 subdinical breast lesions excisions. Valve of uttrasonography in the early diagnosis of bireast cancer, \Gynecol Obstet Biol Reprod 1997: $26: 27.31$.

51. Laine $H \mathbb{R}$, Tukeva T, Mikkola P. Holmström T. Assessment of mommography and ultrasound examination in the diagnosis of breast cancer. Eur I Ultrasound 1996; 3:9. 14.

52. Lam WW, Yang WT, Chan YL, Stewart IE, King W, Metreweli C. Role of MIBI breast scintigraphy in evaluation of palpable breast lesions. Br J Radiol 1996; 69:1152-8.

53. Morrow $M$, Wong $S$, wenta $L$. The evaluation of breast masses in women younger than forty years of age. Surgery 1998; 124:634-641.

54. Buchberger W, Dekoekkoek-Doll P, Springer P, Obrist P, Dunser M. Incidental findings on sonography of the breasi: clinical significance and diagnostic workup. AJR 1999; 173:921.927,

55. Ciloti $A$, Bagnolesi $P$, Maretti $M$ ef all. Comparison of the diagnostic pertormance of highFrequency ultrasound as a first- or second-line diagnostic tool in non-palpable lesions of the breast. Eur Radiol 1997; 7: 1240-4.

56. Hieken TJ, Velasco JM. A prospective analysis of office-based breast ultrasound. Arch Surg 1998; $133: 504-508$.

57. Butler RS, Venta LA, Wiley EL, Ellis RL, Dempsey PJ. Rubin E. Sonagraphic evaluation of infillrating lobular carcinorria. AlR 1999; 172:325-330.

58. Cox BA, Kelly KM, Ko P, Hertzog L, Stain S. Ulitrasound characteristics of breast carcinonial. Am Surg 1998; 64:934.938.

59. Gordon PB, Goldenberg SL. Malignant breast masses detected only by ultasound. Cancer 1995; $76: 626-30$.

60. Kolb TM, Lichy d, Newhouse $\mathbb{H}$. Occult concer in women with dense breasts: detection with screening US. diagnostic yield and fumor characteristics. Radiology 1998; 207:191 m 199 .

61. Duinn LEM, Guit GL, Koomen AR, Willebrand D. Sensitivity, specificity and predictive values of breast imaging in the detection of cancer. Br J Cancer $199 \% ; 6(3): 377 \times 381$.

62. Den Heeten GJ, Van Rooil WJJ, Roukema $\sharp A$. Echogratie is van belong als oanvullend onderzoek biil mammogratie. Ned Tijdschr Geneaskd 1993; 137:2378-2383.

63. Skaane P, Sager EM, Olsen JB, ef al. Diagnastic value of ultrasonography in patients with palpable mammographically noncalcified breast tumors. Adta Radiol 1999; 40:163.8.

64. Zonderland HM, Hermans, Hascher HC, Schipper J, Obermann W. Additional value of US to mammography: profit and loss. Eur Radial 1994; 4:51 i-516.

65. Diop-Ba S, Badione M, Niang EH, Ly Ba A, Affidja A, Favre Y. UContribution of mammagiraphy and echography to the diagnasis of breast cancer in Dakar: aproposi of 25 cases]. Dakar Med $1997 ; 42: 114-7$ 
66: Murdakt $G$, Kibar $M$, Alparsun $A$, Boga $H$. The use of $T c-99 \mathrm{~m}$ sestamu imaging in patients with breast masses: A complementary adjunct to uttrasonography and mammography. Ann Med Sci $1997 ; 6: 33.39$.

67. Richter $K_{5}$ Hamm $B$. Heywang-Kobrunner SH, ef al. [Aufomated mammany sonography and mammography: the differentiation of benign and malignant breast lesions). Rofo Fortschr Geb Rontgenstr Neven Bildgells Verfahr 1998; $169: 245-52$.

68. Ambrogetti $\mathrm{D}$, Ciatho $\mathrm{S}$, Calarzi $\mathrm{S}$, Muraca MG. The combined diagnosis af male breast lesions: a review of a series of 748 consecutive cases], Radial Med (Torino) 1996; $11: 356-9$.

69. Ciatto $S$, Rosselli del Turca $M$. Catarzi $S$, Morrone D. Bonardi $R$. The diagnostic role of breast achographyl. Radiol Med (Torino) 1994; 88:221-4.

70. Yang WT, Suen M, Ahuja A, Metreweli C. In wivo demanstration of microcalcification in breast concer using high resolution ultrasound. Br J Radiol 1997; 70:685-90.

71. Catarai $S_{s}$ Giuseppetti GM, Rizzatto $G$, ef al. IA multicenter study for the evaluation of the diagnostic efficiency of mammography and echagraphy in nompalpable breast neoplasms. Radiol Med (Torina) 1992; 84:193-7.

72. Muller-Schimpfle M, Stern W, Stoll P, Kaiser JW, Claussen CD. [Mammography and manmary ultrasonography: which examination sequence is preferable?]. Rofo Fortschr Geb Rontgenstr Neven Bildgeb Vertahr 1997; 167:348-54 


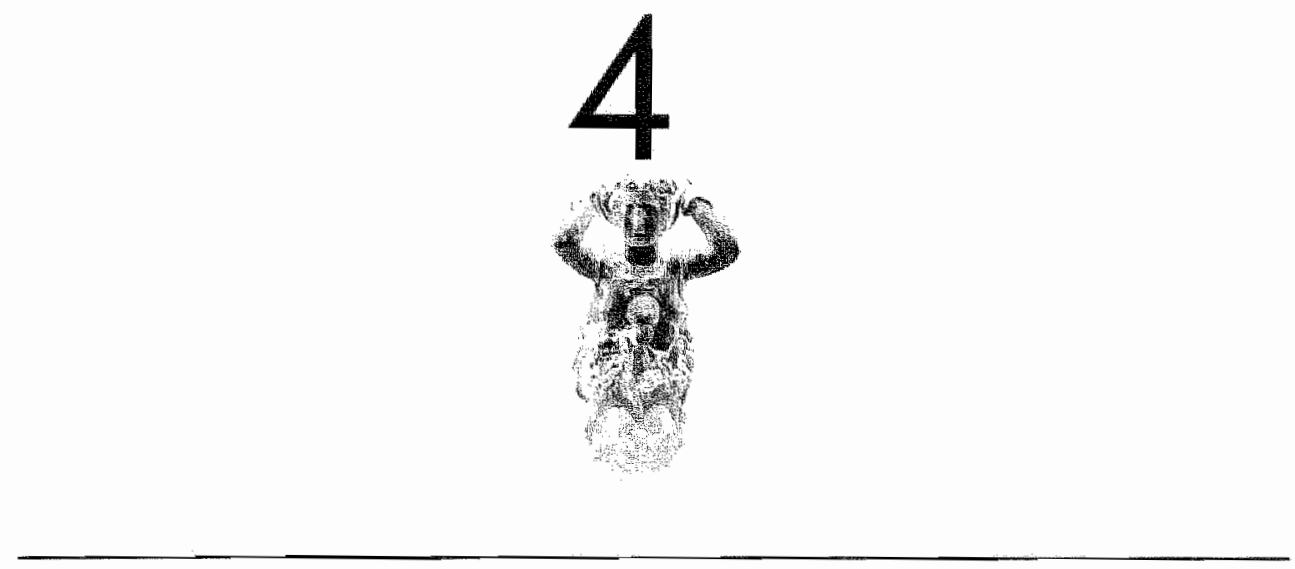

\section{THE ADDITIONAL DIAGNOSTIC VALUE OF ULTRASONOGRAPHY IN THE DIAGNOSIS OF BREAST CANCER}

Karin Flobbe, Anne Marie Bosch, Alfons G.H. Kessels, Geerard L. Beets, Patricia J. Nelemans, Maarten F. von Meyenfeldt, Jos M.A. van Engelshowen

Arch Int Med, 2003 (in press) 


\section{Abstract}

\section{Background}

The use of ultrasonography in diagnostic breast imaging is increasing. Restricting ulltrasonography to subgroups of patients who benefit mast, would result in a more efficient and effective application. This study assessed the diagnostic value of ultrasonography as adiunct to mammography and clinical examination in the detection of breast cancer and the feasibility of selecting subgroups of patients who benefit most.

\section{Methods}

Between October 1999 and August 2000 all consecutive patients referred for breast imaging underwent additional ultrasonography after mammography and clinical examination.

Results were scored on a 5-point grading scale of increasing suspicion for malignancy. Pathology results during 12 manths follow up were used as criterion standard.

$\mathrm{ROC}$ curve cinalysis assessed the diagnostic value of ultrasonography in the whole population and in subgroups of patients according to indication for referral and age.

\section{Results}

3835 breasts were examined in 2020 patients, with a $6.3 \%$ prevalence of breast cancer.

Breast ultrasonography detected 8 extra malignancies and correctly downgraded 332 cases to a negative diagnosis. ROC curves showed a significant improvement in diagnostic value by adding ultrasonography to mammography and clinical examination (AUC CE+MAM+US: 0.99 versus CE+MAM: $0.95, p=0.002)$. The diagnostic yield improved significantly in patients referred for palpable breast lumps or referred from the national breast cancer screening program. Less pronounced was the value in patients referred for other symptomatology or for follow up of a prior breast malignaney.

When screening breast imaging of the contralateral breast was performed, or in asymptomatic patients referred for reassurance or follow up of a prior benign lesion, the value of additional ultrasonography remained undefined because of the small number of malignancies.

\section{Conclusion}

Systematic application of breast ultrasonography improved the overall diagnostic yield.

The diagnostic value increased mast in patients with palpable breast lumps and patients referred with abnormal screening mammagrams. 


\section{Introduction}

With a lifetime risk of $10 \%$ breast cancer is a major public health problem in women in Western countries". Its diagnosis and treatment is creating a financial burden to the health care system.

In addition to mammography, ultrasonography has become the most widely used imaging method in the diagnosis of breast disease, especially in patients with palpable masses and normal or non-conclusive mammographic results ${ }^{2 \cdot 4}$. Numbers from our hospital show that the application of additional ultrasonography has increased from in $28 \%$ of patients referred for mammography in $1994^{5}$ to over $35 \%$ in 1999 . This is partly the result of the wider availability and accessibility, the broadening clinical indications and the idea that physicians believe to be less likely to be blamed for doing more testing than for doing too little .

As a consequence, many examinations are actually redundant and will not only lead to rising health care costs, but also to unnecessary inconvenience and discomfort to the patient, unnecessary work-up because of false-positive results and increasing waiting lists.

To reduce this health care problem and to aim for a more effective and efficient use, additional ultrasonography should be restricted to those subgroups of patients who benefit most from it.

A number of studies have assessed the diagnostic value of clinically indicated breast ultrasonography as adjunct to mammography ${ }^{7.12}$. Despite combining mammography with ultrasonography resulted in a higher sensitivity, in 3 studies the increase in sensitivity was reached at the expense of a decrease in specificity $7,8,10$. None of these studies have applied ultrasonography systematically in consecutive patients in order to obrain evidence-based information on subgroups of patients with the highest diagnostic yield.

The aim of this prospective study was therefore to assess the diagnostic value of breast ultrasonography as adjund to mammography and clinical examination in a consecutive set of patients referred for diagnostic breast imaging. Furthermore, the feasibility of selecting subgroups of patients who benefit most from additional ultrasonography was studied.

\section{Patients and Methods}

Between October 1999 and August 2000 all consecutive patients referred to our radialogy department for diagnastic breast imaging underwent additional ultrasonography affer clinical examination and mammography. Maastricht University Hospital is a 700-bed referral hospital with a large regional function.

Patients were informed about the study by mail preceding their scheduled visit as well as in the department prior to their imaging examination, after which informed consent was signed. Patients were excluded from the study when ultrasonography could not be performed because of logistic reasons or when no informed consent was given. As in The Netherlands a system of collective health insurance makes thealth care available to the whole population, no patients were excluded from the studly due to inability to pay or lack of insurance.

Investigations were performed in fixed order during a single visit. Bilateral elinical examination, performed in standing and sitting position, was followed by stlandard craniocaudal and mediolateral oblique mammograms (Siemens Mammomatw2 unit / 
Kodak Mir-R film sereen combination then followed by whole breast ultrasonography (ATL5000, $12.5 \mathrm{MHz}$ linear array transducer). Conforming to dinical practice all examinations were pertormed and interpreted with full knowledge of prior test results.

Tests were carried out by a theam of radiologists with a special interest in diagnostic breast imaging and over 5 years of experience in mammography and breast ultrasonography. In one patient all examinations were performed by the same radiologist. Additionally, study procedures were monttored and registered by a resident who was present at all examinations of all patients (AMB).

All relevant patient characteristics and the description, size and location of lesions found at the different diagnostic examinations, were registered in a standardized fashion. The diagnosis based on clinical examination, mammography and ultrasonography was scored separately per breast on a 5-point grading scale with increasing suspicion for malignancy, as $1=$ normal, $2=$ benign, $3=$ uncentain benign, $4=$ suspect malignant, $5=$ mallignant, $0=$ indeterminate (based on the Bl-RADS lexicon for mammagraphy and under development for ultrasonography by the American College of Radiology ${ }^{13,14}$ ).

Additional to these separate diagnoses a combined diagnosis of clinical examination and mammography together (CE + MAM) was calculated by taking the maximum diagnostic score of these madalities. Finally, a final diagnosis based on clinical examination, mammography and ultrasonography together (CE+MAM+US) was defined mathematically as the maximum score of the madalities in case of a benign or malignant diagnosis. When scores differed more than one grade of suspicion of malignancy or when either of the two modalities included an uncertain benign score, the overall diagnasis of the radiologist interpreting all examinations ruled.

The additional diagnostic value of ultrasonography was determined by comparing the accuracy of CE+MAM + US with the accuracy of CE + MAM.

As it approaches clinical implications, indeterminate clinical examinations (score $=0$ ) as in e.g. mastopathy, were recoded as benign (score=2) and indeterminate mammography or ultrasonography results as uncertain benign (score $=3$ ) for analysis.

The criterion standard for the presence or absence of breast cancer was determined by pathology results from core needle biopsies, excision biopsies and other surgical interventions during a follow up period of 12 months. An additional 2 months was added accounting for administrative routing of test results at the end of the follow up period.

Pathology results were retrieved from the hospital pathology department and the Dutch Network and National Database for Pathology (PALGA). As all national hospital pathology departments are linked to this database, subsequent malignancies diagnosed elsewhere would not go unnoticed. Breast cancer status was considered negative when no pathology was reported in either system.

Receiver operating characteristic (ROC) curves were constructed for the imaging results of clinical examination, CEHAMM and CE+MAM+US. Areas under the curve (AUC) were calculated as a measure for the diagnostic performance and differences were calculated and tested according to the methods of Hanley et al. 15, 16. Furthermore, ROC curves were analyzed for subgroups of patients according to indications for referral and age. 


\section{Results}

There were 2720 scheduled imaging examinations, of which 112 were cancelled and 84 were excluded from the study, as patients had been included on earlier visits. In 279 cases additional ultrasonography was not realized because of logistical reasons and 225 patients refused informed consent. The patients excluded from the study had a comparable prevalence of breast cancer, age distribution, reason for referral, and imaging interpretation.

A total of 2020 consecutive patients were included in the study and underwent clinical, mammographic and ultrasonographic examination of both breasts. The population consisted of 2000 women and 20 men with a mean age of 50.2 years (range $16.8-$ 90.3). Patients were referred by general practitioners $(n=1044)$, surgeons $(n=712)$ and other specialists $(m=264)$. Indications for referral were: a palpable breast lump ( $n=470$ patients), other breast symptomatology like pain, skin or nipple abnormalities $(n=486)$, follow up of priar breast malignancy $(n=438)$, follow up of prior benign breast disease $(n=152)$, mammographic abnormalities detected through the national breast cancer screening program ( $n=144$ ), family history of breast cancer $(n=234)$, patients' anxiety $(n=13)$ or other asymptomatic reasons $(n=83)$. These last 3 indications for referral were combined as "reassurance".

One patient was included twice as both visits concerned different indications in different breasts. There were 182 patients who had prior mastectomy because of o history of breast cancer in whom the contralateral breast was investigated and in 23 cases only one breast was examined for other reasons.

Consequently 3835 breasts were examined in 2020 patients.

After a follow up of 12 months a fotal of 129 malignancies were found in 127 patients, leading to a prevalence of $6.3 \%(127 / 2020)$. Two patients had bilateral breast cancer. Thirteen malignancies were carcinomas in situ only, 116 were invasive carcinomas.

In 123 cases malignant pathology was found as a result of the diagnostic imaging described. Six malignancies were detected after respectively 3,7 , and $12(n=4)$ months follow up. In 3 cases a malignancy was found during the radiological follow up of benign calcifications ( 1 after 3 and 2 after 12 months). Two patients presented with a new palpable lesion at 7 and 12 months after the initial breast imaging in this study, which reported normal readings. Finally, in 1 patient yearly radialogical follow up of a prior breast malignancy led to the detection of a new lesion after 12 months.

\section{Diagnostic performance}

Using a cut-off point between benign and probably benign results, thus defining scores 3,4 and 5 as positive and scores 1 and 2 as negative results, clinical examination detected $69 \%$ of all malignancies $(89 / 129)$, mammography detected $83 \%(107 / 129)$, and ultrasonography detected $88 \%(113 / 129)$. The specificity reached 93\% (3616/3910) for clinical examination, $92 \%(3405 / 3706)$ for mammagraphy and $96 \%(3556 / 3723)$ for ultrasonography.

Table 1 shows the test results of CE+MAM+US and CE+MAM categorized by absence or presence of breast cancer. The sensitivity and specificily of CE +MAM was $92 \%$ $(118 / 129)$ and $87 \%(3226 / 3706)$ respectively, for CE+MAM+US this was $97 \%$ $(125 / 129)$ and $95 \%(3512 / 3706)$ respectively. 
Table 1: Results of clinicol examination combined whith manmography (CE+MAM) and the find diagniogis (CE+MAM+US) by malignancy for all cases $(n=3835$ ). Par A includes cases positive for malignancy, part $\mathrm{B}$ indudes cosses negative for malignanoy.

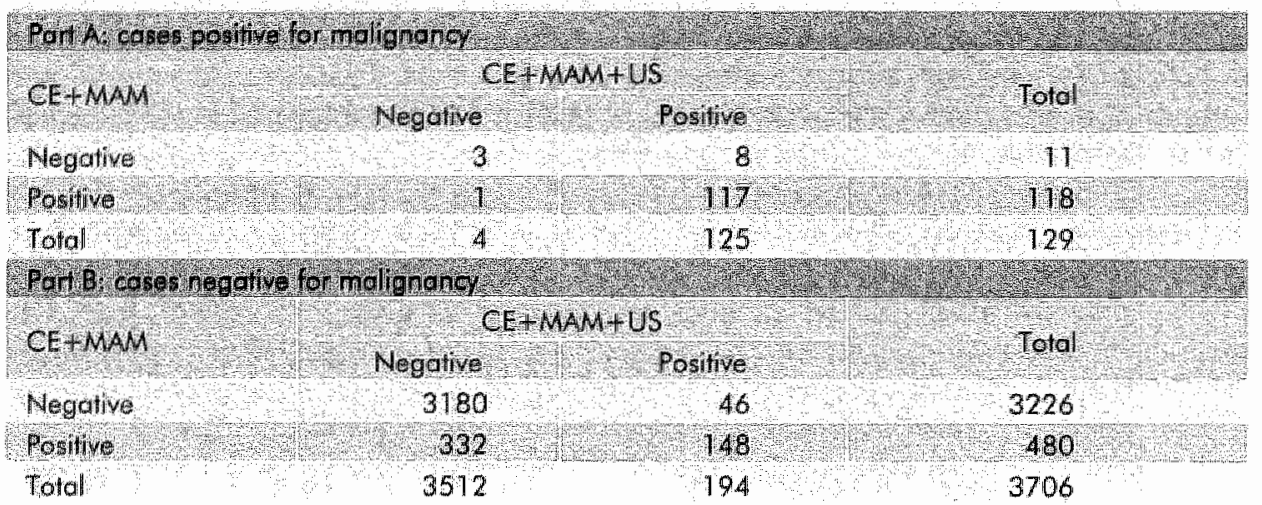

Calculations: sensitivity $C E+M A M=118 / 129=92 \%$, specificity $C E+M A M=3226 / 3706=87 \%$, positive predictive value $C E+M A M=118 /(118+480)=20 \%$, negative predictive value $C E+M A M=3226 /$ $(11+3226)=99.6 \%$, sensitivity CE +MAM $+U S=125 / 129=97 \%$, specificity $C E+M A M+U S=3512 / 3706=95 \%$, positive predictive value $C E+M A M+U S=125 /(125+194)=39 \%$, negative predictive value CE+MAM+US $=3512 /(4+3512)=99.8 \%$

Breast ultrasonography detected 8 extra malignancies $(7$ invasive ductal carcinomas and 1 lobular carcinoma in situ), which were missed by clinical examination and mammography. A detailed description of these cases is shown in table 2. Furthermore, ultrasonography correctly downgraded 332 cases from a positive to a negative diagnosis. On the contrary, there were 46 false-positive ultrasonographic examinations and in 1 case ultrasonography incorrectly downgraded the imaging result to a negative diagnosis.

\section{ROC curves}

ROC curves were constructed for the results of clinical examination, CE+MAM and CE+MAM+US for all 3835 cases (figure 1). Comparing the AUC of these curves, there was a significant increase in diagnostic performance by application of additional ultrasonography

(AUC CE +MAM+US: 0.99 versus $C E+M A M: 0.95, p=0.002$ ). Furthermore, AUC for $C E+M A M$ and $C E+M A M+U S$ were both significantly different from the AUC for $C E$ alone (AUC CE + MAM+US:0.99 and CE+MAM:0.95 versus CE:0.84, both $p<0.001)$. Twelve hundred twenty-eight patients were referred for imaging of a single breast; 792 patients for examination of both sides. Thus, of the 3835 breasts examined, breast imaging was done on referral in 2812 cases and as screening of the contralateral side in 1023 cases. In table 3 AUC of ROC curves for these groups show that the additional diagnostic value of ultrasonography was highest in the referred cases (AUC: 0.98 versus $0.95, p=0.001 \%$. In patients where screening breast imaging of the contralateral side was performed or when reassurance was the reason for referral, no additional diagnostic value was demonstrated for ultrasonography $(p=$ not applicable because of small numbers). 
Table 2: Results of diagnostic imaging tests of 8 extro cases of breasi cancer detected by ultrasonography lage, menopausal state, indication for refral, results from dinical exemination. mammagraphy and ultrasonography?

\begin{tabular}{|c|c|c|c|c|c|c|c|c|}
\hline$A$ & fe & 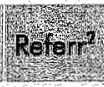 & & 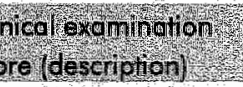 & & 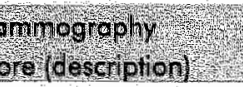 & & 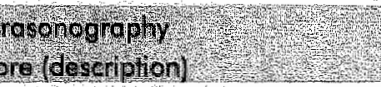 \\
\hline 42 & Pre & Palp & 1 & (No abnormalities) & 1 & (No abnormalifies) & 3 & $\begin{array}{l}\text { Lobulated, hypoechoic } \\
\text { homogeneous, smooth } \\
\text { bordered lesion? }\end{array}$ \\
\hline 45 & Pre & Polp & 2 & $\begin{array}{l}\text { Palpoble lunp. } \\
\text { round } \\
\text { eircumseribed] }\end{array}$ & $1+$ & (No abnornalities) & 3 & $\begin{array}{l}\text { (Irregular, round, } \\
\text { (uypoechoic, hoterogeneous } \\
\text { (esion behind aspiraled cyst) }\end{array}$ \\
\hline 36 & Pre & Polp & 0 & $\begin{array}{l}\text { (Palpable lump: } \\
\text { lobular) }\end{array}$ & $\overrightarrow{1}$ & (No abnormalities) & 4 & $\begin{array}{l}\text { (lregular, labulated, } \\
\text { hypoechoic, hetterogeneous } \\
\text { lesion) }\end{array}$ \\
\hline 43 & Pre & $\begin{array}{l}\text { Fu } \\
\text { benign }\end{array}$ & 0 & $\begin{array}{l}\text { No abnornolitiss, } \\
\text { ndeterminate) }\end{array}$ & 1 & $\begin{array}{l}\text { Mo obmornalities, } \\
\text { demsetissue) }\end{array}$ & 4 & (lregular hypoechoiclesion) \\
\hline 45 & Pre & $\begin{array}{l}\text { FU } \\
\text { malign }\end{array}$ & 1 & (No abnormalities) & 1 & (No abnomalities) & 4 & $\begin{array}{l}\text { (irregular, lobulated, } \\
\text { hypoedhoic, heterogeneous } \\
\text { lesion with shadowing) }\end{array}$ \\
\hline 66 & Post & mus & & No abrennal fies) & 11 & No abnormalifes) & 4 & 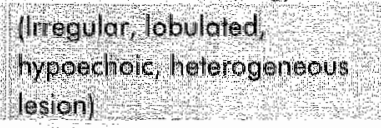 \\
\hline 77 & Post & Symp & 1 & (No abnormalities) & 2 & $\begin{array}{l}\text { (Circunscribed } \\
\text { benign lesion) }\end{array}$ & 5 & $\begin{array}{l}\text { (liregular, lobulated, } \\
\text { hypoechoic, heterageneous } \\
\text { lesian with shadowing) }\end{array}$ \\
\hline 57 & Post & Contra & 2 & $\begin{array}{l}\text { (Polpoble lump: } \\
\text { roune) }\end{array}$ & 2 & $\begin{array}{l}\text { (Benign } \\
\text { calcificofions) }\end{array}$ & 5 & $\begin{array}{l}\text { (rregular hypoechoic, } \\
\text { heterageneous lesion with } \\
\text { shadowing) }\end{array}$ \\
\hline \multicolumn{9}{|c|}{ Menopausal state: pre = premenopausal, posi $=$ pastmenopausal } \\
\hline & & S & & & & rat o r o & & \\
\hline
\end{tabular}

Table 3: Areas under the ROC curves for clinical examination combined with mammography (CE+MAM) and the final diagnosis (CE+MAM+US) for cases with and without a teasan for refer ral for diagnostic breast imaging

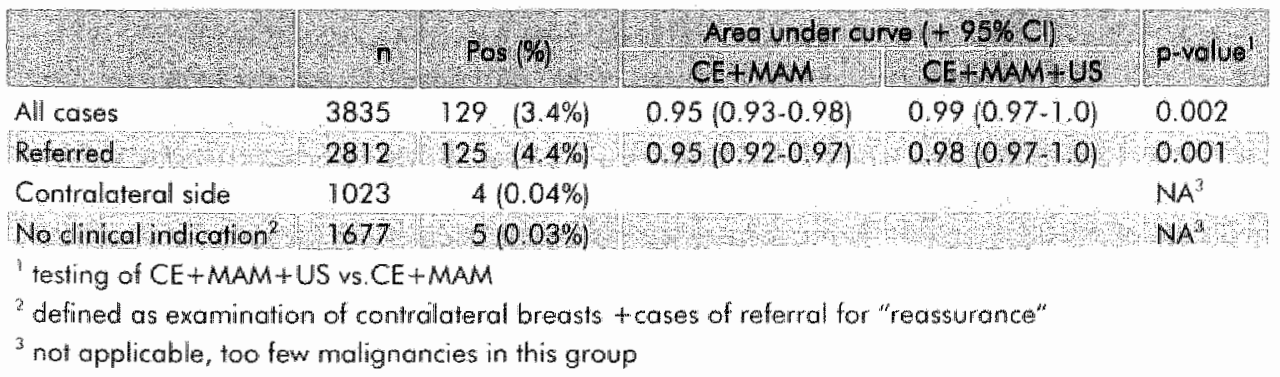




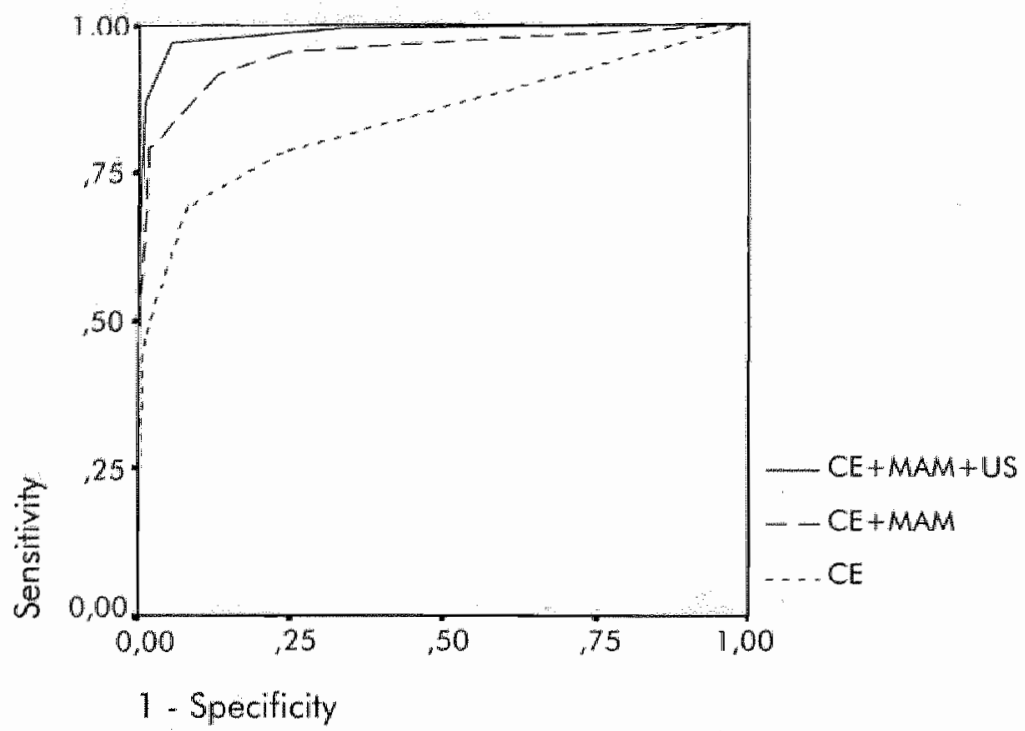

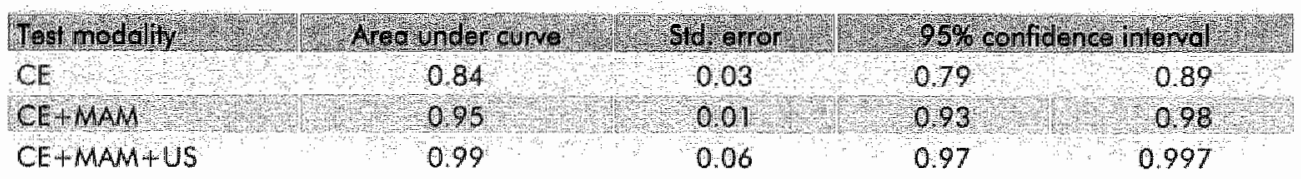

Figure 1: ROC curve of clinical examination (CE), clinical examination cambined with mammography (CE+MAM) and the final diagnosis (CE-MAM+US) far all cases $(n=3835)$, Table shows areas under the curve

\section{Indications for breast ultrasonography}

In order to study subgroups of patients who benefit most from additional ultrasonography, the diagnostic value was calculated through ROC curves by indication for referral and age categories (table 4). The diagnostic value improved significantly in patients with palpable breast lumps $(p=0.004)$, most pronounced for age group $<50$ years, and in patients referred through the national breast cancer screening program (women $>50$ years, $p=0.05$ ).

In the patients referred for palpable lumps ultrasonography correctly downgraded 133 positive clinical and mammographic examinations. Furthermore, ultrasonography detected 3 new malignancies at the cost of 11 false-positive results.

Of the 147 cases referred by the national breast cancer screening program, 40 mammagrams and elinical examinations were negative. Ultrasonography did not detect new malignancies in this group, but correctly downgraded 29 positive mammograms to a negative diagnosis.

Additional ultrasonography also increased the diagnostic value in patients referred for other symptomatology like pain and nipple or skin abnormalities $(p=0.28)$ and in patients referred for follow up of prior breast malignancy $(p=0.16)$, although the difference in AUC was not statistically significant.

In patients referred for follow up of a prior benign abnormality, additional ultrasonography detected 1 extra malignancy and confirmed 2 malignant diagnoses 
Table 4: Areas under the ROC curves for elinical examination conbined with mammography $(C E+M A M)$ and the final diagnosis $(C E+M A M+U S)$ by indication for referral and age groups $(n=2812)$

\begin{tabular}{|c|c|c|c|c|c|c|c|}
\hline 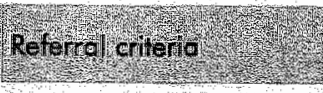 & Age & W & ros 120 & 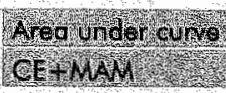 & 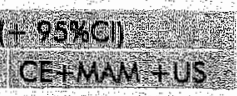 & 18. & M \\
\hline \multirow[t]{3}{*}{ Palpable lomp } & Total & 496 & $55(71 \%)$ & $0,92(088-0,97)$ & $0.98(0,9610)$ & 0004 & \\
\hline & $\leq 50 y$ & 354 & 21 & 0.8710 .770 .971 & $0.66(0.6210)$ & 10.03 & \\
\hline & $350 y$ & 142 & 34 & $0.95(0.910099)$ & $099(098-10)$ & 0,03 & \\
\hline Follow up NBCSPB & $>50 y$ & 147 & $47(28 \%)$ & 0920.87 .097 & $0.96(0.930 .09)$ & 005 & \\
\hline \multirow[t]{3}{*}{ Sympiomatic comploints } & Total & 600 & $17(3 \%)$ & $0.94(0,8710)$ & $098(0.95 \cdot 1.01$ & 0,28 & \\
\hline & $\leq 50 y$ & 397 & 5 & $0.97(0.921 .0)$ & $0.96(0.907 \mathrm{Jo})$ & 0.89 & \\
\hline & $>50 y$ & 203 & 12 & $0.93(0.8270)$ & $0.98(005 / 0)$ & 024 & 1 \\
\hline \multirow[t]{3}{*}{ Follow up minalignancy } & Total & 692 & $81 \%$ & $078105710)$ & $092(0,77,071$ & 016 & \\
\hline & $\leq 50 y$ & 156 & 4 & $0.72(0.39-10)$ & $0.84(0.56-1,13)$ & 0.26 & 1 \\
\hline & $350 y$ & 536 & 4 & $0.85(0.58-1,12)$ & $099(0,9910$ & 0.30 & 1 \\
\hline \multirow[t]{3}{*}{ Follow up benign obn. } & Total & 223 & $3(1 \%)$ & & & NA & \\
\hline & $\leq 50$ y & 123 & ไt & & & $\mathrm{NA}$ & \\
\hline & $>50 y$ & 100 & 2 & & & $N A$ & \\
\hline \multirow[t]{3}{*}{ Reossuronce? } & Total & 654 & $1(<18)$ & & & NA. & \\
\hline & $\leq 50$ y & 459 & 1 & & & $N A$ & \\
\hline & $>50 y$ & 195 & 0 & & & Nat & \\
\hline \multicolumn{8}{|c|}{ "testing of CE + MAM+US vs. CE +MAM } \\
\hline \multicolumn{7}{|c|}{$\begin{array}{l}2 \text { malignancies detected only by breast ultrasonography (1 case was referred for the contrallateral } \\
\text { breast) }\end{array}$} & \\
\hline \multicolumn{8}{|c|}{${ }^{3}$ notional breast cancer screening program } \\
\hline${ }^{4}$ not applicable, too few & nalignan & cies in & this group & & & & \\
\hline & 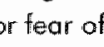 & & & & & & \\
\hline
\end{tabular}

by clinical examination and mammography $(p=$ nat applicable because of small numbers).

Finally, among the 654 cases referred for reassurance, because of fear or a family history of breast cancer, ultrasonography missed the single malignancy in this group, which was detected by clinical examination and mammography $(p=$ not applicable because of small numbers). There were 12 false-positive ultrasonographic examinations of which 4 were also false-positive mammographically.

For the 8 patients in whom only breast ultrasonography detected a malignancy the indications for referral were: palpable breast lumps $(n=3)$, follow up of prior malignancy $(n=2)$, follow up of prior benign abnormality $(n=1)$ and breast symptoms $(n=1)$. In 1 case the cancer was found "by chance" while the reason for referral was a palpable mass on the contralateral side.

\section{Discussion}

In this outpatient population systematic application of ultrasonography as adjunct to clinical examination and mammography significantly increased the diagnostic performance. The diagnostic gain of ultrasonography was found in the detection of 8 extra malignancies that were missed at elinical examination and mammography. Further profit was shown by the downgrading of false-positive clinical and 
mammographic results $(n=332)$. Most of these were cysts or fibroadenoma, although not all of them were confinmed by pathology ${ }^{2}, 4.1 \%, 18$.

On the other hand, diagnostic lass was reflected by 46 false-positive and 1 falseregative ultrasonographic result.

The final diagnasis of CE+MAM+US had a sensitivity of $97 \%$ and specificity of $95 \%$. Integrated diagnoses combining results of mammagraphy and ultrasonagraphy have been reported in several studies ${ }^{2}, 5,7-12,19$. However, many studies fail to explain how this integrated diagnosis was obtained and anly few studies describe consecutive sets of patients. Comparison with our data should therefore be done carefully, but lower sensitivities and slightly higher specificities are reported $5,12,19$. This may be explained by their study design in which ultrasonography was only applied on clinical indication. In our study, systematic ultrasonography increased the number of true and falsepositive diagnoses, affecting both sensitivity and specificity.

The prevalence of breast cancer in this population was $6.3 \%$ and is consistent with results of these other studies in consecutive patients, reporting prevalences of $5-7.1 \%$ 5. 12,19

The prevalence was somewhat lower in patients excluded from the study (4\%), but we believe this does not affect the generalizability of the study.

Despite the overall increase in diagnostic yield by systematic application, breast ultrasonography should be restricted to subgroups of patients who benefit most in order to reduce costs, time load and harmful consequences of unnecessary examinations. According to aur results the application of breast ultrasonography was most beneficial to patients referred for palpable breast lumps and patients with an abnormal screening mammogram referred by the national breast cancer screening program. Applying these criteria to our population, ultrasonography would be indicated in $30 \%$ of patients referred for diagnostic breast imaging to the radiology department of a referral hospital (614/2020).

In the current literature the presence of a palpable mass in young women is a welldescribed indication for breast ultrasonography as initial diagnostic imaging test $3,4,18$, 20 or als adjunct to mammography 12,19 . While mast studies are referring to women of 35 years and younger, our results are applicable to women of 50 years and younger. Ultrasonography detected additional malignancies in 8 patients, of whom 3 were referred because of a palpable mass and 1 patient had a palpable lump at clinical examination. According to current dinical guidelines all palpable masses should undergo cytological investigation, which wauld have detected these malignancies as well. However, ultrasonography still has an important diagnostic role in these cases by completing "triple assessment", consisting of clinical examination, radiological imaging and cytology diagnosis, which facilitates treatment planning. Furthermore, as a proportion of the cytological investigations will be indeterminate, these ultrasonography results will be very valuable.

An abnomal sicreening mammogram has not been reported in the literature as indication for additional ultrasonography, but palpable or non-palpable nonconclusive mammographic abnormalities are discussed $12,18,19,21,22$. In the patients referred from the national breast cancer screening program, ultrasonography reduced the number of false-positive mammograms, by downgrading a quarter of all positive cases.

The increase in diagnostic value was not significant in patients referred with breast symptoms or patients referred for follow up of a prior malignancy. Remarkably, in this last group the largest absolute increase in AUC was found, but the small number of 
positive cases and the relatively high standard errors prevent us from drawing any definitive conclusions ${ }^{15}$.

Furthermore, in the groups of patients referred for follow up of a previous benign lesion or for reassurance there were too few molignant cases for constructing $\mathrm{ROC}$ curves and no additional value for ultrasonography could be demonstrated.

The role of breast ultrasonography in screening asymptomatic patients is a controversial one, because of the high numbers of false-positive and false-negative results $2,4,23,24$. Our data show 5 malignancies in the cases without a clinical indication (table 3 ), of which 4 malignancies were found in contralateral breasts and only 1 malignancy in the group referrals for reassurance (table 4), suggesting a poor diagnostic yield of breast imaging as a whole in these patients.

An alternative way for recoding indeterminate test results for analysis, would be through the comparison of likelihood ratios for each level of suspicion ${ }^{25}$, and recoding them as the level that is most alike. Doing so, the results would change slightly as indeterminate mammograms would be recoded as negative findings, but our final conclusions would be similar. However, we believe that our applied method of recoding appraaches clinical practice best, as indeterminate mammograms will always result in additional testing. Furthermore, the Bl-RADS lexicon also treats indeterminate mammagrams as positive ${ }^{13}$.

Recoding indeterminate clinical examinations as positive results, as done for mammography and ultrasonography, also would not affect the AUC $(0.83$ vs 0.84$)$ or change our conclusions.

Many diagnostic studies report unequal follow up periods for patients included over several months or years, by using one end point. As a consequence, these studies are biased in their definition of the criterion standard, as the length of follow up is different for each case. Therefore, in the current study an equal follow up period of 12 months was used for all patients, extended with 2 months for administrative transactions of results at the end of this period. The period of 12 months was chosen to minimize the chance of detection of newly developed (interval) cancers and maximizing the chance of detecting the malignancies present. Nevertheless, when including the total range of follow up from October 1999 to October 2001 (median: 19 months, range: $14-24$ months) no additional false-negative imaging results were found. It should be noted that despite the passive nature of the follow up in which patients did not undergo repeat testing after 12 months, we believe that the registration system used covered all pathology available for the whole study population.

It should be noted that the indications for breast imaging in this study were defined by the referring doctors and symptoms could not always be canfirmed by the specialist conducting the clinical examination, e.g. the palpation of a palpable lump. As such situations reflect clinical practice we decided to use the specified reasion for referral in these cases rather than our findings at clinical examination.

Associated is the fact that additional indications for ultrasonography could be defined based on results of clinical examination and mammography. However, by applying the current set of criteria in daily practice, the advice to perform or withhold additional ultrasonography could be given at the stage of referral for breast imaging. Doing so, the planning of breast imaging could be optimized and the number of redundant ultrasonographic examinations reduced. Additional research will be needed to determine the cost-effectiveness of the application of breast ultrasonography in these specified groups of patients.

Concluding, systematic application of additional breast ultrasonography improved the diagnostic performance in this population. Although the overall diagnostic yield 
improved, the number of unnecessary examinations can be reduced by restricting breast ultrasonography mainly to patients with palpable breast lumps and patients referred with abnormal screening mammograms. Implementation of these evidencebased indications in clinical practice is expected to lead to more efficient and effective use of breast ultrasionography. 


\section{References}

1. Harris $J R_{r}$ Lippman ME, Veronesi U, Willet W. Breasil cancer (1). N Engl J Med 1992; 327:31928.

2. Smith DN. Breast ultrasound. Radiol Clin North Am 2001; 39:485-97.

3. Skaane P. Ultrasonography as adjunct to mammography in the evaluation af breast tumors. Acta Radiol Suppl 1999; 420:1 -47.

4. Jackson VP, Reynolds HE, Hawes DR. Sonagraphy of the breast. Semin Ultrasound CT MR 1996; $17: 460-75$.

5. Flobbe K, wan der Linden $\mathrm{ES}_{7}$ Kessels AG, van Engelshoven JM. Diagnostic value of radiological breast imaging in a non-screening population. Int J Cancer 2001; 92:616.8.

6. Hillman BJ. New imaging technology and cost contaiment. AJR Am J Roentgenol 1994; 162:503-6.

7. Hardy JR, Powles TJ, Judson I, et al. How many tests are required in the diagnosis of palpable breast abnormalities? Clin Oncol (R Coll Radiol) 1990; 2:148.52.

8. Mass HA, Britton PD, Flower CD, Freeman AH, Lomas DJ, Warren RM. Haw reliable is modern breast imaging in differentiating benign from malignant breast lesions in the symptomatic population? Clin Radiol 1999; 54:676-82.

9. Ozdemir $A$, Oznur, II, Vural $G$, et al. T1.201 scintigraphy, mammography and ultrasonography in the evaluation of palpable and nonpalpable breast lesions: a correlative study. Eur J Radial $1997 ; 24: 145-54$.

10. Ruhland F, Heinrich J, Budner $M$, Jeschke A. [Diagnostic value of Mammography and Breast Ultrasound for Clinically Occult Lesions of the Breast]. Geburtsh-Fravenheilk. 2000; 60:104*110.

11. Skcane P, Engedal $K$, Skjennald $A$. Interobserver variation in the interpretation of breast imaging. Comparison of mammography, ultrasonography, and both combined in interpretation of palpable noncalcified breast masses. Acta Radial 1997; 38:497-502.

12. Zonderland $H M$, Coerkamp EG, Vijver $M, J$, wan de, Voorthuisen $A, E$. Diagnosis of breast cancer: Contribution of US as an adjunct to mammography. Radiology 1999;213:413-1422.

13. American College of Radiology. Assessment categories. Hlustrated breast imaging reporting and data system (Illustrated BI-RADS\}. Reston: VA: American Callege of Radiology, 1995.

14. Mendlelson EB, Berg WA, Merritt CR. Toward a standardized breast ultrasound lexicon, Bll-RADS: ultrasound. Semin Raentgenol 2001; 36:217-25.

15. Hanley JA, Mc Neil B.J. A method of comparing the areas under receiver operating characteristic curves derived from the same cases. Radiology $1983 ; 1.48: 839-843$.

16. Hanley JA, MCNeil BJ. The meaning and use of the area under a receiver operating chardacteristic (ROC) Curve. Radiology 1982; 143:29-36.

17. Skaane P. The additional value of US to mammography in the diagnosis of breast cancer. A prospectiwe study. Acta Radiol 1999; 40:486-90.

18. Mendelson EB, Tobin CE. Critical pathways in using breast US. Radiographics 1995; 15:935-45.

19. Duijm LEM, Guit GL, Koomen AR, Willebrand D. Sensifivity, specificity and predictive values of breast imaging in the detection of cancer. Br J Cancer 1997;76 (3):377.381

20. Hurd TC, Edge SB. Breast cancer umaging. Surg Oncol Clin N Am 1999: 8:1-15.

21. Houssami $N$, Irwig L. Likelihood ratios for clinical examination, mammography, ullrasound and fine needle biopsy in women with breasl problems. The Breast 1998; 7:85.89.

22. Oord JCW, Vliet AMvd, Thyn CJP, Mak B, Hoogeboom GJ. The value of ullirasound mammography in palpable breast masses. Fortschr Röntgenstr 1991; 155, 1:63-66.

23. Kolb TM, Lichy J, Newhouse JH. Occulf cancer in women with dense breasts: detection with screening US- diagnostic yield and tumor characteristics. Radiology 1998, 207:191.199.

24. Kopans DB. Breast-cancer screening with ultrasonography. Lancell 1999; 354:2096\%97. 
25. Sacket DL, Haynes RB, Tugwell P, Guyat GH. Clinical Epidemiology: A basic science for dinical medicine: Lippincott Willems \& Wilkins Publishers, 1991 


\section{PREDICTIVE DIAGNOSTIC VARIABLES IN THE DIAGNOSIS OF BREAST CANCER: THE ROLE OF ULTRASONOGRAPHY}

Karin Flobbe, Alfons G.H. Kessels, Anne Marie Brosch, Geerard L. Beets, Maarten F. von Meyenfeldt, Jos M.A. van Engelshoven

(Submitted) 


\section{Abstrad}

\section{Airn}

To determine which diagnostic intomation from medical history, clinical examination, manmography and ultrasonography contributes to the prediction of breast cancer.

To study the contribution of additional ultrasonagraphy next to mammography and clinical examination in the prediction of breast cancer for different potient populations.

\section{Methods}

2020 consecutive patients referred for breast imaging underwent bilateral clinical examination, mammography and ultrasonography. Pathology results during 12 months follow up were used as reference standard for breast cancer.

A prediction model was designed by multivariate logistic regression analysis.

ROC curve analysis studied the contribution of ultrasonography for different subgroups of patients according to the reason for referral and other characteristics.

\section{Results}

The diagnostic algorithm for breast cancer included: age, menopause, specific breast symptoms, diagnosis of clinical examination, mammographic calcifications and the integrated diagnosis resulting from ultrasonography, mammography and clinical examination.

ROC curve analysis showed that each step in the diagnostic work-up improved the predictive value of the model. Using all available diagnostic information a sensitivity of $95 \%$ and specificity of $92 \%$ could be reached.

Stratified analysis showed that additional ultrasonography significantly improved the predictive walue of the madel in patients referred for palpable masses $(p=0.04)$. Among patients without a palpable lump. ultrasonography contributed most to the diagnasis in the subgroup of premenopausal patients $(p=0.39)$.

\section{Conclusion}

All stages of the diagnostic imaging work-up contributed to the diagnosis of bieast cancer. Additional ultrasonography impraved the predictive value of the model most significantly in patients referred for a palpable lump. 


\section{Introduction}

Every year about 10.000 new breast cancers are diagnosed in The Netherlands. Apart from the group of patients who are diagnased through the national breast cancer screening pragram, most new cases are delected by diagnostic breast imaging performed by radialogists in a hospital setting.

Routine diagnostic breast imaging in the radiology departments of most hospitals consists of clinical examination, mammography, and ultrasonography when indicated. All information on the lesions and abnormalities found by these tests is combined with the knowledge of patient characteristics from medical history into one overall diagnosis indicating the suspicion of breast cancer. Much has been written in the literature about the typical features of breast malignancies on clinical examination, mammography and ultrasonography, but very little has been reported about the specific contribution of each test in defining an overall diagnosis.

The most common clinical indications for breast ultrasonography as adjunct to mammography are the differentiation between cysts and solid masses and the further evaluation of a palpable mass when mammography is inconclusive ${ }^{1.5}$. However, as a result of broadening indications and increasing availability and accessibility, the application of ultrasonography has increased strongly over the past decade and it is also being used in a number of clinical situations in which no efficacy has been demonstrated. Although breast ultrasonagraphy causes no harm to the patient, its cost and lack of clinical benefit for the patient make the use of ultrasonography in these sifuations unwise ${ }^{6}$. This raises the question of which subgroups of patients obtain most diagnostic information from additional ultrasonography.

The purpose of this study was to determine which diagnostic information from medical history, clinicall examination, mammography and ultrasonography contributes most to the prediction of breast cancer. More specifically, the contribution of additional ultrasonography in the prediction of breast cancer was studied for different patient populations.

\section{Patients and Methods}

\section{Study population}

Between October 1999 and August 2000, 2020 consecutive patients referred to our radiology department for diagnostic breast imaging, underwent additional ultrasonography after clinical examination and mammography. Bilateral dinical examination, performed in upright and supine position, was followed by bilateral standard craniocaudal and mediolateral oblique diagnostic mammograms (Siemens Mammomat-2 unit / Kadak Min-R film screen combination), and then followed by bilateral whole breast ultrasonography (ATL5000 $12.5 \mathrm{MHz}$ Hinear array transducer). Additional mammographic wiews were employed when considered necessary. Conforming to clinical practice, all examinations were carried out and interpreted with full knowledge of prior test results.

The mean age of the study population was 50.2 (range $16.8-90.3$ ). Patients were referred by general practitioners $(n=1044)$, surgeans $(n=712)$ and other specialists $(n=264)$. Unilateral examination was performed in 182 patients with breast ampulations and in 23 patients for other reasons. Consequently 3835 breasts were examined in 2020 patients. 
Indications for referral for breast imaging were: a palpable breast lump $(n=496$ breasts), other breast symptomatology like pain, skin or nipple abnormalities $(n=601)$. follow up for prior breast malignancy $(n=692)$, follow up for prior benign breast disease ( $n=223$ ), mammographic abnormalities detected through the national breast cancer screening program $(n=147)$ and reassurance (family history of breast cancer, patients" anxiety or other asymptomatic reasons, $n=654$ ). Furthermore, 1022 contralateral breasts with no clinical indication for breasit imaging were examined.

After a follow up of 12 months during which pathology results from core needle biopsies, excision biopsies and other surgical interventions were registered, a total of 129 malignancies were found in 127 patients, leading to a prevalence of breast cancer of $6.3 \%(127 / 2020)$. The period of 12 months was chosen to minimize the chance of detection of newly developed (interval) cancers and maximizing the chance of detecting the malignancies present.

All rellewant patient characteristics and the description, size and location of lesions found at the different examinations, were registered. A conclusive diagnosis was scored per breast on a 3-point grading scale with increasing suspicion for malignancy, for clinicall examination alone, for mammography combined with clinical examination and for ultrasonography integrated with mammography and elinical examination. This 3-point grading scale was largely based on the 5-point BI-RADS grading scale for mammography and under development for ultrasonography ${ }^{\prime}, "$, and on the prevalence of breasł cancer per grade on this scale. Narmal scores were caded with indeterminate results into one group, benign and probably benign scores in another, and suspicious malignant and malignant scores in the third group.

\section{Prediction model}

The predictive value of different diagnostic variables in detecting breast cancer was studied by multivariate lagistic regression analysis. Corresponding to the process of diagnostic breast imaging 4 categories of diagnostic variables were defined: the first categary consisted of information generally available from medical history at referral, such as the reason for referral, history of breast disease, and age.

The second category of variables included those obtained by clinical examination, like the presence of a palpable lump or specific breast symptoms. Following, the third category consisted of variables abtained from consequent mammographic examination, like the margins of mammographic lesions and calcifications. Finally, the fourth category of variables was oblained by ultrasonography and included the characteristics of lesions identified. A more detailed description of the included variables is shown in table 1.

First, univariate analysis selected the variables with a significant association with breast cancer $(p<0.15)$. Consequently, these variables were included in a stepwise multivariate regression analysis with the presence of breast cancer as dependent variable (entry at $p<0.10$, removall at $p>0.15$ level). Significant variables of preceding categories were fixed in the model before variables of the next category were added. Then, backward regression analysis was done to eliminate variables with little contributing value on the complete model. The effectiveness of the model in predicting breast cancer was assessed by Hosmer and Lemeshow goodness-of-fit testing?"

The final model was converted into a diagnostic algorithm scoring system. Probability calculation can be done for individual patients by adding up the scores for the outcomes of the different variables. Converting this into a $Z$-score, a p-value can be calculated which represents the probability of breast cancer based on these results. 
Table 1: Diagnostic variables from medical history, dinical examination (CE), mammography (MAM) and ultrasonography (US) and their significance (Sign) in univariate logistic regression ondysis for the prediction of breast cancer $[S=$ significant $(p<0.10), \mathbb{N S}=$ not significant $)$
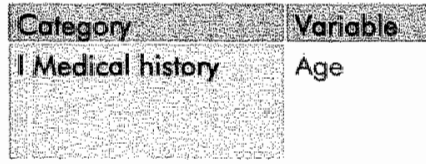

Reason for ireferral

\section{Coding}

$1=<35.0$ years

Sigirite

$2=35.01-50.0$ years

$3=350.01$ years

$0=$ no referrat, contralateral bireast

S

$1=$ reassurance (familly history, fear of patient)

$2=$ follow up of prior malignant abnormality

$3=$ follow up of priar benign abnormality

$4=$ symptomatology

$5=$ palpable lump

$6=$ referral from national screening program

Menopouse

$1=$ premenopausal

$2=$ postmenopausal

History of $\quad 0=$ no prior breasit disease

breast disease $1=$ prior benigm breast disease

$2=$ prior malignant breast disease

Hormone use

$0=$ none, never

1 - yes, ever (oral contraceptives/replacement therapy)

Family

$0=$ no

history ${ }^{21,27} \quad 1=$ yes

Body mass Continuous variable

index

MClnnea

examination

\section{Mammography?}

Lesion present

Margin lesion

Calcification

Aspecific

Palpable lump $0=$ no

$1=$ yes

Specific

$0=$ no

symptoms

$1=y e$

d'orange, ulceration:

symptoms

$0=$ no

$1=$ yes: pain, asymmetry, eczema, scaning, venous marking

Diggnosis CE $0=$ normal/indetermimate

$1=$ benign / probably benign

2 suspiciaus mallignant/malignan

$0=$ no

$1=$ yes

$0=$ none, not applicable

$1=$ circumscribed

$2=i l l$-defined or spiculated

$0=$ no

$1=$ benign calcifications

$2=$ suspect or molignant calcifications

Densiny breasi $\quad 1=0-25 \%$ fot contoining parenchymal

$2=26-50 \%$ : scattered densities

$3=52-75 \%$ : heterogeneously dense

$4=76-100 \%$ extremely dense 


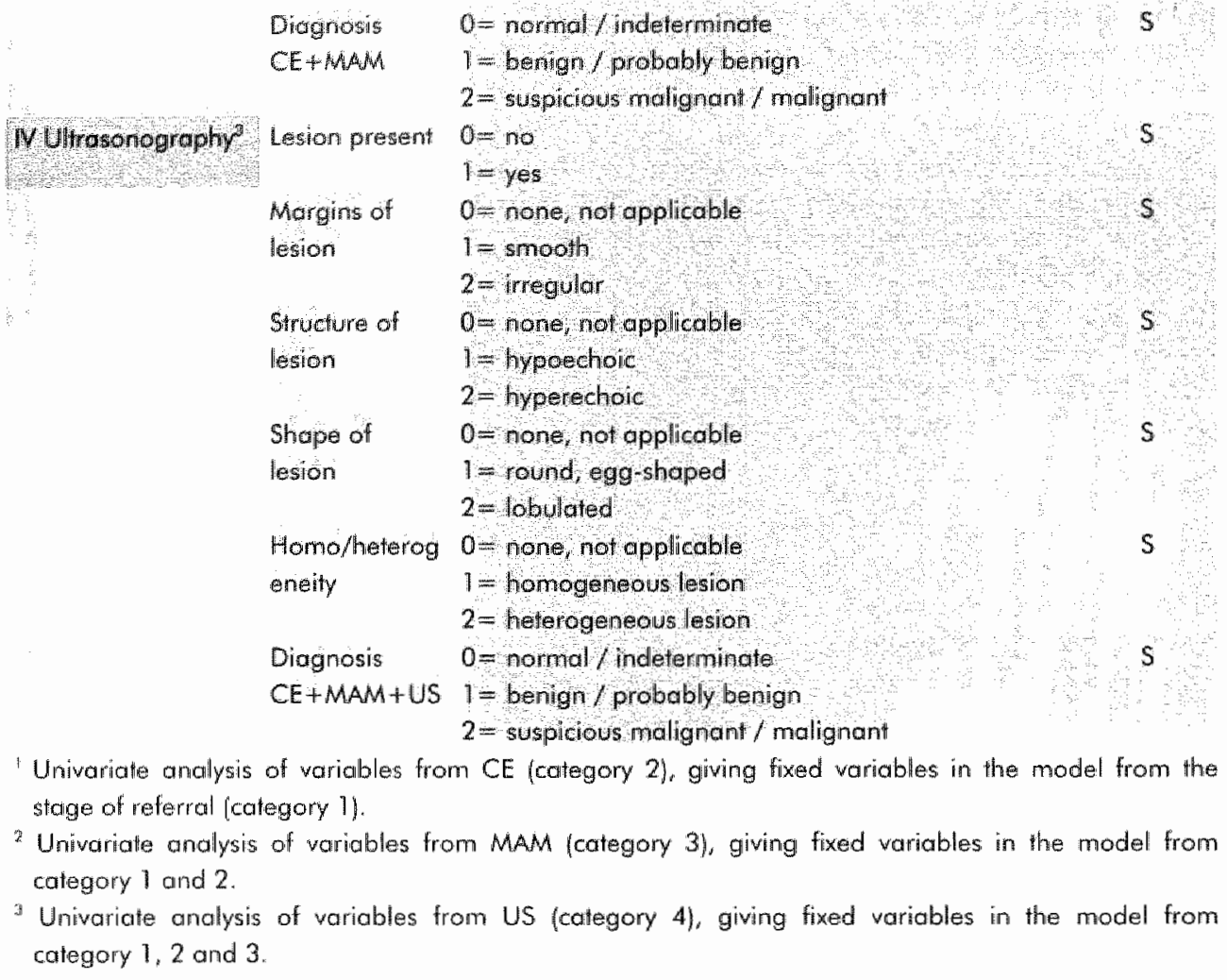

By calculating sensitivities and specificities for the different cut-off points of the predicted probabilities that were generated for each category of variables, receiver operating characteristic (ROC) curves were drawn. Areas under the curve (AUC) were calculated as a measure for the diagnostic performance. The additional diagnostic value of each category was determined by testing the difference in AUC according to the method of Hanley et al. ${ }^{10,11}$.

In order to study the contribution of breast ultrasonography in the prediction of breast cancer, a backward regression analysis was performed including variables of category 1.4 as well as variables of category 1.3 and the resulting ROC curves were compared. Finally, analyses were stratified for different subgroups of patients, according to reason for referral and clinical features.

\section{Results}

\section{Diagnostic algorithm}

Table 1 shows the results of univariate regression analysis of variables from all 4 categories. A family history of breast cancer, the body mass index, aspecific breast symptoms and the density of breast parenchyma on mammography were not related to the presence of breast cancer. 
Including the remaining variables in stepwise multivariate regression analysis resulted in a madel with 10 variables. Backward elimination of redundant variables excluded 4 variables, namely the reason for referral, history of prior breast disease, margins of mammographic lesions and the diagnosis of mammography and dinicall examination. The resulting prediction madel thus included 6 variables: age, menopause, specific breast symptoms, conclusive diagnosis from clinical examination, calcifications at mammography and the integrated diagnosis from ultrasonography, mammography and clinical examination. Hosmer and Lemeshow goodness-of-fit testing showed a good fit of this madel $(p=0.808)$.

This madel was converted into a diagnostic algorithm scoring system for individual breast cancer probability calculation, which is shown in table 2 .

Table 2: Diagnostic allgorithm for breast cancer including variables from medicall history, clinical examination (CE), mammography (MAM) and ultrasonagraphy (US) based on mulfivariate logistic regression analysis

\begin{tabular}{|c|c|c|c|}
\hline Categor & Variable & Coding & Score \\
\hline \multirow[t]{5}{*}{ Medical histary } & Age & $1=<35,00$ years & 0 \\
\hline & & $2=35.01-50.00$ years & 14 \\
\hline & & $3=>5001$ years & 2 \\
\hline & Menopause & $1=$ premenopausal & 0 \\
\hline & & $2=$ pastmenopausal & 18 \\
\hline $\begin{array}{l}\text { MClinical } \\
\text { excimination }\end{array}$ & Specific sympotoms & 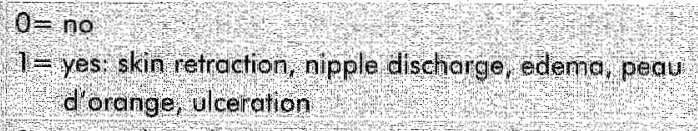 & 0 \\
\hline Het? & Bicignosis SE & 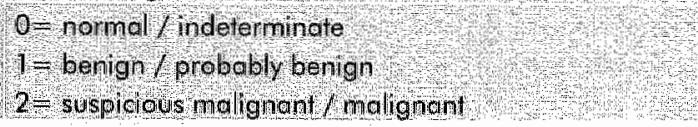 & $\begin{array}{l}0 \\
13 \\
27\end{array}$ \\
\hline \multirow[t]{3}{*}{ III Mammography } & Calcification & $0=$ no & 0 \\
\hline & & $1=$ benign calcifications & -5 \\
\hline & & $2=$ suspect or malignant caleifications & 10 \\
\hline Y & Diognosis? & $0=$ normal / indelleriminates & 0 \\
\hline Ultirasonography & $6 e+M A M+15$ & $\begin{array}{l}1=\text { bengh / probably benge } \\
2 \text { - suspicious molighant / nalignont }\end{array}$ & $\begin{array}{l}31 \\
79\end{array}$ \\
\hline \multicolumn{3}{|c|}{ Probability calculation for individual patient: } & $x=$ \\
\hline \multicolumn{3}{|c|}{ Add up all scores in tatal score $(X)$, range $-5-157$} & $z=$ \\
\hline \multicolumn{3}{|c|}{ Coilrulate $Z$-score: $Z=X-98$} & $P=$ \\
\hline
\end{tabular}

Calculate probability of malignancy $P: e^{m / 10} /\left(1+e^{z / 10}\right)$

example 1: a premenopausal potient, 48 years old, is having no specific breast symploms and an probably benign dinical examination because of a palpable lump. Some benign calcifications are found by mammography and the combined diagnosis from ultrasonography, mammography and dinical examination was suspicious. The total score according to our algarithm is: $101, Z=3$, and the predicted probability of malignancy is $p=0.574$

example 2: a postmenopausal patient, 60 years old is referred with an abnomal screening marnmogram from the rational breasi cancer screening program. She has no specific breast symptoms and a normal clinical examination. There are some suspect calcifications an mammography but the overall diagnosis from ultrasonography, mammography and clinical examination was benign. The total score according to our algorithm is: $61, Z=-37$, and the predicted probability of malignancy is $p=0.024$ 


\section{Contribution of ultrasonography}

ROC curves of the generated predicted probabilities from this model are plotted in figure 1. The AUC increased when adding diagnastic variables from each consecutive category.

Figure 1: ROC curve of predictive value of wariobles included from medical history, clinical examination (CE), mammography (MAM) and ultrasonography (WS) by multivariate lagistic regression analysis.

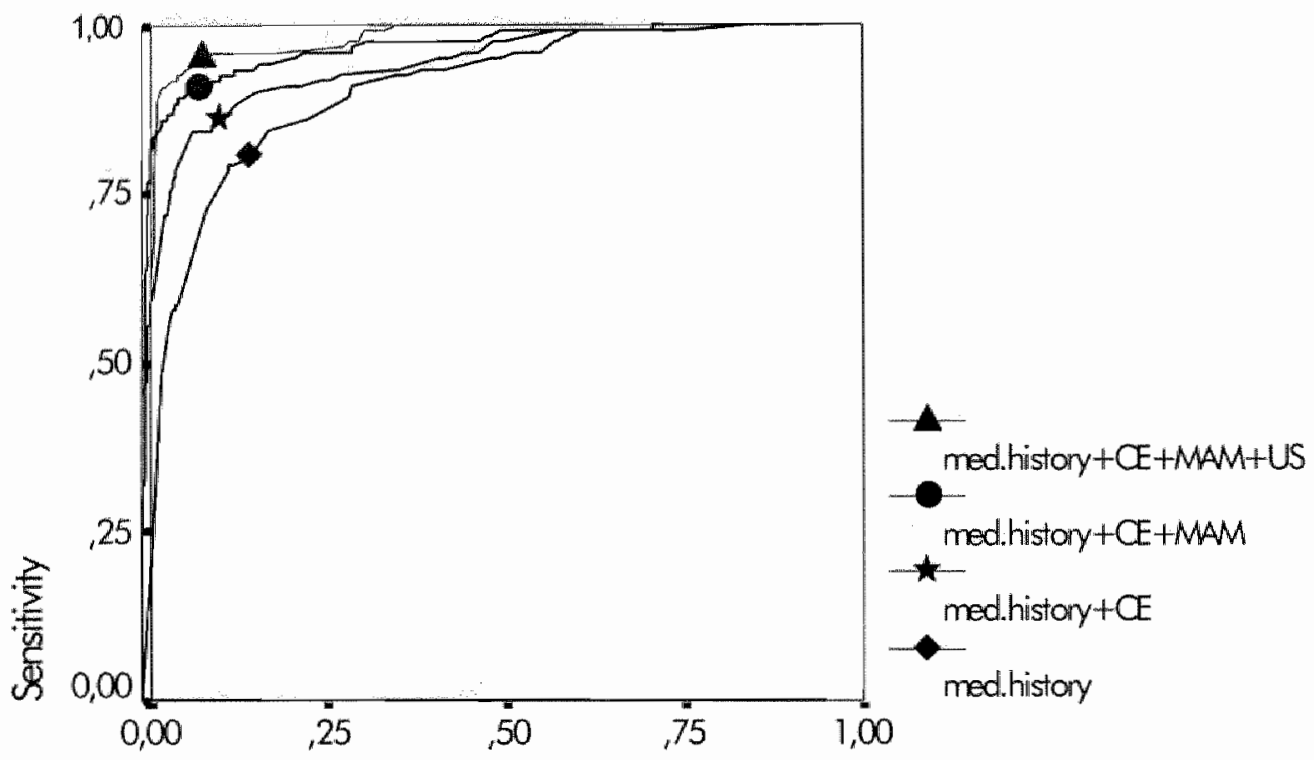

\section{1 - Specificity}

\begin{tabular}{|c|c|c|}
\hline Cologon - & Area under curre & 95010 \\
\hline Medieal history & 0.897 & $0.868-0.925$ \\
\hline Madical Wuitory t CE & 0097 & $0912-0962$ \\
\hline Madical history +CE $-M A M$ & 0.966 & $0.947-0.985$ \\
\hline Madical histon + CE + MAM+U & 0984 & $0974-0994$ \\
\hline
\end{tabular}

An AUC of 0.984 was obtained when including information from all categaries. When selecting the point of the curve that is nearest the top left-hand corner, a sensitivity of $95 \%$ and a specificity of $92 \%$ can be reached.

Comparing the ROC curve of the complete model, including variables from medical history, dinical examination, mammography and ultrasonography (cat 1-4, AUC: $0.984)$ with the curve for medical history, clinical examination and mammography only (cat1-3, AUC: 0.966) showed that the increase in predictive value by adding ultrasonography approached statistical significance $(p=0.057)$. 


\section{Subgroups of patients}

The prediction model was further analyzed for different subgroups of patients according to the reason for referral. The $A \cup C$ of the resulting ROC curves are shown in table 3.

Table 3: Areas under the ROC curves (AUC) for prediction models by multivariate logistic regression with ultrasonography [variables categary $1-4$ ] and without ultrasonography (variables category 1-3) for different reasons of referral

\begin{tabular}{|c|c|c|c|c|}
\hline Reoson for leferral & 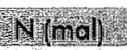 & MUE con & AUC ext 6 & prolugos \\
\hline Palpable lump & $496(55)$ & 0986 & 0,955 & 0.04 \\
\hline National screening program & $(47(4)$ & 0.953 & 0941 & 0.64 \\
\hline Symptomatolagy & $601(17)$ & 0995 & 0.990 & 0.38 \\
\hline Follow up nialígnancy & $692(8)$ & 0917 & 0.834 & 0.29 \\
\hline Follow up benign abnormality & $223(3)$ & & 0.919 & \\
\hline Regussurance & 654111 & 0069 & 0.969 & \\
\hline No reason contralateral side & $1022(4)$ & 1.000 & 1.000 & \\
\hline
\end{tabular}

In patients referred for a palpable breast lump additional ultrasonography significantly improved the predictive value of the model $(p=0.04)$. The largest increase in AUC was found for patients referred for follow up of a prior breast malignancy $(p=0.29)$.

In patients referred from the national screening program and patients with other breast symptomatology there was a smaller increase in AUC $p=0.64$ and $p=0.38$ respectively).

Finally, in patients referred for follow up of a benign lesion, for reassurance and when the contralateral side was examined, no increase in AUC was demonstrated when adding ultrasonography to the model.

Table 4 shows similar analyses for different clinical situations in patients without palpable lumps. For premenopausal women there was an increase in AUC of 0.062 when adding ultrasonography to the model $(p=0.39)$.

For the other subgroups of patients no substantial difference in AUC was demonstrated for the models with and without ultrasonography. Furthermore it is shown that there was almost no difference between the performance of the models in patients with or without prior history of breast cancer, or patients with or without dense breast parenchyma.

Table 4: Areas under the ROC curves (AUC) for prediction models by multivariate logistic regression with ultrasonography (variables category $7-4$ ) and without ultrasonagraphy (variables category $1-3$ ) for different clinical characteristics in cases without palpable lumps

\begin{tabular}{|c|c|c|c|c|}
\hline Cliniceloharacteristics & N(mog) & $A U G \cot 1 / 4$ & Ne cat 1.3 & Proloo \\
\hline Premenopausal & $1610(6)$ & 0.978 & 0.916 & 0.39 \\
\hline Postmenopqusal & $1140(20)$ & 0.970 & 0.976 & 0.75 \\
\hline Priar histong breast disease & $2074(21)$ & 0990 & 0.998 & 0.45 \\
\hline No prior history breast disease & $658(7)$ & 0985 & 0975 & 0.44 \\
\hline Dense breast parenchyma & $1096(6)$ & 0.969 & 0.969 & \\
\hline No dense breast parenchyma & $1765(22)$ & 0.971 & 0.972 & 0.96 \\
\hline
\end{tabular}




\section{Discussion}

This study shows that diagnostic information from all different stages of the diagnostic work-up contributed in the prediction of breast cancer, including the medical history, clinical examination, mammography and ultrasonography. ROC curve analysis showed that by combining information from all categories an AUC of 0.984 was obtained and a sensitivity of $95 \%$ and specificity of $92 \%$ could be reached. Furthermore. it was demonstrated that in this study population the performance of additional ultrasonography improved the model's predictive value for breast cancer more or less significantly. This was illustrated by the inclusion of the inlegrated diagnosis of ultrasonography, mammography and clinical examination as variable in the prediction model. The contribution of the diagnosis of mammography combined with clinical examination was non-significant ( $p$-walue $>0.15)$ and was excluded from the model, which may be explained by the obviously strong interaction with the integrated overall diagnosis.

Based on $\mathbb{R O C}$ curve analysis, we showed that breast ultrasonography mainly contributed to the prediction of breast cancer in patients referred for palpable lumps, and to a lesser degree in patients referred with an abnormal screening mammagram and patients referred for other symptomatology. In patients referred for follow up of a prior breast malignancy the increase in AUC was largest, but not stalistically significant. This may be explained by the low number of malignancies in this group $(n=8)$. However, it should be concluded that there is an important contributing role for breast ultrasionography in the prediction of breast cancer in this group of patients.

A palpable breast lump is a well-established indication for breast ultrasonography ${ }^{1.3,}$ 5. Purasiri el al. reparted a diagnostic index based on diagnostic scores of clinical examination, mammography, ultrasonography, age and fine needle aspiration cytology in patients with palpable lesions 12 . In contrast to our results, their model failed to show any predictive walue for ultrasonography in these patients.

Furthermore, Roche et al. reparted a scoring system for breast imaging in patients with palpable lumps, but analyzed diagnostic scores of cytology combined with radiology, consisting of the combination of mammography and ultrasonography which makes it impossible to define the role for ultrasonography separately ${ }^{13}$.

In both examples, fine needle aspiration cytology was included in the madel as it has become part of the routine diagnostic work-up of palpable breast lesions 14. 15. However, our model represents the process of routine diagnastic breast imaging at a radiology department, and therefore only includes clinical examination and radiological imaging.

In order to define more subgroups of patients in whom ultrasonography contributed in the prediction of breast cancer, patients without a palpable lump were studied further. Within the different subgroups of patients as specified in table 4 , premenopausal patients had a larger increase in AUC than postmenopausal patients by adding ultrasonography to the model. Aithough the increase in AUC was not significant, which may be explained by the small number of malignancies in the group of premenopausal women, it should be concluded that ultrasonography does contribute substantially to the prediction of breast cancer in these patients.

The additional predictive value of ultrasonography was not influenced by the presence of dense breast parenchyma or a priar history of breast cancer. This is a notable result as some siludies conclude that billateral whole-breast ultrasonography, when 
performed in patients with dense breast tissue, is useful in detecting breast cancer not discowered with mammography or clinical breast examination. However, in these studies the reported cancer detection rate was very low 1620 . Possibly, the low number of malignancies in our patien group is an explanation for this finding.

It was surprising that in univariate analysis a positive family history was not related to the presence of breast cancer in this population, despite its well-known role as a risk factor for breast cancer 21 . This may be explained by the composition of our study population, presenting with a higher prevalence of breast cancer than the general population.

Also, several statistically significant variables from univariate analysis did not contribute significantly to the final prediction model and were therefore excluded, e.g. the use of hormones, the reason for referral and the presence of a palpable lump. Apparently, the predictive value of these variables was weakened by the inclusion of other, stronger, variables. Likewise, in univariate analysils all ultrasonographic characteristics were statistically significant, e.g. the shape and the margins of suspect lesions, but in multivariate analysis only the final ultrasonography diagnosis (integrated with mammography and clinical examination), was included. This may be explained by the acquisition of the diagnosis. A 3 -point grading scale with increasing suspicion of malignancy was used to define the diagnosis of each modality. As these diagnostic scores integrate all findings of a test, they will actually contain information on the other variables in the analysis as well, leading to the exclusion of ather" contributing variables from the model. From this result, it can be concluded that this scoring system is very powerful.

Diagnostic algorithms as presented may be helpful in medical decision-making in daily practice, by estimating a patient's probability of having breast cancer. Many imethads have already been developed to estimate the risk of breast cancer for women with a given age and risk factors in the general population ${ }^{22,23}$. Next to the fact that these models do not include the results of imaging tests, they are not applicable to our outpatient population, because a different distribution of risk factors and breast cancer prevalence would require a different composition of predictive variables. The algorithm presented here is therefore only applicable to a comparable outpatient population referred for breast imaging, having a prevalence of breast cancer of around $6 \%$. We believe this will concern the patient popullations of most breast imaging clinics and radiology deportments in hospitals in and outside The Netherlands ${ }^{24.26}$.

Nevertheless, the value of this model in clinical practice may be argued. After having performed clinical examination, mammography and ultrasonography the radiologist may not so much be interested in the patient's chance of having breast cancer, but rather in whether the patient should be discharged or referred for additional diagnostic procedures. In order to fill these needs, future research should be aimed at the expansion of the madel with variables an pathological tests, such as fine needle aspiration cytology, core needle biopsy and excision surgery.

Meanwhile, the current model demonstrates clearly which variables are most significant in the realization of a final imaging diagnosis. In order to improve the performance of diagnostic breast imaging in radiology departments, a standard registration of these specific variables should be encouraged. 
Concluding, the prediction model showed that all stages of the diagnostic imaging work-up for breast disease contributed to the diagnosis of breast cancer. Additional ultrasonography improwed the predictive value of the model most significantly in patients referred for a palpable lump. Furthermore, among patients without a palpable lump, ultrasonography contributed most to the diagnosis in the subgroup of premenopausal patients. 


\section{References}

1. Skoane P. Ultrasonography as adjunct to mammography in the evaluation of bieast tumors. Acta Radiol Suppli 1999: 420:1-47.

2. Bassett LW. Imaging of breast masses, Radial Clin North Am 2000; 38:669-91, vii-vili.

3. Jackson VP, Reynolds HE, Hawes DR. Sonography of the breast. Semin Ultrasound CT MR 1996; 17:460-75.

4. Mendelson EB, Tobin CE. Critical pathways in using breast US. Radiographies 1995; 15:935-45.

5. Zonderland HM. The role of ultrasound in the diagnosis of breast cancer. Semin Liftrasaund CT MR 2000; $21: 317-24$.

6. Jackson VP. The eurrent rale of ultrasonography in breast imaging. Radial Clin North Am 1995: 33.1161 .1170

7. American College of Radiology. Assessment categories. Illustrated breast imaging reporting and data system (Illustrated BI-RADS). Reston; VA: American College of Radiology, 1995.

8. Mendelson EB, Berg WA, Merrit CR. Toward a standardized breast ultrasound lexicon, BI-RADS: ultrasound. Semin Raentgenol 2001; 36:217-25.

9. Hosmer DW, Lemeshow S. Applied Logistic Regression. New York: John Wiley \& Sons, Inc, 2000:392.

10. Hanley JA, MC Neil BJ. A. method of comparing the areas under receiver operating characteristic curves derived from the same coses. Radiology 1983; 148:839-843.

11. Hanley $J A$, MaNeil $B J$. The meaning and use of the area under a receiver operating characteristic (ROC) curve. Radiolagy 1982; 143:29-36.

12. Purasiri P, Abdalla M, Heys SD, ell al. A novel diagnostic index for use in the breast clinic. J R Call Surg Edinb 1996; $41: 30-34$.

13. Roche NA, Given-Willsan RM, Thomas VA, Sacks NPM. Assessment of a scoring system for breasi imaging. Br J Surg 1998; 85:669-672.

14. Vetto 1, Pommier R, Schmidt $W$, et al. Use of the "triple test" for polpable breast lesions yields high diagnastic accuracy and cost savings. Am J Surg 1995; 169:519-22.

15. Morris A, Pommier RF, Schmidt WA, Shilh RL, Alexander PW, Vetto JT. Accurate evaluation of paipable breast masses by the triple test score. Arch Surg 1998; 133:930-4.

16. Kolb $T M$, Lichy J, Newhouse $J H$. Occult cancer in women with dense breastls: detection with screening US- diagnostic yield and tumor characteristics. Radiology 1998; $207: 191$ - 199.

17. Kopans DB. Breast-cancer screening with ultrasonography. Lancet 1999; 354:2096-97.

18. Kaplan SS. Clinical utility of bilaterail whole breast US in the evoluation of women with dense breast tissue. Radiology 2001; 221:641.9.

19. Buchberger $W$, Dekoekkoek-Doll $P$, Springer $P$, Obrist $P$, Dunser $M$. Incidental findings on sonography of the breast: clinical significance and diagnostic warkup. AJR 1999; 173.921 .927

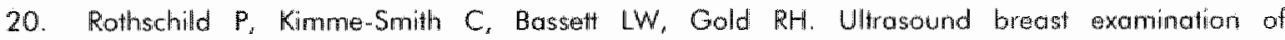
asymptomatic patients with normal but radiodense mammograms. Ultrasound Med Biol 1988; $14: 113-9$.

21. McPherson $K$, Steel CM, Dixon JM. ABC of breast diseases. Breast cancerwepidemiology, risk factors, and genetics. Bmi 2000; $321,624-8$.

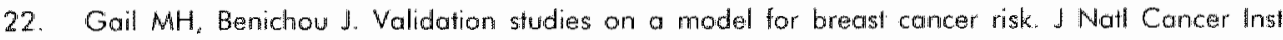
$1994 ; 86: 573.5$.

23. Gail MH, Brinton LA, Byar DP, ef al. Projecting individualized probabilities of developing breast cancer for white females who are being examined annually. I Natt Cancer Inst 1989; 81:1879. 86.

24. Duilm LEM, Guit GL, Koomen AR, Willebrand D. Sensitivity, specificity and predictive values of breast imaging in the detection of cancer. $\mathrm{Br} J$ Cancer 1997; 76 (3):377-381. 
25. Flobbe $K$, van der Linden $E S$, Kessels $A G$, wan Engelshowen $M M$. Diagnostic value of radiological breast imaging in a non-screening populahion. Int J Cancer 2001; 92:616-8.

26. Zonderlanid HM, Coerkamp EG, Vijuer $M$, $f$, van de, Voorthuisen $A$, E. Diagnosis of breast cancer: Contribution of US as an adjund to mammography. Radiology 1999; $213: 413-1422$.

27. var Asperen $\mathrm{CJ}$, de Bock $\mathrm{GH}_{\text {, }}$ van der Horsit $F$, de Koning HJ, Ruigers EJT. Screening op mammacarcinoom buiten hel landalijk bevolkingsonderzoek, op grond van individuele risico. inschatting. Ned T v Gen 2001; 145:120-125. 


\section{COSTS AND EFFECTS OF THE USE OF ULTRASONOGRAPHY IN THE EVALUATION OF PALPABLE BREAST MASSES}

Karin Flobbe, Alfons G.H. Kessels, Johan L. Severens, Geerard L. Beets, Harry J. de Koning, Maarten F. von Meyenfeldt, Jos M.A. van Engelshoven

(Submitted) 
Abstract

Aim

To study the cost-effectiveness of incarporating ultrasonography in the triple test for evoluating palpable breasit masses.

\section{Methods}

A decision analytic madel was used to compare the conventional strategy of immediate fine needle aspiration cytology (FNAC) following mammography and clinical examination with 3 different experimental strategies of prior ultrasonography.

In strategy 1, a cut-off between benign and probably benign ultrasonography results was used for further referral for FNAC; in strategy 2, this cut-off was shifted to a cut-off between normal and benign results; and in strategy 3, prior ultrasonography was only performed in patients with normal, benign results on mammography and clinical examination, whereas immediate FNAC was performed in patients with suspicious lesions. Empirical data were obtained from a prospective study in 522 breasts with a palpable mass, including 93 malignancies. Outcome variables included the fotal costis and the expected number of life years. Sensitivity analysis was performed on all parameters in the model.

\section{Results}

All strategies reported similar life expectancies, namely 31.0 life years. Cost-minimization demonstrated that experimental strategy-3 was the least expensive strategy (e 2946). Experimental strategy-2 was the most costly strategy $(\in 3475)$. Compared to the conventional strategy of immediate FNAC [ $€$ 3087), both ultrasonagraphy strategy 1 and 3 were preferred.

Sensitivity analysis showed that the proportion of suspicious or benign FNAC results and the proportion of false-negative ultrasonography results were the most influential variables on the cosi outcome of the model.

\section{Conclusion}

A reduction in total costs for the diagnosis and treatment of breast cancer can be established when incorporating diagnostic ultrasonography in the triple test for the evaluation of palpable breast masses. 


\section{Introduction}

Breast cancer is the leading cause of death in women in the Western world and the diagnosis and treatment have become a financial burden to health caite services. Many patients are referred by their general practitioner to a hospital setting for diagnostic breast imaging of a palpable breast mass. Routine diagnastic work-up of palpable breast masses includes the performance of clinical examination, mammography and fine needle aspiration cytology (FNAC), combined as the "triple test". Several studies have shown that the triple test is accurate and can replace open surgical biopsy for diagnosis when all 3 components are concordant (all indicating a benign condition or all indicating a malignant condition) $)^{1, ?}$.

Additionally, a palpable breast lump has become an important indication for ultrasonographic examination ${ }^{3}$. . Several prospective studies have demonstrated the diagnostic value of ultrasonography as an adjunct to mammography in these patients and report sensitivities and specificities of $93 \%-99 \%$ and $67 \%-97 \%$ respectively 12.6 The usefulness of ultrasonography lies in the differentiation between solid and cystic masses. A $100 \%$ accuracy in the diagnosis of a cyst can be reached when strict criteria are used, consisting of a round oval shape or gently lobulated, circumscribed margin, anechoic echagenicity and acoustic enhancement". By diagnosing cysts, ultrasonography can reduce the suspicion for breast cancer and save patients from additional pathological examinations, including FNAC. In many cases, the radiologist will perform ultrasonography-guided fine needle aspiration of cystic fluid, but the examination by the pathologist can be spared and will reduce patient charges. Furthermore, ultrasonography may detect abnormalities which are palpable but mammagraphically accult, e.g. because of radiologically dense breast tissue.

These effects indicate that ultrasonography could be incorporated in the triple test for pallpable breast masses. Vetto ef al. studied the accuracy of a modified triple test in 55 women younger than 40 years, in which ultrasonography substituted mammography ${ }^{17}$. As the sensitivity of mammography is lower in younger patients with dense, glandular breasts, ultrasonography can be performed as initial imaging study in these patients, next to clinical examination. The authors report a high diagnastic accuracy reducing the need for routine open biopsy, resulting in an overall reduction in patient charges. However, when expanding this study to patients older than 40 years, ultrasonography would have to be applied as an adjunct to mammography rather than as a substitute. Furthermore, the costs of performing ultrasonagraphy in all these patients are considerable and the suitability of its application in daily clinical practice will therefore also depend on the cost-effectiveness.

In an earlier prospective study at the radiology department of Maastricht University Hospital, we assessed the diagnostic value of ultrasonography as an adjunct to mammography and clinical examination in the evaluation of 492 patients with 522 palpable breast masses.

The aim of the present study was to assess the cost-effectiveness of incorporating ultrasonography in the triple test for evaluating palpable breast masses. Three different scenarios were studied and in ordier to compare the associated costs and effects with the routine conventional triple test, a decision analytic model was designed. 


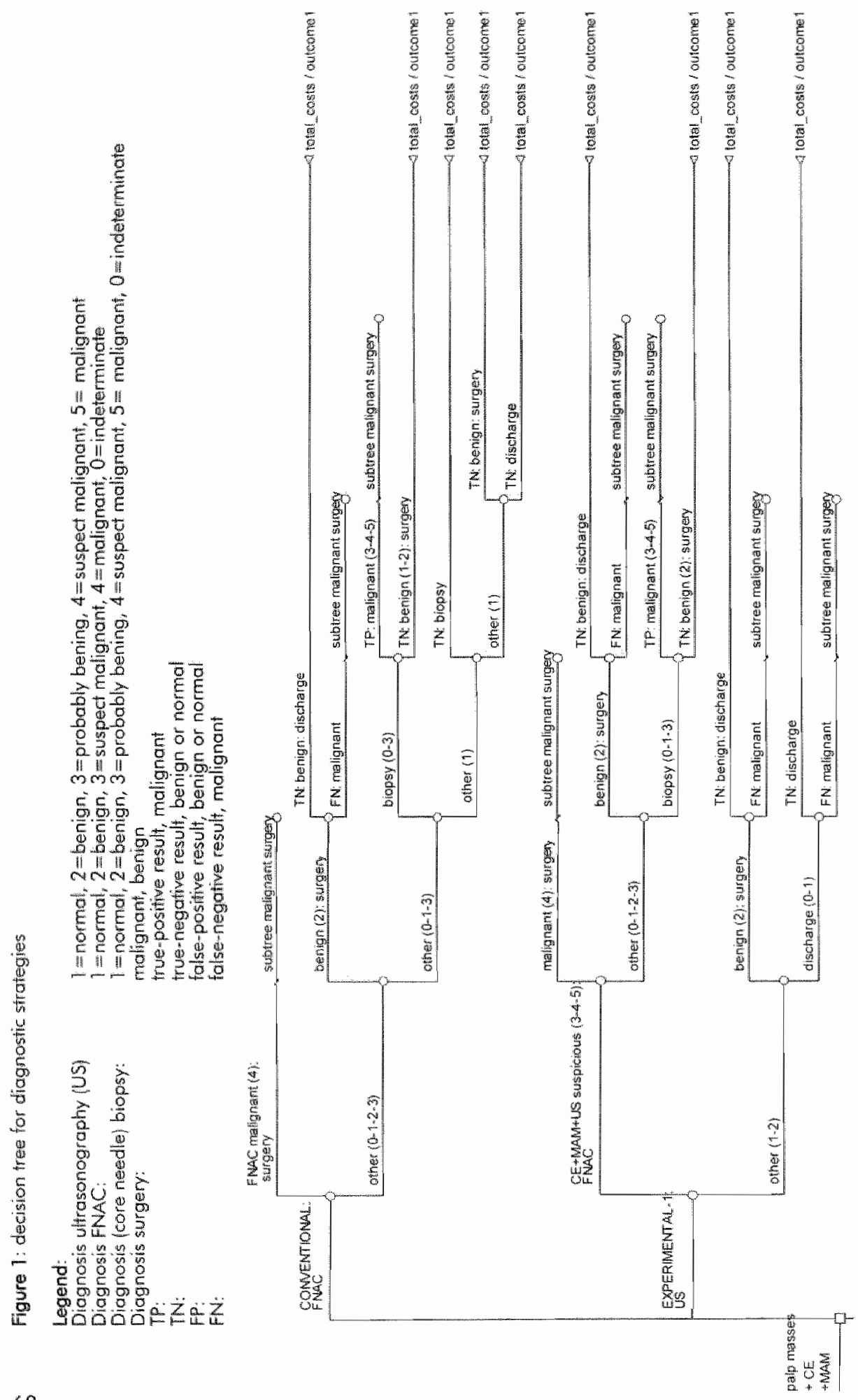




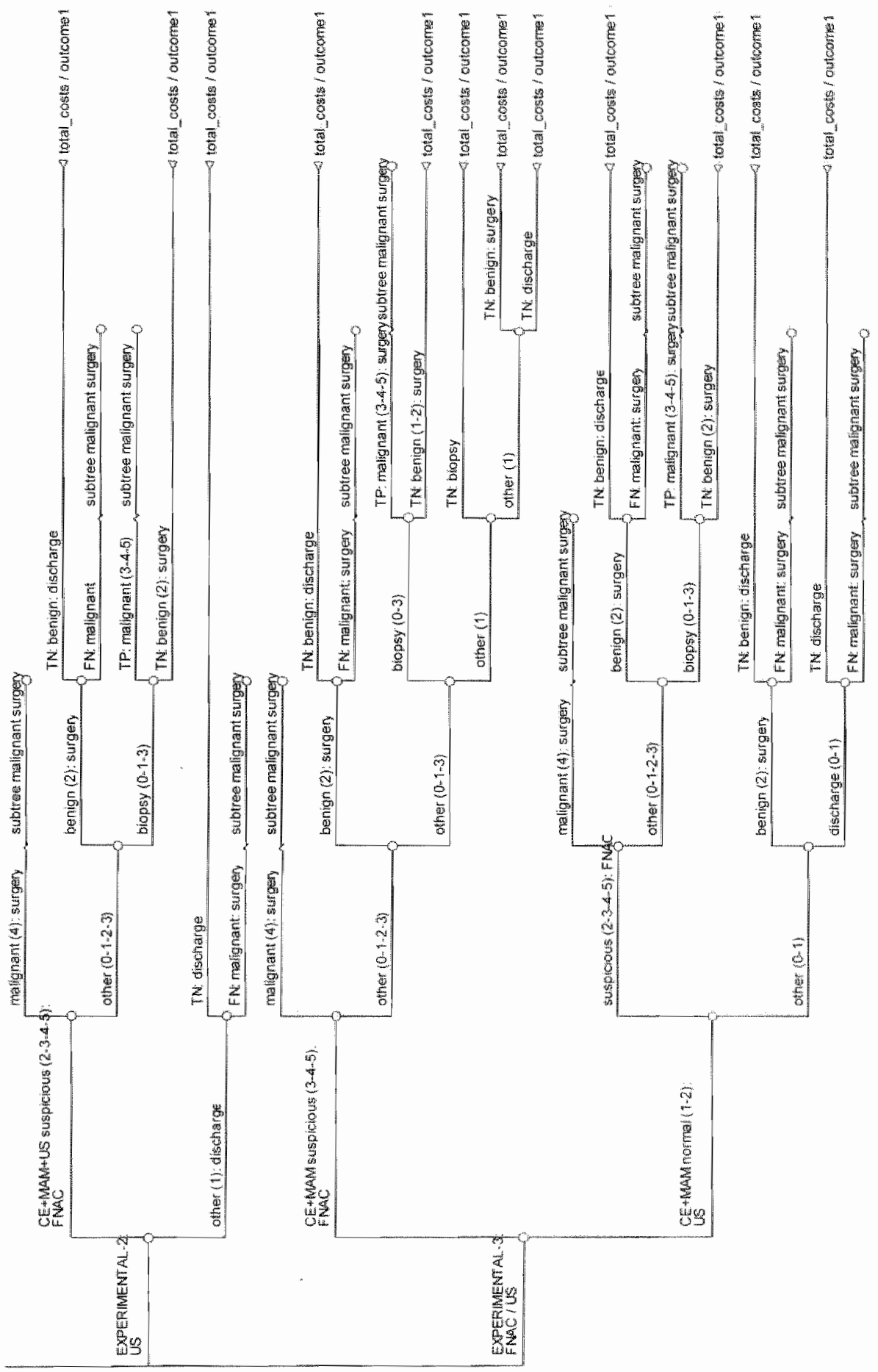




\section{Methods}

\section{Diagnostic strategies}

Four different strategies following the performance of mammography and dinical examination in patients with palpable breast masses were compared (table 1).

The conventional strategy consisted of immediate FNAC after mammography and dinical examination in all patients, according to the triple test.

In experimental strategy-1, prior ultrasonography was performed in all patients and a cut-off point between benign and probably benign results was used for referral for additional FNAC. Patients were discharged when no abnormality or a cyst was found. When a solid benign structure was detected, such as a fibraadenoma, simple excision was performed. All suspicious findings on ultrasonography were eventually excised; none were discharged.

In experimental strategy-2, the effect of shiffing the cut-off point for referral for FNAC between normal and benign ultrasonography results was studied. Assumptions were similar to those in experimental strategy-1.

In experimentall strategy-3, prior ultrasonography was only performed in patients with normal or benign results on mammography and clinical examination, whereas immediate FNAC was performed in patients with suspicious lesions.

Table: 1: Different diagnostic strategies analyzed

\begin{tabular}{|c|c|c|c|}
\hline Conventional & $C E+M A M 1,2,3,4,5$ & FNAC $12,3,4,5$ & \\
\hline Expentinentall & $\mathrm{CE}+\mathrm{M} \times \mathrm{m}, 2,3,4,5$ & 101,3 & $\begin{array}{l}\text { Dischange } \\
\text { FlaC }\end{array}$ \\
\hline Experimental-2 & $\mathrm{CE} \perp \mathrm{MAM}, 2,3,4,5$ & $\begin{array}{l}\text { US } 1 \\
\text { US } 2,3,4,5\end{array}$ & $\begin{array}{l}\text { Discharge } \\
\text { FNAC }\end{array}$ \\
\hline Experinnenlals & 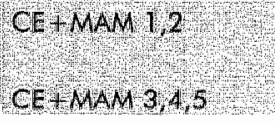 & 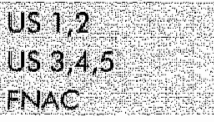 & $\begin{array}{l}\text { Dischirge } \\
\text { rNAC }\end{array}$ \\
\hline
\end{tabular}

Lagend: $C E=$ dinical examination, MAMA = mammography, US = ultrasonagraphy, FNAC = fine meedle anpiration cytology, diagnostic scores: $1=$ normal, $2=$ benign, $3=$ probably benign, $4=$ suspicious malignant, $5=$ malignant

As empirical data were not available for all strategies, a decision analytic model was constructed using the computer program Decision Analysis by TreeAge (DATA3.5; TreeAge software, Williamstown, Mass). A shot version of the decision tree comparing the strategies (square made) is shown in figure 1. The model included diagnostic procedures such as ultrasanography, FNAC and histological core needle biopsy; primary therapeutic events such as excision biopsy, surgery, radiotherapy, chemotherapy and hormonal therapy; and treatment of local recurrences, distant recurrences and palliative care at the terminal stage of the disease. Ultrasonographyguided fine needle aspiration of a cyst was regarded as part of diagnostic ultrasonography, unless cytological examination was requested from a pathologist.

A distinction was made bewween surgery of a benign lesion (excision biopsy) or a malignant lesion (curative, malignant surgery). 
The routes following FNAC were the same for all strategies; either surgery of a malignant lesion, surgery a a benign lesion or core needle biopsy of a lesion of

uncertain nature was performed. Additionally, in the conventional strategy, d proportion of patients with normal FNAC results underwent funther biopsy or surgical excision, in order to rule out a false-negative result while no ultrasonographic confirmation of the diagnasis was available.

In figure 2, the subtree for surgical treatment of malignant breast lesions is shown. Surgery of a mass that was radiologically diagnosed as malignant could reveal a tiruepositive or false-positive result. Further distinction was made between cases with a bad prognosis leading directly to palliative care, surgery with and without adjuvant chemotherapy and hormonal therapy, and occurrence of a locall or systemic recurrence.

Figure 2: subtree for surgery of malignant breast lesions

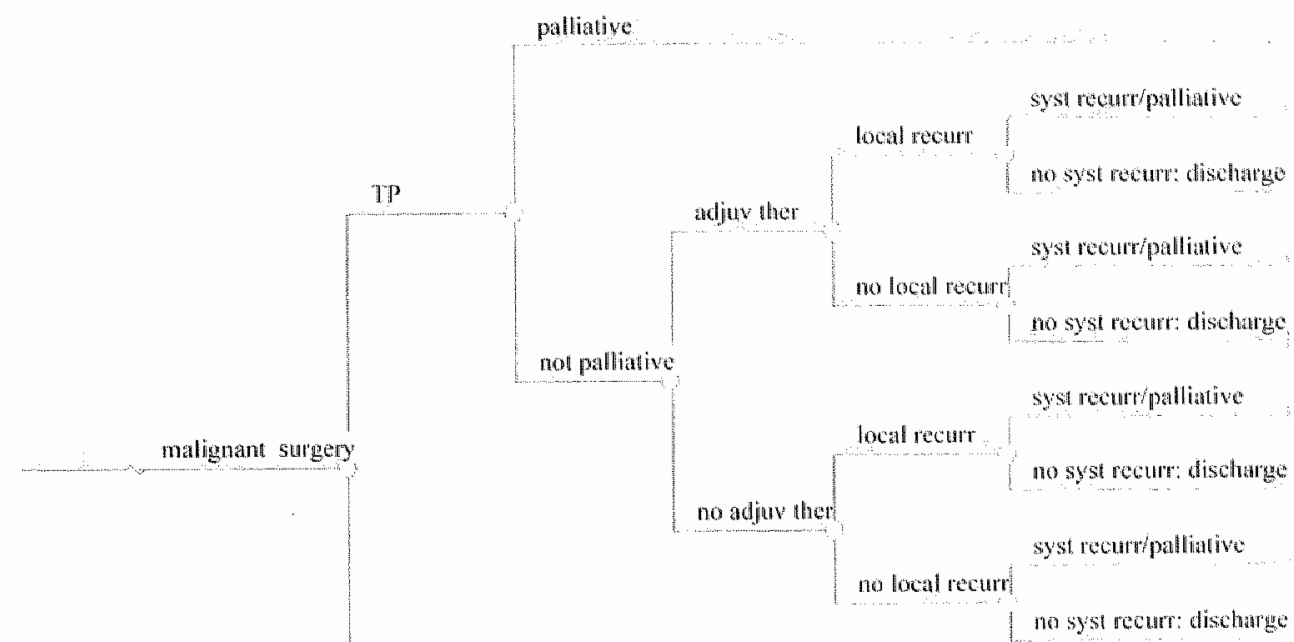

Fip: 曲:

Legend:

TP:

true-posifive result, malignant

FP:

follse-positiwe result, benign or nominal

It was assumed that all malignancies detected by ultrasonogiraphy in the experimental strategies were detected by FNAC in the conventional strategy. Consequently, the prevalence of malignancy and the discharge-rate were equal in all strategies.

The outcome of each clinical pathway of the model reflected either the tatal costs, adding up the costs of all diagnostic and therapeutic medical events, and the average expected number of life years, that was retrieved from the Dutch institute for health statistics and adapted for advanced death by disease. 


\section{Dalla sources}

In the prospective clinical study that formed the basis of this decision analysis, 3835 breasts in 2020 patients were examined by both clinical examination, mammography and ultrasonography (methodology as described in chapter 4). From the tolal study population all cases with a palpable lump were selected $n=522$ breasts, 492 patients). The mean age of the study population was 49 years (range 17 $-90)$.

After a follow up of 12 months during which pathology results from core needle biopsies, excision biopsies and other surgical interventions were recorded, a total of 93 malignancies were reported, leading to a prevalence of breast cancer of $19 \%$ $(93 / 492)$ in this population.

The decision model was designed on the level of breasts $(n=522)$.

The diagnosis from ultrasonography was integrated with results of mammography and clinical examination and scared on a 5-point grading scale of increasing suspicion for malignancy, as $1=$ normal, $2=$ benign, $3=$ probably benign, $4=$ suspect malignant, $5=$ malignant, which was adapted from the BI-RADS-lexicon for mammography and under development for ultrasonography 8.12 . In accordance with clinical practice, for the definition of positive and negative cases, a cut-off point was used between benign (2) and probably benign (3) results. All patients with palpable masses and positive imaging results were subsequently referred for FNAC.

Furthermore, a combined diagnosis from mammography and clinical examination together and results firom core needle biopsy were scored on a similar grading scalle. FNAC was recorded on a 4 -point grading scale, as $1=$ normal, $2=$ benign, $3=$ suspect malignant / atypia, $4=$ malignant, $0=$ indeterminate. The presence of malignancy as a result of surgery was registered as a dichotomous variable.

Chance nodes (indicated by a circle) in the model represented the diagnastic or therapeutic actions at different grades on these diagnostic scales (e.g. in experimental strattegy-1, FNAC was performed when ultrasonography reported a suspicious diagnosis (score 3,4 or 5 ): see figure 1 ).

Mast probabilities required for experimental strategy-1 were retrieved from our clinical study. Data on the other strategies were adapted from these data or composed hypothetically by consulting an expert panel and by using clinical guidelines (table 2). Additionally, for all phases of the model relevant literature was reviewed.

Results of cost calculation studies in our hospital formed the basis of the costs used in the model, complemented with data from the Dutch Health Care Insurance Board is and the Dutch farmacotherapeutic guidelines ${ }^{20}$. The used costs are integral and include costs for personnel, material, capacity and departmental overhead. Costs were specified in Euros (E), with 1 Euro beingl equal to 0.85 American dollar (index 2000 ). In table 3 , an overview is given of the different cost components of each cost item in the madel. A more detailed calculation of the costs is available from the authors on request.

Palliative care was defined as medical care during the terminal phase of the disease, lasting from the diagnosis of distant, systemic recurrences to the time of death. Data on all medical events during this period were adapted from a study of de Koning et al. 21,22 . The probabilities and cosis used were updated for the year 2000 according to recent guidelines and experts' opinion. 
Due to the health care perspective chosen for this study, direct costs to patients, costs of home care, out of pocket expenses resulting from visits to health care institutions, community care costs, the costs of lost productivity and the impact on the quality of life were not included in this study.

Table 2: Madel parameters and range of sensitiwity analysis

\begin{tabular}{|c|c|c|c|}
\hline 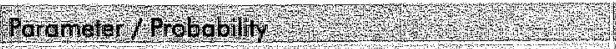 & Honcs & renget & 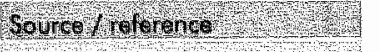 \\
\hline Experimental Strotegy & & & \\
\hline Suspicious $(3-4-5)$ US result & 0.349 & $0.314-0.385$ & Clinical study MUH \\
\hline Malignant $(4)$ FNAC result atier US & 0.324 & $0.267-0.386$ & Clinical study MUH \\
\hline TP result surgery after malignant FNAC \& US & 0.983 & $0.922 \cdot 0.999$ & Clinical study MUH \\
\hline Benign (2) FNAC result after US & 0.439 & $0.363-0.517$ & Clinical situdy MUUH \\
\hline FN resull surgery offer benign FNAC \& US & 0.074 & $0.026 \cdot 0.1162$ & Clinical study MUHH \\
\hline Mallignant $(3-4-5)$ biopsy result afier FNAC \& US (TP) & 0.435 & $0.333-0.541$ & Clinical study MUH \\
\hline Surgery after benign (2) US result & 0.126 & $0.098-0.160$ & Clnnical study MUH \\
\hline FN result surgery after benign US result & 0.023 & $0.001 \cdot 0.106$ & Clinical study MUH \\
\hline FN result of discharge after normal (!) US result & 0.000 & $0.000-0.050$ & Clinical study MUH \\
\hline Malignant $44 \|$ FNAC result & 0.115 & $0.058-0.173$ & Assumption, expert panel \\
\hline TP result surgery after malignant (4) FNAC & 0.983 & $0.492-1.000$ & Assumption, expent poinel \\
\hline Benign (2) FNAC result & 0.208 & $0.104-0.312$ & Assumption, expert ponge! \\
\hline FN result sungery after benign $(2)$ FNAC & 0.042 & $0.021 \cdot 0.063$ & Assumption, expert pane? \\
\hline Biopsy after probably benign (0-3) FNAC resulit & 0.189 & $0.095-0.280$ & Assumption, expent ponel \\
\hline Malignant $(3-4-5)$ biopsy result atter FNAC (TP) & 0.435 & $0.218-0.653$ & Assumption, expert panel \\
\hline Biopsy after nomal (I) FNAC result (TNS) & 0.300 & $0.150-0.450$ & Assumption, expent panel \\
\hline Surgery alter normal (1) FNAC (TN) & 0.140 & $0.070 \times 0.210$ & Assumption, expert panes \\
\hline Experimental Strotegy 2 & & & \\
\hline "Suspicious" (2-3-4-5) US result & 0.761 & $0.728 \cdot 0.791$ & Clinicol study MUUH \\
\hline Malignant (4) FNAC result after US & 0.1 .49 & $0.120 \cdot 0.181$ & Adapted from clinical study MU \\
\hline TP resull surgeny after malignant FNAC \& US & 0.983 & $0.922-0.999$ & Adapted from clinical study MU \\
\hline Benign (2) FNAC resull after US & 0.580 & $0.534-0.625$ & Adapted from clinical study MU \\
\hline FN resutf surgery after berugin FWAC \& US & 0.107 & $0.073 \cdot 0.151$ & Adopted from clinical st wdy MU \\
\hline Malignanil $(3-4-5)$ biopsy resull atter FNAC \& US (TP) & 0.099 & $0.081 \cdot 0.150$ & Adapted from dinical atidy MU \\
\hline Surgery ofter benign (2) US result & 0.000 & $0.000 \times 0.050$ & Adapied from clinical study MU \\
\hline FN resull surgen atter benign US resull & 0.000 & $0.000 \cdot 0.050$ & Adiopted rrom clinical situdy MU \\
\hline FN result of discharge atter normali (1) US resulti & 0.000 & $0.000 \cdot 0.050$ & Aclapted from cinical study MU \\
\hline Malignant (4) FNAC result & 0.115 & $0.0589-173$ & Agsurnplion, expert panel \\
\hline TP resuli strgery after molignont (4) FNACC & 0.983 & $0.492 \cdot 1.000$ & Assumption, expert ponel \\
\hline Bengin (2) FNAC result & 0.208 & $0.104 \cdot 0.312$ & Assuriplion, expert pounel \\
\hline FN result surgery after benign (2) FNAC & 0.042 & $0.021-0.063$ & Assumption, expart punel \\
\hline Bropsy after probably berign $(0-3)$ FNAC reswilt & 0,189 & $0.095-0.280$ & Assumption, expent panel \\
\hline Mallignont $(3-4-5)$ biopsy result after FWAC (TP) & 0.435 & $0.218-0.653$ & Assumption, experl ponel \\
\hline Biopsy afier nomal (1) FMAC resull [TN] & 0.300 & $0.150-0.450$ & Assumption, expert pomel \\
\hline Surgen after normal (1) FNAC ITN) & 0.140 & $0.070 \times 0.210$ & Assumplion, exper pantel \\
\hline Expenmantal Strategy 3 & & & \\
\hline Suspicious $(3.4-5)$ CE-MAM resull & 0.753 & $0.712 \cdot 0.784$ & Clinical sludy MUH \\
\hline Suspicious $(3-4-5)$ US result & 0.078 & $0.043-0.128$ & Adopled from clinzical siludy MU \\
\hline Molignant (4) FNAC resull after US & 0.200 & $0.037-0.507$ & Adopled from clinical situdy MU \\
\hline
\end{tabular}


TP resull sugen olter matignom FHAC \& US

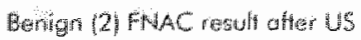

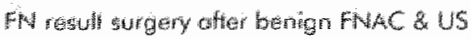

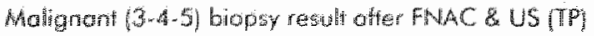

Surgery ofter benign 12 US ranult

Flu resull aurgery ghter bentign US result

FWresulf of discharge after nomal (1) US resula

Molignont (4) FWAC restill

TP result surgery after malignam (4) FNAC

Benign (2) FNAC result

Fiv resull surgery after benign (2) FNAC

Biopsy after probably benign (1-3) FNAC resull

Mallignan $(3-4-5)$ biopsy result offer FNAC (TP)

Biopsy after normal (1) FNAC resull (TN)

Surgery after momol (1) FNAC ITN)

\section{All stratiegies}

Aedivwant therapy wills primary surgery

Local recurrence ofier prinary surgery

Pallichive slage ofter diagnosis

Pollichive sloge after adjuwaril therapy

Pallintiwe stoge after non-adjusant therapy

Palliative stoge atter local recurrence

\section{Expocted lifo years}

LE Polliative stage ofter diagnasic thest

LE Polliative stage affer local recurrence

LE Pelliative stage after local \& distant recurrence

LE Disease-free after diognostic test

LE Disease-free after trealment
1.000

0.500

0.000

0.250

0.199

0.000

0.000

0.148

0.983

0.275

0.043

0.247

0.46

0.298

0.137
0.1930.007

0.0000050

$0.001-0.106$

0.06600168

0,00000050

$0,000,0.050$

$0.190,180$

0.4921000

02350,318

0.0150 .097

0.2040295

0.3410556

0.24500 .356

0.09100194
Adopted rom dinncal study MU

Adcipted from dinnical sưdy MU

Adopled from ctinical study MU

Adepted rom clinical study MU

Adopted from ctlnical study MU

Adepted trom clinucal study au

Adapted from clinucal study MU

Assunnotion, expert panel

Assumption, expert ponel

Assumpition, expert panel

Assumption, expert ponel

Assumpition, Expert panel

Assumption, expert ponel

Assumplion, expert panel

Assumption, expert panel

1 Range accarding to $90 \%$ confidence intervals of empirical data or $50-150 \%$ of assurmed and adapted dato:

Lagend: US = Ullasonography / MUH = Macsitricht University Hospital / TP= true-positive result / FN= folse-negative result / LE - life expectancy / Diagnosis imaging: l = nomal, 2 =benign, $3=$ probably berign, 4: suspect mallignant, 5 =malignan / Diagnosis FNAC: $1=$ momal, $2=$ benign, $3=$ suspect malignant, 4 malignam, 0 -indeterminate / Diagnasis "core needle biopsy: $1=$ inormal, $2=$ benigin; 3 :- probably benign, 4 = susped malignant, 5 malighant, 0 =indeterminate / Diagnosis surgery: malignant, benign.

\section{Cost-effectiveness analysis and sensitivity analysis}

Baseline cost-effectiveness analysis calculated the total costs and average life expectancy fior each strategy. Univariate one-way sensitivity analysis was performed for all parameters in the model, over a range of values according to the $90 \%$ confidence interval for empirical data of the clinical study, or from $50 \%$ to $150 \%$ of the deterministic variables in the model (table 2). The effect on the costs and life expectancy was studied and threshold analysis was performed to identify the walues at which the preferred strategy would alter. 


\section{Results}

\section{Base-case analysis}

The results of base-case cost-effectiveness analysis are presented in table 4.

In experimental strategy-1, 182 (35\%) ultrasonographic examinations resulted in probably benign or malignant results (diagnostic score 3-4-5) and were followed by FNAC, leading to additional costs of 614,560 (182* 680$\}$. Furthermore, in 340 cases FNAC was prevented compared to the conventional strategy, saving $E 7,140\left(340^{*} \in\right.$ $101-(80)$. One result was false-negative and an additional excision biopsy $(\epsilon 1,089)$ was performed preceding malignant surgery. The associated additional costs of this strategy compared to the conventional strategy were roughly $e 8,509$.

In the conventional strategy, additional costs with respect to the experimental strategy included the confirmation of normal cytology results by core needle biopsy or excision $(e 50,360)$.

Table 3: Total costs in Euros ( $\Theta$ ) per item in the model

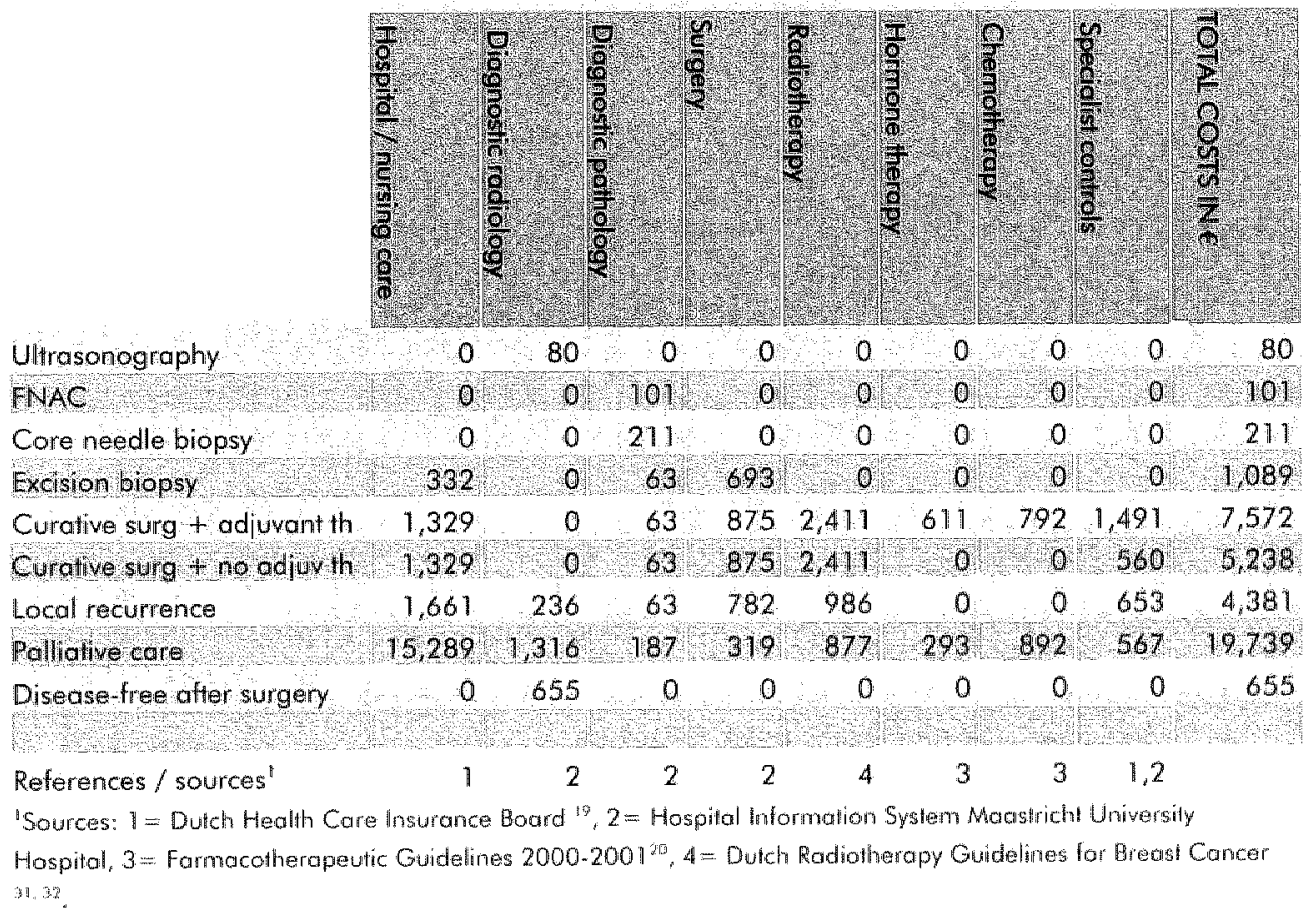

Cost-effectiveness analysis showed that this strategy was less costly than the conventional one (e 3010 versus $E 3087)$.

Shifting the cut-off to normal (1) and benign (2) ultrasonography results, resulted in 397 referrals $(76 \%)$ for additional FNAC (experimental strategy-2). This included an increase of 215 FNAC examinations compared to experimental strategy-1 or $E$ 21,715 . It was assumed that no extra malignant FNAC results were generated and that most extra cases were diagnosed as benign through surgery and core needle 
biopsies. The remaining 125 cases were either discharged or a benign lesion was surgically excised. As a consequence, this experimental strategy was more costly $€ \in$ 3475 ) compared to the conventional strategy.

In experimental strategy-3, 393 cases $(75 \%)$ with a suspicious abnormality on mammography or elinical examination (diagnostic score 3-4-5) were referred for immediate FNAC. The remaining 129 normal (1) or benign (2) cases underwent prior ulfrasonography. It was assumed that no false-negative ultrasonography resulted from this group. The total casts of this strategy were $€ 2946$, which was $€ 141$ less costly than the conventional strategy of immediate FNAC.

Table 4: Results of basew - case costueffectiveness analysis

\begin{tabular}{|c|c|c|c|c|}
\hline 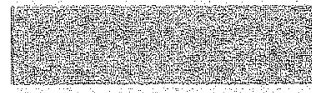 & iromeg & Exper & 16. & \\
\hline No. FNAC performed & 522 & 182 & 397 & 403 \\
\hline No. US pertormed & 0 & 522 & 522 & 129 \\
\hline TPUS & & 92 & 93 & 3 \\
\hline FP 118 & & 90 & 304 & 7 \\
\hline TNUS & & 339 & 125 & 119 \\
\hline FVIS & & 1 & 0 & 0 \\
\hline Costs (E) diagnosis & 82 & 165 & 294 & 69 \\
\hline Costs (e) trealment & 1472 & 1412 & 1748 & 1444 \\
\hline Costs $(6)$ follow up core & 1433 & $\mathrm{I} 433$ & 1433 & 1433 \\
\hline Costs (E totel & 3087 & 3010 & 3475 & 2946 \\
\hline LE (years) & 310 & 31.0 & 31,0 & 370 \\
\hline Pieferred strategy & & us & FNAC & US \\
\hline
\end{tabular}

Legend: US = ultrosongonaphy / TP US = true positive US resull/FP US= false-positive US result / TN US= truenegative US result / FM US = falsenegalive US result / LE = life expectancy / cosis ( 6 ) rotal= cosis of diagnosis threatment thollow up cale aftar treatment.

The total number of FNAC and ultrasonography examinations performed was highest in experimental strategy-2 ( $n=919,522 \mathrm{FNAC}$ and 397 ultrasonography) and lowest in the conventional strategy $(n=522,522$ FNAC and 0 ultrasonography). The table also reports the number of positive and negative ultrasonography examinations, indicating the number of cases in which additional action followed, rather than the number of "malignant" diagnoses. It is shown that strategy-3 obtained the lowest number of false-positive and false-negative results.

Furthermore, table 4 shows the costs splitted for diagnosis, treatment and follow up care in these strategies. It is shown that the costs for diagnosis were minimized to an average of $€ 69$ per patient in experimental strategy-3. Experimental strategy-2 was most costly in both diagnosis and treatment. Costs of follow up care for malignancies were equal for all strategies $(\epsilon$ 1433) as well as the average life expectancy $(31.0$ years).

Overall, the madel showed that experimental strategy-3 with selected ultrasonography as additional dlagnostic modality, was the cheapest strategy as compared to the conventional strategy and both other experimental strategies. 


\section{Sensitivity analysis}

One-way sensitivity analysis was performed for all parameters in the model, comparing each experimental strategy with the conventional strategy. The cost rankings for the different strategies remained stable over a range of costs from 50 to $150 \%$ of base-case estimates. Furthermore, sensitivity analysis of life expectancy outcome wariables showed no impact on the strategy being preferred.

In table 5, all variables that influenced the strategy preferred in the model are reported. These variables mainly influenced the cost outcome of the model, while no impact was demonstrated on the life expectancy. Most important influential variables included the proportion of suspicious and benign FNAC results and the proportion of false-negative ultrasonography results. For experimental strategy- 1 nine influential variables were identified, whereas there were only 1 and 2 influential variables in experimental strategies -2 and -3 respectively.

Table 5: Results of sensitivity analysis and threshold analysis

\begin{tabular}{|c|c|c|}
\hline Probability & Heringer & Throsholdonatysis \\
\hline \multicolumn{3}{|l|}{ Experimental / strategy ] } \\
\hline Suspicious $(3-4-5)$ US result & 0.349 & $>0.36$ \\
\hline Mallignant (4) FNAC result affer US & 0.324 & $>0.35$ \\
\hline Benign (2) FNAC result after US & 0.439 & $<0.37$ \\
\hline FN result surgery after benign FNAC \& US & 0.074 & $>0.13$ \\
\hline Malignant $(3-4-5)$ biapsy result after FNAC \& US (TP) & 0.435 & $>0.48$ \\
\hline FN result of discharge offer $(0-1)$ US result & 0.000 & $>0.01$ \\
\hline Malignant (4) FMAC result & 0.115 & $<0,11$ \\
\hline Biapsy after probably benign $(0-3)$ FNAC resulf & 0.189 & $<0.17$ \\
\hline Malignant $(3-4-5)$ biopsy result after $\mathrm{FNAC}^{2}$ & 0.435 & $<0.39$ \\
\hline \multicolumn{3}{|l|}{ Experimental strategy? } \\
\hline Malignant (4) FNAC result after US & 0,149 & $<0.14$ \\
\hline \multicolumn{3}{|l|}{ Experimental strategy 3 . } \\
\hline FN result of discharge after $(0-1)$ US result & 0.000 & $>0,06$ \\
\hline Malignant (4) FNAC result ${ }^{2}$ & 0.148 & $>0.17$ \\
\hline \multicolumn{3}{|c|}{ "Value of prabability al which FNAC would be preferred over US strolegy } \\
\hline & & \\
\hline
\end{tabular}

\section{Discussion}

This study showed an overall reduction in costs in two of the three experimental strategies of performing prior ultrasonography in patients presenting with a palpable breast lump, as compared to routine FNAC examination. In the cheapest strategy ultrasonography was performed mainly in patients with a palpable mass without suspicion on mammography and clinical examination.

The reported number of average expected life years was similar in the different strategies ( 31.0 years). This is explained by the relative short time period in clinical practice between diagnostic imaging and surgical excision leading to the definitive diagnosis. False-negative ultrasonography results could lead to a possible delay of diagnosis, but will be diagnosed shortly after excision biopsy of an assumed benign lesion. It should be noted that a different design of the strategy in which no further 
testing would be done, more delay of diagnosis could be expected with a possible loss of life expectioncy.

Also, as the number of detected malignancies is expected to be equal in all strategies, the average life expectancy per patient will be similar. As a consequence, this study focused on cost-minimization rather than on cost-effectiveness.

The most important role for ultrasonography in the evaluation of palpable breast masses is in the differentiation between solid and cyst masses. Patients with demonstrated cysts are generally discharged, offen after aspiration of the mass, while patienits with solid benign masses such as fibroadenoma are mostly referred for surgical excision and patients with suspicious lesions are referred for FNAC.

Experimental strategy-1 and-2 in our model illustrated the effect of changing the cutoff used for referral for additional FNAC. Obviously, strategy-2 resulted in higher expenses for both diagnosis and treatment than strategy-1, as all benign lesions were referred for FNAC and more benign excisions followed as a consequence. Based on lower costs, the conventional strategy was preferred to experimental strategy-2. It may therefore be concluded that diagnostic ultrasonography would have no role in the triple test, when benign imaging results would still be confirmed by FNAC.

Conversely, when only referring suspicious lesions for FNAC, ultrasonography would be a cost-saving strategy (strategy-1). Finally, experimental strategy-3 further reduced costs by only performing ultrasonography in cases without a suspicious mammogram or clinicall examination. This finding suggests that there is no role of ultrasonography in the diagnosis of obviously malignant lesions on mammography and clinical examination.

It may be argued that, although FNAC of palpable masses is mostly performed palpation-guided, ultrasonography could be used also as a guiding modality. Diagnostic ultrasonography could then practically be performed during the same visit. However, in the Netherlands, FNAC is performed and examined mostly by pathologists, while diagnostic ultrasonography is performed by radiologists.

Also, in order to diagnose a cyst, the radiologists may aspirate cystic fluid on ultrasonographic guidance, which may easily be sent in for cytological examination by the pathologist. However, this was regarded as a different diagnostic modality in our model with a separate cost price. Experimental strategy-2 showed furthermore, that FNAC examination of all imaging-detected benign lesions, such as cysts, would lead to an unnecessary increase in costs. This suggests that routine cytolagical examination of all breast fluids is not recommended ${ }^{23}$.

Various sources were used for the costs of diagnostic and therapeutic actions in this model. When adjusting the costs for diagnosis and treatment of breast cancer reported by Will et al. ${ }^{24}$, for the distribution of stages of breast cancer as detected in our prospective study (22\% stage I, $40 \%$ stage $11,38 \%$ stage $11 \mathrm{I}, 0 \%$ stage $\mathrm{V}$ ), this would result in 9333 Canadian $\$(1995)$ or 66,813 . This amount is comparable with the average costs of curative surgery with and without adjuvant chemotherapy and hormonal therapy found in our study, being $e$ 6405, especially when consildered that we excluded the costs of diagnosis and staging from our calculations. Furthermore, Will's calculated costs of treating a local recurrence was 6,405 Canadian $\$$, or $€$ 4,676 and comparable to the estimated amount of $\in 4,381$ in the current study.

The casts of palliative care were adapted from the study of de Koning ef al. in $1990^{21}$, and were raised by $29 \%$ according to the clinical situation in 2000 from $\in 15,281$ to $€$ 
$19,739)$. Other studies in different settings have also calculated these costs, reporting $\epsilon_{15,385^{24}}$, $e 8659^{25}$ and $€ 7049^{2 *}$. The comparison of data between different countries is difficult because of different methodologies regarding length of time for initial and terminal care, different comparator years as well as different health care systems and currencies. Furthermore, a variation of costs results from differences in treatment approaches, the nature of health care systems and the patient populations used in the analysis.

In the present study no discount rates were applied to the costs or life expectancy. The life expectancy and the number of malignancies, and thus the costs of follow up care, were equal in all strategies. Furthermore, most actions were performed within ane year, so it was believed that this would not influence our findings. Furthermore, nonmedical costs were assumed to be the same for all strategies and were thus excluded from the model. Besides, they are difficult to obtain and their use is controversial ${ }^{24}$.

As sensitivity analysis showed that the costs used in this madel had little influence on the results of the analysis and as they are comparable with other studies, we conclude that our cost data are valid.

Variables that influenced the results of the model, as demanstrated by sensitivity analysis, included the proportion of suspicious and benign FNAC results and the proportion of false-negative ultrasonography results. Most of these variables were identified from experimental strategy-1. It may be concluded that the results are applicable to this particular study population, as the values used in experimental strategy-1 for base-case analysis are empirical data from a large prospective study.

A decision analytic model as discussed in this paper may be a valuable tool to guide health policymakers in decisions related to strategies to improve the efficiency of the healthcare system and to make care delivery more efficient and less costly ${ }^{24}$. On a national or international level, the difference in costs between the strategies analyzed in this study may be regarded as negligible. This would suggest there is no relevant economic difference between performing immediate FNAC or prior ultrasonography in these patients. However, as ultrasonography is being used increasingly in radiological practice in the evaluation of breast masses, there is a need for an efficient and appropriate implementation. Furthermore, patients' preference for non-invasive testing and the emotional reassurance that a visible imaging test can offer above pathological results, indicates a social argument in favor of ultrasonography.

We believe that on the level of lacal radiology departments, the diagnostic strategies analyzed illustrate a feasible and desirable gain in efficiency of diagnostic breast imaging. It was shown that the costs savings of strategy-3 compared to the conventional strategy included $62 \%$ of the costs for diagnostic procedures. However", scheduling additional ultrasonography in patients with a palpable moss would be done most efficiently early in the diagnostic work-up, e.g. at the stage of referral to the radiology department. Therefore, the performance of ultrasonography in all patients with palpable breast masses, as examined in strategy-1, would be more practical in clinical practice than the selection of patients after performance of clinical examination and mammography, as examined in strategy-3, despite the difference in total costs of E 64 per patient and a smaller reduction in diagnostic costs compared to the conventional strategy of $\in 17$.

Concluding, the results of this study indicate that incorporating ulttrasonography in the triple test for evaluation of palpable breast masses can result in a reduction of the total costs for the diagnosis and treatment of breast cancer. The least expensive 
strategy consisted of prior ultrasonography of lesions without suspicion of breast cancer based on mammography and elinical examination, and immediate FNAC of suspicious lesions. While the cost saving of this selective application of ultrasonography is cansiderable, logistic and emotional arguments plead for the performance of ultrasonography in the diagnostic work-up of all patients with palpable breast masses.

Furthermore, it should be realized that this model analyzed some hypothetical strategies. This emphasizes the need for more prospective clinical research studying the elinical impact of these strategies, in terms of diagnostic performance as well as in terms of their impact on the efficiency of diagnostic breast imaging planning. 


\section{References}

1. Hermansen $C_{f}$ Skovgaard Poulsen $H_{\text {, Jensen }}$, et al. Diagnostic reliability of combined physical excmination, mammography, and fine-needle puncture ("tripletest") in breost tumoris. A prospective study. Cancer 1987; 60:1866-71.

2. Vetto J Pommier $R$, Schmidt $W_{\text {s }}$ el al. Use of the "tripla test" for paipable breast lesions yields high diagnostic accuracy and cost savings. Am J Surg 199: $169: 519-22$.

3. Skaane P. Ultrasanography as adjunct to mammography in the evaluation of breast fumors. Acta Radiol Suppl 1999; 420:1-47.

4. Bassett LW. Imaging of breast masses. Radiol Clin North Am 2000, 38:669:91, vii-viii.

5. Jackson WP, Reynolds HE, Hawes DR. Sonography of the breast. Semin Ultrasound CT MR 1996; $17: 460-75$.

6. Zonderland HM. The role of uitrasound in the diagnosis of breast cancer. Semin Ultrasound $\mathrm{Cr}$ MR 2000; $21: 317-24$.

7. Sabel MS, Staren ED. linnovations in breast imaging: How ultrasound can enthance the early detection of breast cancer. Medscape Womens Health 1997; 2.

8. Mendelson EB, Berg WA, Merritt CR. Toward a standardized breast ultrasound lexicon, BI-RADS: ultrasound. Semin Roentgenol 2001; 36:217-25.

9. Mendeison EB, Tobin CE. Crifical pathways in using breast US. Radiographics 1995; 15:935-45.

10. Smith DN. Breast ultrasound. Radiol Clin North Am 2001; 39:485-97.

11. Baker $J A$, Sao MS. The evolving role of sonography in evaluating solid breast masses. Semin: Ultrasound CT MR 2000; $21: 286-96$.

12. Hardy JR, Powles TJ, Judson I, et al. How many tests are required in the diagnosis of palpable breast abnormalities? Clin Oncol (R. Coll Radial) 1990; 2:148.52.

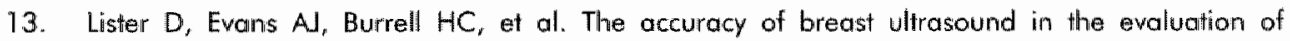
dlinically benign, symptomatic breast lumps. Clin Radiol 1998; 53:490-492.

14. Perre Cl, de Hooge P, Hustinx PA, Muller JW. [Ultrasonographic study of the palpable breast tumor is very useful]. Ned Tijdschr Geneeskd 1993; $137: 2374-7$.

15. Oord JCV, Vliet AMvd, Thyn C.JP, Mak B, Hoogeboom G.l. The walue of ultrasound mammography in palpable breast masses. Fortschr Röntgenstr 1991; 155, 1:63-66.

16. Yang WTY, Mok CO, King W, Tang A, Metreweli C. Role of high frequency ultrasanography in the evaluation of palpable breast masses in Chinese women. J Ultrasound Med 1996; 15:637. 644.

17. Vetto $J T$, Pommier RF, Schmidt WA, Eppich $H$, Alexander PW. Diagnosis of polpable breasit lesions in younger women by the modified triple test is accurate and cost-effective. Arch Surg $1996 ; 131: 967-72$; discussion 972-4.

18. American College of Radiology. Assessment categories. Illustrated breast imaging reporting and data system (Illustrated BI-RADS). Reston: VA: American College of Radiology, 1995.

19. Oostenbrink $J B_{,}$Koopmanschap MA, Rutten FFH. Handleiding voor kostenonderzosk, methoden en richtlijnen voor economische evaluaties in de gezondheidszorg. Amstelveen: College voor Zorgverzekeringen, 2000.

20. Farmacatherapeutisch Kompas 2000/2001: medisch farmaceutische voorlichting ed. Amstelween: College voor Zorgwerzekeringen, 2000.

21. de Koning $H J$, van Ineveld $B M$, de Hass $J C_{\text {, }}$ van Oortmarssen $G J$, $K$ lijin JIG, wan der Maar PJ. Advanced breast cancer and its prevention by screening. Br J Cancer 1992; 65:950.5.

22. de Koning $H J$, van Ineveld $B M$, van Ootmarssen GJ, et al. De kosten en effecten van bevalkingsonderzoek naar borstkanker. Eindrapport Kosten-effectiviteits Analyse. Rotterdam: Instituut Maatschappelijke Gezondheidszorg, Erasmus Universiteit Rotterdam, 1990:1-194.

23. Ciatto $S$, Cariaggi $P$, Bulgaresi $P$. The value of routine cytologic examination of breast cysit fluids. Acta Cytol 1987; 31:301.4. 
24. Will BP, Berthelot JM, Le Petit C, Tomiak EM, Verma $S$, Evans WK. Estimates of the lifetime costs: of breast cancer treatment in Canada. Eur \& Cancer 2000; 36:724-35.

25. Richards: MA, Brciysher S, Gregory WM, Rubenis RD. Advanced breast cancer: use of resources. and cost implications. Br J Cancer 1993; 67:856-60.

26. Hurley SF, Huggins RM, Snyder RD, Bishop JF. The cost of breast cancer recurrences. Br 1 Cancer $1992,65.449-55$

27. Sakarafas GH, Tsiotou AG. Selectian criteria for breast coniservation in breast cancer. Eur J Surg $2000 ; 166: 835-46$.

28. Freedman $\mathrm{GM}$, Fowble BL. Lacal recurrence after mastectomy or breast-conserving surgery and radicition. Oncology (Huntingt) 2000; 14:1561-81; discussion 1587-2, 1582-4.

29. van Tienhoven $\mathrm{G}$, Voogd $\mathrm{AC}$. Peterse $\mathrm{J}$, ef al. Prognosis after treatment for loco-regional recurrence after mastectomy or breast conserving therapy in two randomised trials (EORTC 10801 and DBCG-82TM). EORTC Breast Cancer Cooperative Group and the Danish Breaist Cancer Cooperative Group. Eur I Cancer 1999; 35:32-8.

30. Richtlijn diagnostiek on behandeling van primair mammacarcinoom. Maastricht: Infegraal Kankercentrum Limburg, 1999:1-66.

31. Slotman BJ, Levendag PC, Botke $G$, Leer JWH. Praducttypering in de radiotherapie. Medisch Contact 2000; 55:1198-1201.

32. Behandelingssichtlimen radiotherapie van het operabele mammacarcinoom na mammaamputatie en okselkliertoilet in Nederland.: Landelijk Platform voor Radiotherapie en Mammacarcinoom (LPRM) en NABON, 2000:1-13: 


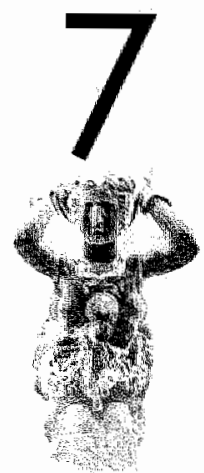

GENERAL DISCUSSION AND CONCLUSIONS 
The studies discussed in this thesis hove focused on the diagnostic performance of ultrasonagraphy in diagnostic breast imaging.

The first objective of the thesis was to assess the diagnostic value of ultrasonography as an adjunct to mammography and dinical examination in the diagnosis of breast cancer.

The prospective study that was described in chapter 2 demonstrated the relevance of rodiological imaging in 1890 patients referred with breast problems, and showed the diagnostic value in addition to results from palpation and age of the patient. However. as mammography and ultrasonography results were only scored as one radiological breast imaging diagnosis, as is usual in clinical practice, it was impossible to study the incremental value of ultrasonography here. Subsequently, our systematic review of all available literature between 1990 and 2000 found little evidence-based support for the well-established role of ultrasonography as an adjunct to mammography in the diagnosis of breast cancer.

In response to this lack of evidence in the literature, the MAMMOED study was performed. It showed, by ROC curve analysis of the imaging diagnoses, that systematic ultrasonography as an adjunct to mammography and clinical examination significantly increased the diagnostic yield in 3835 breasts of 2020 consecutive patients referred for diagnostic breast imaging. Additional ultrasonography detected 8 extra malignancies in this population and correctly "downgraded" 332 cases from a positive to a negative diagnosis.

Furthermore, multivariate logistic regression analysis of diagnostic wariables from medical history, dinical examination, mammography and ultrasonography demonstrated that each step in the diagnostic work-up improved the diagnostic value of the prediction model for breast cancer. Adding results of ultrasonography to the other modalities significantly improved the predictive value of the model.

Based on these findings it can be concluded that in an outpatient population referred to a radiology department for diagnostic breast imaging, additional ultrasonography improved the diagnostic yield.

The second objective of this thesis was to study the feasibility of defining subgroups of patients who benefit most from additional ultrasonography. The systematic literature review showed that mast publications on the additional diagnostic value of ultasonography studied a selected study population, e.g. patients with a palpable breast mass or palients referred for biopsy or surgery. Furthermore, several studies, including our prospective study in chapter 2, performed ultrasonagraphy next to mammography on clinical indication only, leading also to a selected study population undergoing both test modalities. Therefore, none of these studies were able to answer the research question posed. This emphasized the need for a praspective study in which systematic ultrasonography is performed in a non-selected consecutive patient popullation, which was realized in the MAMMOED study. In order to facilitate and optimize the logistic planning of breast imaging early in the diagnostic work-up, it was decided to focus mainly on the reasons for referral when defining subgroups of patients.

Based on the sensitivities, specificities and the p-values resulting from ROC curve analysis of the imaging diagnoses only, additional ultrasonography would be mainly recommended in patients referred for a palpable breast mass or with an abnormal screening mammogram, including $30 \%$ of the total study population. The increase in diagnostic yield by adding ultrasonography to mammagraphy and clinical 
examination was not statistically significant in patients referred for breast symptomatology and follow up of a prior breast malignancy. Finally, due to the very low prevalence of breast cancer, no ROC curves could be plotted for patients referred for follow up of a prior benign lesion, patients referred for reassurance, or when ultrasonography was performed as screening examination of the contralateral breast. It is suggested that diagnostic breast imaging has limited value in these patients.

Logistic regression analysis of several diagnostic wariables from the different modalities confirmed a significant increase in diagnostic yield only in patients referred for a palpable mass.

It should be noted that in both analyses, the largest increase in area under the ROC curve was faund for patients referred for follow up of a priar malignancy, although this was not statistically significant. The most plausible explanation for this is the small number of malignancies in this group, and it has to be concluded that despite the lack of statistical significance, there is actually an important role for ultrasonography in these patients. This finding illustrates the relative value of using $p$-values generated from ROC curve analysis in answering this research question.

A consequence of restricting ultrasonography mainly to patients referred for a palpable breast mass based on these analyses is that several malignancies detected by ultrasonography in the other subgroups would have gane undetected. In this respect, it may be argued that additional pathological tests in the diagnostic work-up, like fine needle aspiration cytology (FNAC) in the triple assessment of palpable breast masses $1-3$ and core needle biopsies in the evaluation of non-palpable mammographic abnormalities ${ }^{4.6}$, would also lead to the correct diagnosis and make the additional diagnostic information from ultrasonography redundant in these cases.

On the other hand, besides the defection of additional malignancies, ultrasonography also correctly "downgraded" many suspicious diagnoses on mammograms and clinical examination to a benign diagnosis. Especially the diagnosis of (non-palpable) cysts may result in a considerable saving of unnecessary FNAC examinations and biopsies. It has been shown that the psychological stress to women undergoing breast biopsy is high and the cost is considerable ${ }^{x}$, so the role of ultrasonography in reducing the number of negative biopsies is crucial. Additionally, patients' preference for uninvasive and fast diagnostic tests with an immediate, visible result will plead for ultrasonography.

Possibly, a different classification of subgroups of patients based on other characteristics might change the selection of clinical indications for ultrasonography. However, the arguments discussed restrain us from making recommendations on the use of ultrasonography in clinical practice, based on the results from ROC curves and logistic regression analysis alone. We conclude that the selection of subgroups of patients who benefit most from additional ultrasonography should be based on more than just these statistical considerations.

In order to do so, the whole process of medical decision-making should be taken into account, including the performance of additional testing such as by pathology, the efficiency of clinical practice, as well as the assaciated casts. Decision analytical modeling as presented in chapter 6 is a possible method of analyzing this. In this model, 3 different diagnostic strategies of incorporating ultrasonography in the triple thest for the evaluation of palpable breast masses were compared to the routine conventional triple test, consisting of immediate FNAC performance after mammography and clinical examination. This design is corresponding to the third objective of this thesis. 
Costmminimization showed that the least expensive strategy would be to perform immediate FNAC in patients with suspicious lesions on mammograms and clinical examination, and to perform prior ultrasonography in patients without suspicious. results. It was concluded that integrating ultrasionography in the triple test would result in a reduction of the total costs for the diagnosis and treatment of breast cancer. These results confirmed the results found by $\mathrm{ROC}$ curve and logistic regression analysis and favor the use of addittional ultrasonography in patients with a palpable mass.

However, when taking into account the aim for improving the efficiency of diagnostic breast imaging planning in radialogy departments, the least expensive strategy was not necessarily the one preferred. As has been mentioned throughout this thesis, it would be more efficient to decide on additional ultrasonography at the stage of referral rather than having to wait first for the results of mammography and clinical examination. This would indicate a prefference for experimental strategy-1 instead of strategy 3 , despite the additional costs of $€ 64$ per patient. It should be realized that strategy-3 is a hypothetical strategy, which needs to be examined further by prospective clinical research, before being implemented in clinical practice.

Elaborating on these results, future resecurch should be directed an the costs and effects of ultrasonography in the other subgroups of patients discussed in this thesis. Integrating the results from clinical epidemiological methodology, such as ROC curves and lagistic regression analysis, with the results from decision analytical modeling will enable us to give recommendations for the use of additional ultrasonography in daily clinical practice.

Furthermore, implementation of these guidelines in clinical practice should be monitored thoraughly. A possible design of monitoring clinical practice in radiology is through a continuous computer registration of procedures and outcomes. This includes a welcome combination of medical research and quality assurance, through analysis of compliance to clinical guidelines and performance of diagnostic imaging tests over time.

Some requirements to guarantee the quality of such a design include the use of standardized and uniform reporting systems, consistent terminology and clear clinical guidelines. Furthermore, a correct sel of data has to be registered in order to be able to answer the research questions posed.

The prediction model, which was presented in chapter 5, demonstrated the most important diagnostic variables from medical history, clinical examination, mammography and ultrasonography that predict the presence of breast cancer. Using this model, probability calculation can be done for individual patients by adding up the scores for the outcomes of the different wariables. Although the applicability of this diagnostic algorithm in clinical practice may be argued, it demonstrated clearly which variables are most significant in the realization of a final imaging diagnosis. Therefore, these variables would be crucial in a continuous registration of outcomes for quality assurance of diagnostic breast imaging.

One of the requirements for the success of this system of quallity assurance is the use of uniform reporting systems and consistent terminology. The different publications analyzed in our systematic literature review used various grading scales and cut-off points for the imaging results (results not showny, which will obviously influence the results in terms of numbers of fallse-positive results, fallse-negative results, sensitivities and specificities. 
The 5-point grading scale that was used as reporting system for breast imaging in the studies discussed in this thesis was based on the BI-RADS-lexicon for diagnostic mammography ${ }^{*}$. This system has been extensively tested and validated by the American College of Radiology and the similar scoring system for ultrasonography is currently being validated". However, it should be noted that the application of these diagnostic scores in our studies differed slightly from this lexicon.

The cut-off point used to define positive and negative imaging results was defined between benign (score 2) and probably benign (score 3) results. Whereas for normal or suspicious malignant results it is obvious whether to call them positive or negative, for probably benign results it is not. One way of dealing with the difficulty of choosing a cut-off point when comparing different diagnostic methods is by constructing ROC curves that plot the sensitivity against the proportion of false-positive results. If the "cost" of a false-negative result is the same as that of a false-positive result, the best cut-off is that which maximizes the sum of the sensitivity and specificity, which is the point near the top left-hand corner ${ }^{10}$. In the ROC curve presented in chapter 4 this method confirmed our choice of a cut-off between benign and probably benign results, representing a sensitivity of $97 \%$ and a specificity of $95 \%$ for combined ultrasonography, mammography and clinical examination. According to the BI-RADSlexicon however, probably benign lesions have a high probability of being benign and a short interval follow up of 6 months is suggested for confirmation. However, we reasoned probably benign lesions are more suspected for malignancy than benign lesions and it prevents a number of false-negative results when classifying them as positive.

In chapter 5 , the cut-off point chosen on the ROC curve corresponded with a sensitivity of $95 \%$ and a specificity of $92 \%$. The sensitivity and specificity resulting from this curve were lower than in chapter 4 , while studying the same imaging modalities in the same study population. This is explained by the use of a 3-point grading scale for the diagnostic scores instead of the 5-point grading scale used in chapter 4 .

Diagnostic score 0 was used to define indeterminate or uninterpretable results, due to imaging flaws or patient characteristics such as dense breast parenchyma at mammography or mastopathy at elinical examination. According to the BI-RADS llexicon, score 0 rather stands for incomplete assessment and these results should not be included in the data analysis ". No consensus exists for the incorporation of indeterminate or uninterpretable results into data assessment.

In chapter 4, a method was chosen that approached clinical implications best, namely by recoding indeterminate clinical examinations like in e.g. mastopathy, as benign (score $=2$ ) and indeterminate mammography or ultrasonography results as probably benign (score $=3$ ) for analysis. It was believed that additional action would always result from indeterminate mammography or ultrasonography results, whereas this is not required after clinical examination. In chapter 5 however, we focused on the prevalence of breast cancer in each category and recoded indeterminate and normal scares into one group, benign and probably benign scores in another, and suspicious malignant and malignant scores in a third group.

Additionally, we have tested other ways of handling indeterminate results, e.g. by recoding them as a separate level of suspicion for breast cancer or deleting them completely from analysis (results not shown) and conclude that, although there were small differences between the outcomes, the method chosen did not influence our 
owerall conclusilons. More research would be needed on the impoct of handling indeterminate results on the outcome of diagnostic imaging.

Defining the reference standard in diagnostic imaging research is a difficult methodological issue. The ultimate "gold" standard would include pathology results of all patients, but it would be impossible and unethical to take a pathology specimen in patients in whom no abnormality was defected.

A possible "silver" reference standard would be to apply active surveillance and subject all patients to repeat imaging testing after a specified follow up period. Howewer, in our opinion this would also be ethically unjustified in patients with negative imaging results. Furthermore, this procedure would interfere with common clinical practice and would intraduce bias as imaging tests function as reference standard for themselves. The reference standard that we have used in our studies could be defined as "bronze": positive cases were confirmed by pathology whereas a 12 month passive follow up period was applied in patients with negative imaging results. This may induce a form of verification bias as more positive results than negative cases may be verified, and may lead to an overestimation of sensitivity and an underestimation of specificity ". However, as the pathology registration system used is of high quality and covers all examinations of all pathology laboratories in The Netherlands, we are confident that subsequent malignancies diagnosed elsewhere would not go unnoticed. Furthermore, the duration of our follow up period is believed to be long enough to maximize the chance of detecting malignancies that were actually missed and to minimize the chance of finding newly developed cancers. We therefore believe that for our study purposes in this clinical situation, our reference standard used was as "gold" as possible.

Summarizing, the conclusions of the studies discussed in this thesis are:

- Radiological imaging tests have large diagnostic value in the diagnosis of breast cancer in addition to results of palpation and age of the patient (chapter 2).

- Based on the literature between 1990 and 2000, little evidence-based support is available to confirm the well-recognized value of ultrasonography as an adjunct to mammography and chinical examination (chapter 3).

- Systematic application of ultrasonography as an adjunct to mammography and clinical examination in 3835 cases significantly improved the diagnostic yield (chapter 4).

- The most important diagnostic variables predicting the presence of breast cancer include: age, menopouse, specific breast symptoms, diagnosis of clinicall examination, mammographic calcifications and the integrated diagnosis resulting from ultrasonography, mammography and clinical examination. The "worst-case" scenario consisted of postmenopausal women older than 50 years, having specific breast symptoms such as skin retraction or nipple discharge, a suspicious clinical examination, suspicious calcifications on the mammogram and a suspicious final diagnosis of clinical examination, mammography and ultrasonography together, resulting in a probability of breast cancer of 0.997 (chapter 5).

- Incorporating ultrasonagraphy in the triple test for the evaluation of palpable breast masses can result in a reduction of the total costs for the diagnosils and treatment of breast cancer (chapter 6).

- Quality assurance of diagnostic imaging could be combined with clinical research by continuous monitoring of compliance to clinical guidelines and test performance (discussion). 
- Integrating the results from clinical epidemiological methodology, such as ROC curves and logistic regression analysis, with the results from decision analytical modeling is required to define subgroups of patients who benefit most from additional ultrasonography and will enable us to give recommendations for it's use in daily clinical practice (discussion).

- Based on ROC curve analysis, logistic regression analysis and decision analytical modeling, it is suggested that ultrasonography is indicated as an adjunct to mammography and clinical examination in the evaluation of palpable breast masses [chapter 4, 5,6+ discussion]. 


\section{References}

1. Vetto J, Pommier R, Schmidt W, al. Use of the "triple test" for palpoble breast lesions yields high diagnostic accuracy and cost sovings. Am I Surg 1995; 169:519-22.

2. Morris KI, Pommier RF, Morris A, ef al. Usefulness of the triple test score for palpable breast masses; discussion 1012-3. Arch Surg 2001; 136:1008-12.

3. Hermanisen $C$, Skovgaard Poulsen $H$, Jensen $\mathbb{J}_{\text {; }}$ et al. Diagnosfic reliability af combined physical examination, mammography, and fine-needle puncture ("riple-test") in breast tumors. A prospective study. Cancer 1987; 60:1866-71.

4. Teh WL, Evans AJ, Wilson AR. Definifive non-surgical breast diagnosis: the role of the radiologist. Clin Radio! 1998; 53:81-4.

5. Pijnappel RM, wan Dalen A, Rinkes IH, van den Tweel JG, Mali WP. The diagnostic accuracy of core biapsy in palpable and non-palpable breast lesions. Eur J Radiol 1997, 24:120-3.

6. Parker SH, Lovin JD, Jobe WE, ef al. Stereolactic breost biopsy with a biopsy gun. Radiolagy 1990: 176:741-7.

7. Taylor KJ, Merritt C, Piccoli $C$, et al. Ultrasourid as a complement to mamimography and breast axamination to characterize breast masses. Ulitasound Med Biol 2002; 28: 19.26.

8. American_College_of_Radiology. Assessment categories. Illustrated breast imaging reporting and data system (lllustrated BI-RADS). Reston: VA: American College of Radiology, 1995.

9. Mendelson EB, Berg WA, Merritt CR. Toward a standardized breast ultrasound lexicon, BI-RADS: ultrasound. Semin Roentgenol $2001 ; 36: 217-25$.

10. Altman DG. Practical statistics for medical research. London: Chapman \& Hall/ CRC, 1999:611.

11. Lijmer JG, Mol BW, Heisterkamp S, et al. Empirical evidence of design-rellated bias in studies of diagnastic tests. Jama 1999; 282:1061-6. 


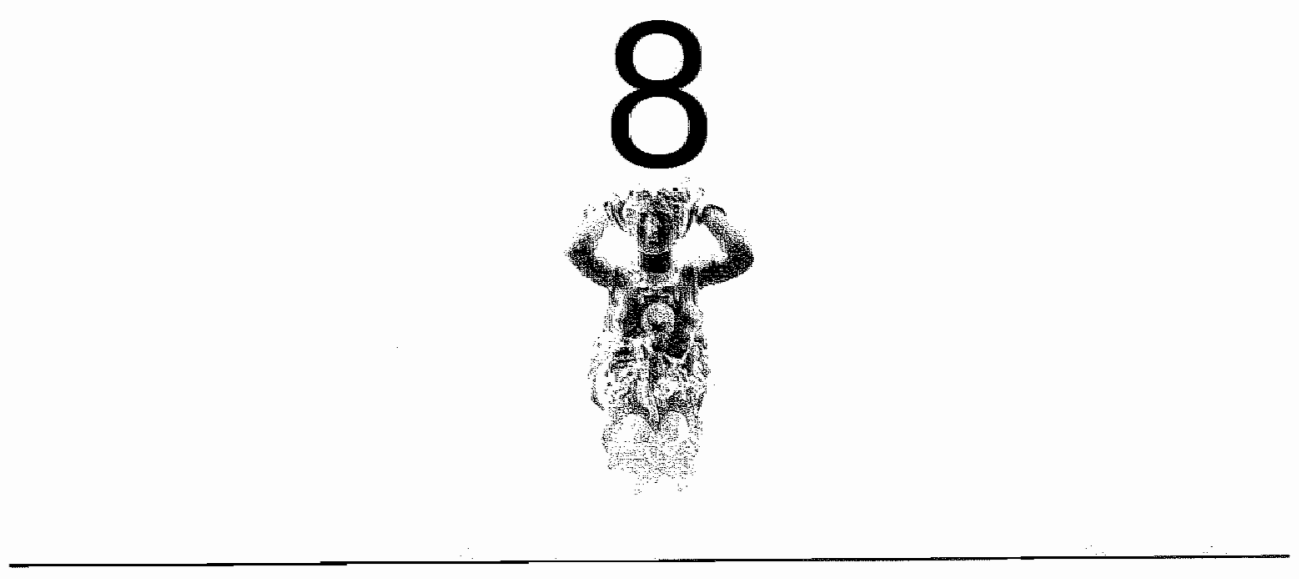

SUMMARY

SAMENVATTING

DANKWOORD

CURRICULUM VITAE 


\section{Summary}

Routine diagnostic breast imaging in the radiology departments of a hospital consists of clinical examination, mammography, and ultrasonography when indicated. This thesis focuses on the diagnostic performance of breast imaging in diagnosing breast cancer and more specifically on the role of ultrasonography herein.

Chapter 2 discusses a prospective study that was performed in 1994, assessing the diagnostic performance of breast imaging in a non-screening population. A consecutive set of 1944 breast examinations in 1890 patients was studied, consisting of palpation and mammography, supplemented with ultrasonography when clinically indicated. In total, 3816 breasts were examined. Pathology results after a follow up of one year were used as reference standard for the presence of breast cancer and demonstrated 118 malignancies in 115 patients $(6.1 \%$ prevalence).

With a cut-off point between benign and probably benign results, a sensitivity of $89 \%$ and a specificity of $98 \%$ was found for radiological breast imaging. There were 13 false-negative and 69 false-positive results. Logistic regression and ROC curve analysis demonstrated that adding the imaging results to the information available from palpation and the age of the patient significantly improved the diagnostic performance. Combining all information a sensitivity of $100 \%$ could be reached hypothetically, with a specificity of around $60 \%$.

This study concludes that radiological breast imaging has an important role in the diagnosis of breast cancer in daily clinical practice. The results on the prevalence of breast cancer and the performance of breast imaging were comparable to other studies in national and international radiology departments.

In this study, additional ultrasonography was performed in $28 \%$ of all patients referred for diagnostic breast imaging. Current practice shows that the use of ultrasonography is increasing, reporting over $35 \%$ of patients undergoing ultrasonography as an adjunct to mammography in 1999. This is partly the result of the wider availability and accessibility, the broadening clinical indications and the belief of physicians that is less likely to be blamed for doing more testing than for doing too little. However, this practice leads to the question what the diagnostic performance is of additional ultrasonography and whether ultrasonography could be restricted to subgroups of patients who benefit most.

The study discussed in chapter 2 was not able to answer these questions. First, as ultrasonography was performed on elinical indication, as decided by the individual radiologist, the study population who had undergone breast ultrasonography was a selected one. Secondly, one definitive radiological diagnosis was given, in which mammography results were integrated with ultrasonography results. This made it impossible to analyze the impact of incremental ultrasonography.

Following, in chapter 3 a systematic literature review was performed in which all publications in MEDLINE and EMBASE between 1990 and 2000, assessing the role of ultrasonography as an adjunct to mammography, were analyzed. Diagnostic adds ratios for mammography and ultrasonography were calculated as a combined measure for sensitivity and specificity and were compared between the different studies. 22 studies were included, showing a large variety of indications for ultrasonography and variations in the diagnostic performance of mammography and ultrasonography. The study shawed that little evidence-based support was available for the well-recognized value of ultrasonography as an adjunct to mammography in 
clinical practice. The method of selecting the study population and the method of ultrasonography interpretation, with or without prior knowledge of mammography results, strongly influenced the performance of mammography and ultrasonography relative to each other.

These results emphasized the need for a prospective study in which systematic ultrasonography is performed in a non-selected consecutive patient population to identify the subgroups of patients in which the highest diagnostic yield would be obtained. In order to facilitate and optimize the logistic planning of breast imaging early in the diagnostic work-up, it was decided to focus mainly on the reasons of referral when defining subgroups of patients.

In chapter 4 , the results are presented of a large prospective study, named the MAMMOED study (MAMmacarcinoom-studie Maastricht: Optimalisatie Echografische Diagnostiek) that was performed at Maastricht University Hospital between October 1999 and August 2000, as part of the Cost Containment Research Program of the Dutch Health Care Insurance Board. Aims of the study were to assess the diagnostic value of ultrasonography as an adjunct to mammography and clinical examination in the detection of breast cancer and the feasibility of selecting subgroups of patients who benefit most.

In 3835 breasts in 2020 consecutive patients referred for breast imaging, bilateral clinical examination, mammography and ultrasonography were performed. Pathology results from biopsy or surgical excision during 12 months follow up were used as gold standard for the presence of breast cancer and reported 129 malignancies in 127 patients $(6.3 \%$ prevalence $)$.

Breast ultrasonography detected 8 extra malignancies and correctly downgraded 332 positive results on mammography and clinical examination to a negative final diagnosis.

ROC curve analysis showed that there was a significant improvement in diagnostic value by adding ultrasonography to mammography and clinical examination. Subgroups of patients were defined according to indication for referral and age. The diagnostic yield improved significantly in patients referred for palpable breast masses, especially in patients younger than 50 years old, or patients referred from the national breast cancer screening program. The increase in area under the ROC curve was not statistically significant in patients referred for breast symptomatology and follow up of a prior breast malignancy. Due to the small numbers and low prevalence of breast cancer, the diagnostic benefit remained undefined for patients referred for follow up of a prior benign lesion, patients referred for reassurance, or when ultrasonography was performed as screening examination of the contralateral breast.

The study concluded that systematic application of ultrasonography significantly improved the overall diagnostic yield, and that the diagnostic value increased most significantly in patients with palpable breast masses and patients referred with abnormal screening mammograms.

In the diagnostic work-up for breast disease, all information on the lesions and abnormalities found by the different tests is combined with the knowledge of patient characteristics from medical history into one overall diagnosis indicating the suspicion of breast cancer. The contribution of each diagnostic test in defining the overall diagnosis was studied by multivariate logistic regression analysis and reported in chapter 5. Additionally, the contribution of additional ultrasonography in the prediction of breast cancer was studied for different patient populations. Patient data 
of the MAMMOED study were used and diagnostic variables were included from medical history, clinical examination, mammography and ultrasonography.

A prediction model for breast cancer was presented, which included the variables: age, menopause, specific breast symptoms, diagnosis of clinical examination, mammagraphic calcifications and the integrated diagnosis resulting from ultrasonography, mammography and clinical examination. Using this model, the probability of breast cancer can be calculated for individual patients by combining the results of the different diagnostic tests. The "worst-case" scenario consisted of postmenopausal women alder than 50 years, having specific breast symptoms such as skin retraction or nipple discharge, a suspicious clinical examination, suspicious calcifications on the mammogram and a suspicious final diagnosis of elinical examination, mammography and ultrasonography together, resulting in a probability of breast cancer of 0.997 .

ROC curve analysis of the generated probabilities for each category of variables, showed that each step in the diagnostic work-up improved the diagnostic value of the prediction model for breast cancer. Adding results of ultrasonography to the other modalities significantly improved the predictive value of the model. Using all available information a sensitivity of $95 \%$ and specificity of $92 \%$ could be reached.

Stratified analysis according to reason for referral showed that additional ultrasonography significantly improved the predictive value of the model in patients referred for palpable masses $(p=0.04)$. Among patients without a palpable lump, ultrasonography contributed most to the diagnosis in the subgroup of premenopausal patients $(p=0.39)$.

It was concluded that, although the value of this prediction madel in clinical practice may be argued, the model demonstrated a set of diagnostic variables, which are most important in the composition of a final imaging diagnosis.

In order to study the costs and effects of the use of additional ultrasonography in the evaluation of palpable breast masses, a decision analytical madel was presented in chapter 6.

The model was based on the subgroup of patients from the MAMMOED study presenting with a palpable mass $(n=522,93$ malignancies). Routine diagnostic workup of palpable breast masses includes the performance of clinical examination, mammography and fine needle aspiration cytology (FNAC), combined as the "triple test ${ }^{\prime \prime}$.

In this madel, 3 different diagnostic strategies of incorporating ultrasonography in the triple test were compared to the routine conventional triple test. In strategy 1, a cut-off between benign and probably benign ultrasonography results was used for further referral for FNAC; in strotegy 2, this cut-off was shiffed to a cut-off between normal and benign results; and in strategy 3 , prior ultrasonography was only performed in patients with normal, benign results on mammography and clinical examination, whereas immediate FNAC was performed in patients with suspicious lesions. Outcome variables included the total costs of strategies and the expected number of life years.

All strategies reported similar life expectancies, namely 31.0 life years. Costminimization demonstrated that experimental strategy-3 was the least expensive strategy $(\epsilon$ 2946). Experimental strategy-2 was the most costly strategy ( $\epsilon$ 3475). Compared to the conventional strategy of immediate FNAC $(\in 3010)$, both ultrasonography strategy 1 and 3 were preferred. 
The sfudy concluded that a reduction of the total costs for the diagnosis and treatment of breast cancer could be achieved by integrating ultrasonography in the triple test.

These results confirmed the results found by ROC curve and logistic regression analysis and favor the use of additional ultrasonography in patients with a palpable mass.

The averall conclusion of this thesis was that systematic application of ultrasonagraphy as an adjunct to mammography and clinical examination significantly improved the diagnostic performance. Integrating the results from clinical epidemiological methodology, such as ROC curves and logistic regression analysis, with the results from decision analytical modeling indicated that in patients with palpable breast masses additional ultrasonography results in more accurate diagnosis at lesser costs. 


\section{Samenvatting}

Het gangbare beeldvormende onderzoek van de mamma bestaat op de meeste radiologie afdelingen uit $\mathrm{klinisch}$ onderzoek en diagnostische mammografie, helgeen kan worden aangevuld met echografisch onderzoek wanneer geindiceerd. Dit proefschrift concentreert zich op het vermogen van deze onderzoeken om borstkanker te diagnosticeren en in het bïzonder de rol van de echografie hierbij.

Hoofdstuk 2 beschrijft een prospectieve studie vitt 1994 naar het diagnostisch vermogen van beeldvormend onderzoek van de mammae in een poliklinische patiëntenpopulatie. $\mathrm{Bij} 1944$ opeenvolgende diagnostische onderzoeken bii 1890 patiënten werden 3816 mammae onderzocht met behulp van palpatie en mammografie, aangevuld met echagrafie wanneer klinisch geïndiceerd.

Als gouden standaard voor de aanwezigheid van borstkanker werden de beschikbare pathologie uitslagen gedurende één jaar follow up gebruikt. Er werden 118 maligniteiten gevonden bij 115 patiënten (115/1890=6,1\% prevalentie). Biij een afkappunt tussen benigne en waarschijnlijk benigne testresultaten had het radiologisch beeldvormend onderzoek een sensitiviteit en specificiteit van respectievelijk $89 \%$ en 98\%. Er werden 13 foutnegatieve en 69 foutpositieve resultaten gevonden.

Met behulp van logistische regressie en $\mathbb{R O C}$ curve analyse werd voorts aangetoond dat het diagnostisch vermogen significant verbeterde wanneer testresultaten wan beeldvormend onderzoek werden toegevoegd aan resultaten wan palpatie en leeftijd. Hypothetisch kon een sensitiviteit van 100\% worden behaald biij een specificiteit van $60 \%$, wanneer alle informatie werd gecombineerd. $\mathrm{Er}$ werd geconcludeerd dat radiologisch beeldvormend onderzoek een belangrijke rol speelt bij de diagnose van borsitkanker in de dagelijkse praktijk.

De resultaten van dit onderzoek en de prevallentie van borstkanker waren vergelijkbaar met die vit andere studies door nationale en internationale radiologie groepen. Aanwullend echografisch onderzoek werd bii $28 \%$ van de patiëntempopulatie uitgevoerd. De huidige praktijk laat echter zien dat deze toepassing van echografie is toegenomen; in 1999 werd op de afdeling radiologie wan het Academisch Ziekenhuis Maastricht bij meer dan 35\% van de patiënten die doorverwezen werd voor diagnostisch beeldvormend onderzoek van de mamma ook een echografie uitgevoerd. Gedeeltelijk is dit het resultaat van de toegenomen beschikbaarheid en toegankelijkheid van echografie, de verbrede klinische indicaties en het geloof van artsen dat hef uitvoeren van teveel testen hen minder snel wordt kwalijk genomen dan het vitvoeren van te weinig testen. Desalniettemin leidt dit tot de vraag wat het diagnostisch vermogen is wan aanvullende echografie in deze patiëntenpopulatie en of echografie beperkt kan worden tot subgroepen patiënten die het meeste baat hebben bii dit onderzoek.

De studie die in hoofdstuk 2 werd beschreven, kon deze vragen niet beantwoorden. Ten eerste werd de echografie hier op klinische indicatie vitgevoerd, zoals bepaald door de individuele radioloog, waardoor de groep patiënten die een echografie ondergingen een sterk geselecteerde populatie was.

Ten tweede werd én definitieve radiologische diagnose gesteld, waarin de testresultaten van mammografie geïtegreerd werden met die van de echografie. Dit maakt het onmogelijk om de invloed van aanvullende echografie te bestuderen.

Vervolgens werd in hoofdstuk 3 een systematisch literatuuronderzoek besproken, waarin alle publicaties uit MEDLINE en EMBASE tussen 1990 en 2000 over de ral van 
echografie als canwulling ap mammografie werden geanalyseerd. Als gecombineerde maat voor de sensitiwiteit en specificiteit werden diagnostische odds ratios berekend voor mammografie en echografie en vergeleken tussen de verschillende studies "In totaal werden 22 studies in het onderzoek meegenomen en lieten een grote verscheidenheid zien in gebruikte indicaties woor echografie en diagnostisch vermogen vain mammografie en echografie.

De studie lieft zien dat er maar weinig literatuur voorhanden is, die de reeds lang geaccepteerde waarde van echografie als aanvulling op mammografie in de klinische praktipk onderbouwt. In de geanalyseerde publicaties had de methode om de pattentenpopulatie te selecteren en de methode van echografie beoordeling, namelijk met of zonder voorkennis van de resultaten van mammografie, een grate invlaed op de prestaltie van mammografie en echografie ten opzichite van elkaar.

De resultaten van dit literatuuronderzoek benadrukten de behoefte aan een prospectief onderzoek wararin systematische echografie wordt vitgewoerd in een nietgeselecteerde patiẻntenpopulatie, teneinde subgroepen patiënten te identificeren met de grootste diagnostische opbrengst. Om de logistische planning wan beeldvormend onderzoek van de mamma op de radiologie afdeling te kunnen vergemakkelijken en te optimaliseren, werd besloten om de subgroepen patiënten voornamelijk in te delen vollgens de verwijsreden.

In hoofdstuk 4 van dit proefschrift werden de resultaten gepresenteerd van een grote prospectieve studie, de MAMMOED studie genoemd, (MAMmacarcinoom-studie Maastricht: Optimalisatie Echografische Diagnostiek). Deze studie werd uitgevoerd in het Academisch Ziekenhuis Maastricht tussen oktober 1999 en oktober 2001 en maakt deel uit van het Doelmatigheidsonderzoek programma van het College vaor Zorgverzekeraars.

Doelen van de studie waren het bepalen van de diagnastische waarde van echografie als aanvulling op mammografie en klinisch onderzoek in het diagnosticeren van borstkanker en de magelijkheid om subgroepen patiënten te selecteren bij wie aanvullende echografie het meeste baat heeft.

In 3835 mammae van 2020 opeenvolgende poliklinische patiënten die door huisarts of specialist doorverwezen werden voor diagnostisch beeldwormend onderzoek, werd bilateraal klinisch onderzoek, mammografie en echografie vitgevoerd. Alle anderzoeken werden gescoord op een 5-punts schaal mell oplopende graad van verdenking op borstkanker: $1=$ normaal, $2=$ benigne, $3=$ onzeker benigne, $4=$ verdacht maligne, $5=$ maligne.

De pathologie vitslagen van biopsieën en chirurgische excisies gedurende 12 maanden follow up werden gebruikt als gouden standaard voor de aanwezigheid van borstkanker. In tataal werden 129 maligniteiten gevonden in 127 patiënten $(127 / 2020=6,3 \%$ prevalentie).

Echografisch onderzoelk detecteerde 8 extra maligniteiten en zorgde voor een correcte aanpassing van 332 verdachte diagnosen op mammografie en klinisch onderzoek in een negatieve einddiagnose. ROC curve analyse liet zien dat er een significante verbetering was van de diagnose, wanneer resultaten van echografie werden toegevoegd aan die van mammografie en klinisch onderzoek. Er werden subgroepen patiënten gedefinieerd volgens de verwijsreden en leeffijd. Aanvullend echografisch onderzoek vergrootte de diagnostische opbrengst statistïsch significant bij patiënten die doorverwezen werden vanwege een palpabele afwijking, wooral wanneer ouder dan 50 jaar en patiënten die werden doorverwezen wanuit het nationaal bevolkingsonderzoek voor borstkanker. 
De toename in oppervlakte onder de ROC curve was niet statistisch significant woor patiënten die doorverwezen werden vanwege andere symptomatologie, zoals piin of tepelvloed, of vanwege follow up van een eerdere maligniteit in de mamma. Tenslotte bleef, vanwege de kleine aantallen en de lage prevalentie borstkanker; de warde van aanvullende echografie onduidelijk voor patiënten die doorverwezen werden vanwege een eerdere benigine afwiking, ter geruststelling, of wanneer een screeningsechografie werd uitgevoerd wan de tegengestelde mamma.

De studie concludeerde dat systematische toepassing van aanvullende echografie in deze patiëntenpopulatie de viteindelijke diagnostische opbrengst verbeterde, en dat dit effect het duidelijkst was voor patiënten die verwezen werden met een palpabele afwijking of met een afwijkend screeningsmammogram.vanuit hel bevolkingsonderzoek.

In de diagnostische work-up voor barstafwijkingen worden alle resultaten van de verschillende onderzoeken gecombineerd met patiëntkarakteristieken vanuit de anamnese tot een einddiagnose en graad van verdenking op borstkanker. De bijdrage van elke diagnostische test in de totstandkoming van deze einddiagnose werd bestudeerd met behulp van logistische regressie analyse en werd besproken in hoofdstuk 5. Tevens werd hier de bijdrage van echografie in de voorspelling van de aanwezigheid van borstkanker voor verschillende patiëntenpopulaties bestudeerd. Hiertoe werden van de patiënten uit de MAMMOED studie verschillende diagnostische variabelen uit de anamnese, klinisch onderzoek, mammografie en echografie gebruikt.

In een voorspellend model voor de aanwezigheid van borstkanker werden de volgende variabelen opgenomen: leeftijd, menopause, specifieke borstklachten, diagnose uit klinisch onderzoek, mammografisch aangetoond kalk en de geïntegreerde einddiagnose van echografie, mammografie en klinisch onderzoek. Met behulp van dit model kan de waarschiinliikheid op borstkanker worden geschat voor individuele patiënten door de testresultaten van de verschillende diagnostische onderzoeken te combineren. Het slechtste scenario bestond vit postmenopausale vrouwen ouder dan 50 jaar, met specifieke borstklachten, zoals huidintrekking of tepelvloed, een verdacht klinisch onderzoek, verdacht kalk op het mammogram en een verdachte einddiagnose van klinisch onderzoek, mammografie en echografie samen, en resulteerde in een geschatte kans op borstkanker van 0.997.

ROC curve analyse van de gegenereerde kansen voor elke categorie variabelen liet zien dat elke stap in de diagnostische work-up de voorspellende waarde van het model verbeterde. Het modell verbeterde sterk wanneer de resultaten wan echografie werden taegevoegd aan de resultaten van de andere modaliteiten. Wanneer alle informatie werd gebruikt, kon een sensitiviteit en specificiteit van respectievelijk $95 \%$ en $92 \%$ behauld worden.

Gestratificeerde analyse naar verwijsreden liet zien dat aanvullende echografie de voorspellende waarde van het madel wooral verbeterde in patiënten die verwezen werden woor een palpabele afwijking $(p=0.04)$. Bii patiënten zonder een palpabele afwijking, droeg echografie het meest bij aan de diagnose in de groep premenopausale patiënten $(p=0.39)$.

Er werd geconcludeerd dat dit voorspellende model, alhoewel de waarde ervan voor de klinische praktijk kan worden betwist, een set diagnostische variabelen presenteert die belangrijk is bij de samenstelling wan een beeldvormende einddiagnose. 
Vervolgens werd in hoofdstuk 6 een besliskundig model gepresenteerd; dat de kosten en effecten bestudeert van de toepassing wan aanwullende echografie bil de evaluatie van palpabele borstatwijkingen. Dit besliskundig madel werd gebaseerd op de groep potienten uit de MAMMOED studie die een palpabele afwilking hadden ( $n=522,93$ maligniteiten). Het gangbare beeldwormend onderzoek bij palpabele afwijkingen bestaat uit klinisch onderzoek, diagnostische mammografie en dunne naald cytologie (FNAC), samen de "triple test" genoemd. In dit besliskundige model werden 3 verschillende diagnostische strategieën waarbij echografisch onderzoek werd geintegreerd in de triple test, vergeleken met deze routine conventionele methode. In strategie I werd een afkappunt ussen benigne en waarschijnlijk benigne echografie vitslagen gebruikt voor verdere doorvenwijing voor $F N A C$; in strategie 2 werd dit afkappunt verlegd tussen normale en benigne uitslagen; en in strategie 3 werd aanwullende echografie alleen vitgevoerd bij patiënten met normale, benigne resultaten op mammografie en klinisch onderzoek, terwijl directe FNAC uitgevoerd werd in patiënten met verdachte laesies. De vitkomstmaten waren de totale kosten van de strategieën en het verwachte caantal levensjaren.

Alle strategieën hadden een gemiddelde levensverwachting van 31,0 jaar. Kostenminimalisatie liet zien dat experimentele strategie 3 de goedkoopste was ( $E$ 2946). Experimentele strategie 2 was de duurste strategie (e 3475). Vergeleken met de conventionele strategie van directe FNAC ( $E$ 3010), ging de voorkeur uit naar echografie strategieẻn 1 en 3 .

De studie concludeerde dat een reductie van de totale kosten van de diagnose en behandeling wan borstkanker bewerkstelligd kan worden wanneer echografie in de triple test zou worden opgenomen.

Deze resultaten bevestigden de resultaten van de ROC curve en logistische regressie analyse en moedigen het gebruik van echografie in patiënten met een palpabele afwijking aan.

Uit de resultaten van de verschillende studies die beschreven worden in dit proefschrift kan geconcludeerd worden dat systematische toepassing van echografie als aanvulling op mammografie en klinisch onderzoek in een poliklinische patiëntenpopulatie de diagnostische opbrengst significant verbeterde.

Het combineren wan de resultaten van klinisch epidemiologische methodologie zoals ROC curves en logistische regressie analyse, met de resultaten van besliskundig modelleren, wijzen erop dat het giebruik van aanvullende echografie bij patiënten met een palpabele afwijking een meer nauwkeurige diagnose kan bewerkstelligen tegen lagere kosten. 


\section{Dankwoord}

Met veel plezier kijk ik terug op de hijd warin de MAMMOED studie is uitgevoerd. Ik heb het erwaren als een waardevolle en lleerzame periode. Dit proefschrift is het resultaat van de inspanning en het enthousiasme van een heel team mensen, wan wie ik de belangriikste hier graag wil noemen.

Allereerst will ik Professor Jos van Engelshoven, mijh promotor, bedanken voor de mogelikheid om dit onderzoek uit te voeren. Met plezier werkte ik reeds aan andere onderzoeksprojecten op de afdeling radiologie, maar het vitwoeren van promotieonderzoek ging pas echt kriebelen toen de aanvraag voor deze studie me onder ogen kwam. Gelukkig werd mijn woorzichtige informeren door hem van hatte gesteund!

Voor mii was dit project een eerste kennismaking met de "chïrurgen-manier" van denken, waar ik als gezondheidswetenschapper veel van heb geleerd. Ik wil miin tweede promotor, Professor Maaten von Meyenfeldt, bedanken voor zijn inhoudelijke begeleiding bii de uitvoering van dit project. Tijdens onze wekelijkse MAMMOED. teambesprekingen was ook de bijdrage van Geerard Beets onmisbaar. Geerard, daarnaast was je altijd bereid am tijd wrij te maken en intensief mee te denken, dankjewel!

Anne Marie Bosch wil ik bedanken voor het includeren van de patiënten in de studie en het uitvoeren van vele echo-onderzoeken; het was een enorme klus. Ook jii bent bijna klaar met je proefschrift over jouw deel van deze studie. Succes met de laatste loodjes en je opleiding chirurgie!

Een ander hardcore lid van het MAMMOED-feam was Fons Kessels, die altijd weer oplossingen wist te bedenken voor methodologische en statistische obstakels. Fons bedankt voor je (eigen-)wijze raad en de gezelligheid van je dagelijkse bezoekjes. Ik hoop dat we, na ontbinding van het MAMMOED-team, nog binnen vele projecten zullen samenwerken.

Patty Nelemans, bedankt voor je kritische commentaar op de diverse artikelen en vele andere belangrijke zaken. Ik hoop dat we de prettige samenwerking tussen de afdelingen epidemiologie en radiologie kunnen voortzetten.

Verder wil ik Peggy Habets bedanken voor de administratieve ondersteuning en de (oneindigel) data-invoer van alle 2020 patiënten. Ontelbare uren heb je doorgebracht achter de pc om de stapels formulieren te verwerken en de gegevens te controleren! Ine Kengen, alweer vier jaar zijn we kamergenoten; bedankt voor de gezelligheid en voor je werk aan de lay-out van dit proefschrift.

Tevens wil ik de radiologen bedanken, die de velle mammogrammen en echo. onderzoeken voor deze studie hebben beoordeeld: Kristel Vranken, Dick Koster en Aernout Borstlap; de betrokken radiologisch laboranten, de collega-onderzoekers op de afdeling en alle 2020 patiënten die bereid waren aan de studie mee te doen.

Miin paramimfen, Josephine Giesen en Mariëlle van Gijn, wil ik bedanken voar hun steun tijdens het project en op deze belangrijke dag. Onze wriendschappen gaan alweer een lange tijd terug en via Johannesburg, New Yark en Parijs kwamen we alle drie weer in Maastricht uit. Ik hoop dat ik jullie nog lang als wriendinnen mag hebben. Verder wil ik langs deze weg mijn ouders, familie en wrienden bedanken woor hun support thijens de periode van dit onderzoek.

Lieve Gijs, bedankt dat je altijd weer achter me staat. Jauw steum en aanmoediging theeft me geholpen om ook deze klus te klaren. 


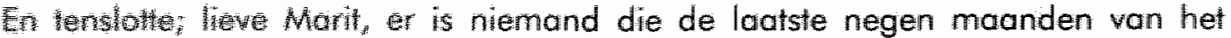

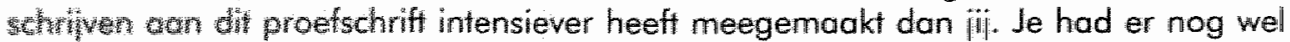
asen weet wan mar door jou heb ik me tach nog aan de planning gehouden. Dacher 


\section{Curriculum Vitae}

Karin Flobbe werd geboren op 23 september 1972 in Wemeldinge (Zld). Van 1984 - 1990 doorliep zii het Atheneum aan het Titus Brandsmacollege te Dordrecht.

Daarna studeerde ze aan de Faculteit Gezondheidswetenschappen van de Rijksuniversiteit Limburg (huidige Universiteit Maastricht) waar zij in december 7995 haar doctoraal diploma Biologische Gezondheidkunde behaalde.

Tijdens deze studie doorliep zii wetenschapsstages aan het Department of Infectious Diseases van de Universiteit van Oxford te Engeland (januari - juli 1994, o.l.v. Prof dr Dominic Kwiatkowski), en bij het Medical Research Council in Gambia in West-Afrika (augustus 1994 - februari 1995, o.l.v. Prof dr Geoff A.T. Targett).

$\mathrm{Na}$ haar afstuderen werkte zii vervolgens 2,5 jaar als wetenschappelijk onderzoeker aan het Departement Community Health van de Universiteit van Pretoria in ZuidAfrika (1996 - 1998, o.l.v. Prof dr Carel B. IJsselmuiden).

Vanaf november 1998 is zii werkzaam als wetenschappelijk onderzoeker aan de afdeling Radiologie van het Academisch Ziekenhuis Maastricht, o.l.v. Prof dr Jos M.A. van Engelshoven, alwaar ze in oktober 1999 haar promotieonderzoek binnen de MAMMOED studie begon. Na het voltooien van dit proefschrift zal ze zich als post-doc op deze afdeling blijven bezighouden met de opzet en vitvoering van diverse wetenschappelijke onderzoeksprojecten naar diagnostische testen. 
Karin Flobbe was born on September 23rd, 1972 in Wemeldinge (Zld.)

From 1984 - 1990 she attended secondary education at the Titus Brandsmacollege in Dordrecht.

Consequently, she studied at the Faculty of Health Sciences at the Rijksuniversiteit Limburg (currently Maastricht University) and obtained her MSic in Biological Health Sciences in December 1995.

During her studies she performed research projects at the Department of Infectious Diseases at the University of Oxford in the United Kingdom (January - July 1994, chairman Prof dr Dominic Kwiatkowski) and the Medical Research Council in The Gambia in West Africa (August 1994 - February 1995, chairman Prof dr Geoff A.T. Targett).

After graduating, she has worked as a research fellow at the Department of Community Health at the University of Pretoria in South Africa for 2,5 years 11996 1998, chairman Prof dr Carel B. IJsselmuiden).

From November 1998, she has been working as a research fellow at the Department of Radiology at Maastricht University Hospital, chairman Prof dr Jos M.A. van Engelshoven, where she started her PhD on the MAMMOED study in October 1999. After completing this thesis, she will continue her work as a post-doc in this department on the co-ordination of scientific research projects on diagnostic imaging tests. 


\section{Publications}

Flobbe K, Bosch AM, Kessels AGH, Beets GL, Nelemans PJ, won Meyenfeld MF, van Engelshoven JMA. The additional diagnostic value of ultrasonography in the diagnosis of breast cancer. Arch Int Med, 2003 (in press).

De Haan MW, Kroon AA, Flobbe K, Kessels AGH, Tordoir JH, Van Engelshoven IMA, De Leeuw PW. Renovascular disease in patients with hypertension: detection with duplex ultrasound. I Hum Hypertens. 2002 Jul; 16(7):501-7.

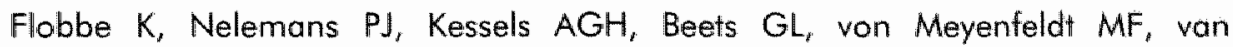
Engelshoven JMA.

The role of ultrasonography as an adjunct to mammography in the detection of breast cancer. a systematic review. Eur J Cancer. 2002 May; 38(8):1044-50.

Van der Ven $A J$, Hommels $M$, Kroon AA, Kessels $A G H$, Flobbe $K$, van Engelshoven JMA, Bruggeman CA, de Leeuw PW. Chlamydia pneumoniae seropositivity and systemic and renovascular atherosclerotic disease. Arch Intern Med. 2002 Apr 8;162(7):786-90.

Flobbe K, van der Linden ES, Kessels AGH, van Engelshoven JMA. Diagnostic value of radialogical breast imaging in a non-screening population. Int $J$ Cancer. 2001 May 15;92(4):616-8.

Drakeley Cע, Flobbe K, Greenwood BM, Targett GAT. Plasmodium falciparum gametocytes in Gambian adults.Ann Trop Med Parasitol. 2000 Jun;94(4):399-401.

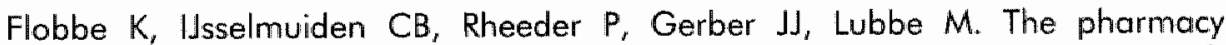
screening project- an evaluation of pharmacy-based screening programmes. S Afr Med J. 1999 Sep;89(9):980-6.

Bethell DB, Flabbe K, Cao XT, Day NP, Pham TP, Buurman WA, Cardosa MJ, White NJ, Kwiatkowski D. Pathophysiologic and prognostic role of cytokines in dengue hemorrhagic fever.J Infect Dis. 1998 Mar;177(3):778-82.

\section{Abstracts}

Flobbe K, Bosch A.M, Kessels A.G.H, Beets G.L, von Meyenfeldt M.F, van Engelshoven J.M.A. The role of ultrasonography as adjunct to mammography and clinical examination in the detection of breast cancer. Radiology. 2002; 222 (3):876.

Flobbe K, Bosch A.M, Kessels A.G.H, Beets G.L, von Meyenfeldt M.F, van Engelshoven J.M.A. The diagnostic value of ultrasonography as adjunct to mammography and clinical examination in breast cancer detection. Eur 1 Cancer. $2001 ; 37($ suppl.6): 5168.

Flobbe K, van der Linden E.S, Kessels A.G.H, van Engelshoven J.M.A. Diagnostic value of radiological breast imaging in a non-screening population. Eur $\downarrow$ Cancer. 2000;36(suppl.5): 5131 . 